\title{
Mediterranean Propolis from the Adriatic Sea Islands as a Source of Natural Antioxidants: Comprehensive Chemical Biodiversity Determined by GC-MS, FTIR-ATR, UHPLC-DAD-QqTOF-MS, DPPH and FRAP Assay
}

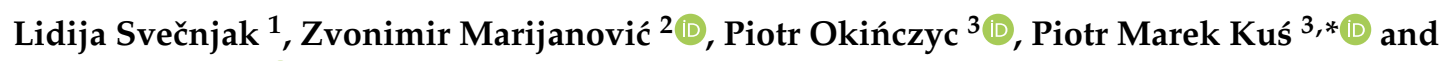 \\ Igor Jerković $2, *$ (i) \\ 1 Faculty of Agriculture, University of Zagreb, Svetošimunska cesta 25, 10000 Zagreb, Croatia; \\ lsvecnjak@agr.hr \\ 2 Faculty of Chemistry and Technology, University of Split, Ruđera Boškovića 35, 21000 Split, Croatia; \\ zmarijanovic@ktf-split.hr \\ 3 Department of Pharmacognosy and Herbal Medicines, Wrocław Medical University, ul. Borowska 211a, \\ 50-556 Wrocław, Poland; piotr.okinczyc@umed.wroc.pl \\ * $\quad$ Correspondence: piotr.kus@umed.wroc.pl (P.M.K.); igor@ktf-split.hr (I.J.); Tel.: +48-71-784-02-11 (P.M.K.); \\ $+385-21-329-436$ (I.J.)
}

Received: 1 April 2020; Accepted: 17 April 2020; Published: 20 April 2020

check for updates

\begin{abstract}
There is no systematic report about propolis chemical biodiversity from the Adriatic Sea islands affecting its antioxidant capacity. Therefore, the samples from the islands Krk, Rab, Pag, Biševo and Korčula were collected. Comprehensive methods were used to unlock their chemical biodiversity: headspace solid-phase microextraction (HS-SPME) and hydrodistillation (HD) followed by gas chromatography and mass spectrometry (GC-MS); Fourier transform mid-infrared spectroscopy (FT-MIR); ultra high performance liquid chromatography with diode array detector and quadrupole time-of-flight mass spectrometry (UHPLC-DAD-QqTOF-MS) and DPPH and FRAP assay. The volatiles variability enabled differentiation of the samples in 2 groups of Mediterranean propolis: non-poplar type (dominated by $\alpha$-pinene) and polar type (characterized by cadinane type sesquiterpenes). Spectral variations (FT-MIR) associated with phenolics and other balsam-related components were significant among the samples. The UHPLC profiles allowed to track compounds related to the different botanical sources such as poplar (pinobanksin esters, esters and glycerides of phenolic acids, including prenyl derivatives), coniferous trees (labdane, abietane diterpenes) and Cistus spp. (clerodane and labdane diterpenes, methylated myricetin derivatives). The antioxidant potential determined by DPPH ranged $2.6-81.6 \mathrm{mg}$ GAE/g and in FRAP assay $0.1-0.8 \mathrm{mmol} \mathrm{Fe}^{2+} / \mathrm{g}$. The highest activity was observed for the samples of Populus spp. origin. The antioxidant potential and phenolic/flavonoid content was positively, significantly correlated.
\end{abstract}

Keywords: $\alpha$-pinene; cadinane type sesquiterpenes; eudesmol isomers; bulnesol and guaiol; clerodane; labdane and abietane diterpenes; methylated flavonoids; esters of phenolic acids; DPPH and FRAP capacity

\section{Introduction}

Apis mellifera L. propolis, known as the bee glue, combines resins collected by the honey bees from different plant organs, and with beeswax that honey bees additionally incorporate. It has been shown that propolis possesses antioxidant, antibacterial, antifungal and antiviral properties, as well as 
other beneficial biological activities such as anticancer, anti-inflammatory, antiulcer, hepatoprotective, immunostimulating, antidiabetic, etc. [1-4]. The efficacy of propolis in different in vitro and in vivo protocols suggests its therapeutic properties [1,3]. Reported biological activities have been related to propolis chemical complexity. Propolis has been investigated by utilizing various analytical tools [5] in order to determine its composition, physico-chemical and bioactive properties, as well as specific chemical markers.

Since the 1960s, numerous studies have revealed propolis composition variability $[2,6,7]$ with more than 300 natural organic compounds: flavonoids, phenolic acids and their esters, polyphenols, terpenes (particularly sesquiterpenes, diterpenes and triterpenes), lignans, steroids, hydrocarbons, amino acids and others. Their abundance has been influenced by botanical and geographical factors, as well as by the season [2,3]. According to the specific chemical composition, different types of propolis are referred in the literature [3]: (a) Poplar type (Populus spp.), (b) Birch type (Betula verrucosa Ehrh.), (c) Green type (Baccharis spp.), (d) Red type (Dalbergia spp.), (e) Clusia type (from Clusia spp.), (f) Pacific type (Macaranga tanarius (L.) Mull.Arg.) and (g) Mediterranean type (mostly from Cupressaceae/Juniperus family). Propolis of the European poplar and Brazilian red and/or green (Baccharis spp.) types from the continental geographical regions have been widely studied; on the other hand, propolis from more remote locations with specific flora (such as islands), have been investigated only sporadically. There are several records on the island propolis: Pacific propolis from Taiwan, Okinawa and Indonesia islands [8-10], and Mediterranean propolis from Malta, Gozo, Cyprus and Greek islands [11]. In last decade, a new type of Greek Mediterranean propolis was reported that contains mainly diterpenes (e.g., communic, cupressic and isocupressic acids and totarol) and almost no phenolics [12].

Due to its specific geographical position on the dividing line between several biogeographic regions and ecological, climatic and geomorphologic conditions, Croatian flora shows high biodiversity with many endemic plants; the ratio of plant species (ca. 10,000 taxa) and territory sets Croatia amongst three European countries richest in flora [13]. Such biodiversity is expected to influence the composition of propolis. Adriatic region of Croatia is populated by a number of islands of which 48 are inhabited. Propolis is regularly being collected from approximately 15 islands as an apicultural by-product. This type of propolis mostly originate from Cupressus sempervirens L., Juniperus spp., Pinus halepensis Miller, Pinus nigra J.F.Arnold, Quercus ilex L., Fraxinus ornus L. and Olea europaea L., depending on the vegetation that dominates on specific microlocation/island [5,14].

Research papers on Croatian propolis exist [14-18] and report great variability of Croatian propolis from the continental and Adriatic region. According to the data from available literature, Mediterranean propolis from Croatia has been investigated in several studies [14,18]. However, there is no systematic report about propolis chemical biodiversity from the Adriatic Sea islands as a part of Mediterranean type propolis. Therefore, specific goals of the present study on unlocking Mediterranean propolis from the Adriatic sea islands as source of natural antioxidants are: (a) to select typical propolis from 5 Croatian islands; (b) to isolate volatiles of the samples by headspace solid-phase microextraction (HS-SPME) and hydrodistillation (HD) and to analyze them by gas chromatography and mass spectrometry (GC-MS); (c) to obtain full chemical profile of the samples by Fourier transform mid-infrared spectroscopy (FT-MIR); (d) to determine non-volatile composition of the samples by ultra high performance liquid chromatography with diode array detector and quadrupole time-of-flight mass spectrometry (UHPLC-DAD-QqTOF-MS); (e) to compare the obtained results mutually and with other Mediterranean type propolis; (f) to determine antiradical and total antioxidant activities of the samples by DPPH and FRAP assay.

\section{Materials and Methods}

\subsection{Sampling of Mediterranean Propolis from the Adriatic Sea Islands}

Seven raw proplis samples were obtained directly from the Carniolan honey bee (Apis mellifera carnica Pollmann) hives maintained on the islands by the local beekeepers. The samples were collected 
during 2017 from beehives situated on 5 Croatian islands along the Adriatic Sea coast: Krk $(n=3$ from different island locations; K1P-Omišalj, K2P-Pinezići, K3P-Draga Bašćanska), Rab (RP), Pag (PP), Biševo (BP) and Korčula (KP). The samples were stored in the glass containers in the dark at room temperature, prior to the analyses.

\subsection{Headspace Solid-Phase Microextraction (HS-SPME) and Hydrodistillation (HD) Followed by Gas Chromatography and Mass Spectrometry Analysis (GC-MS)}

HS-SPME was performed with a manual SPME holder using three fibers covered with Polydimethylsiloxane/Divinylbenzene (PDMS/DVB), Carboxen/PDMS (CAR/PDMS) and DVB/CAR/PDMS obtained from Supelco Co. (Bellefonte, PA, USA). For HS-SPME, the finely grinded samples ( $1 \mathrm{~g}$; manually grinded on a hand grinder) were placed separately in $10 \mathrm{~mL}$ glass vials and hermetically sealed. The vials were maintained at $60^{\circ} \mathrm{C}$ during equilibration $(15 \mathrm{~min})$ and extraction (45 min). Thereafter, the SPME fiber was withdrawn and inserted into GC-MS injector $\left(250{ }^{\circ} \mathrm{C}\right)$ for $6 \mathrm{~min}$ for thermal desorption. The procedure was similar as in previous paper [18]. HS-SPME was done in triplicate and the results are presented as mean values.

HD was performed in a modified Clevenger apparatus for $2 \mathrm{~h}$ with $1 \mathrm{~mL}$ of the solvent trap of the pentane:diethyl ether $(1: 2 v / v)$ and $10 \mathrm{~g}$ of the sample cut into small pieces. The volatile oil dissolved in the solvent trap was passed through a layer of $\mathrm{MgSO}_{4}$ in a small glass funnel and carefully concentrated by a slow flow of nitrogen, to the volume of $0.2 \mathrm{~mL}$. HD was performed in triplicate and the results are presented as mean value.

Gas chromatography and mass spectrometry (GC-MS) analyses were done on an Agilent Technologies (Palo Alto, CA, USA) gas chromatograph model 7890A equipped with a mass spectrometer (MSD) model 5977E (Palo Alto, CA, USA) and HP-5MS capillary column (5\% phenyl-methylpolysiloxane, Agilent J and $\mathrm{W})$. The GC conditions were the same as reported previously [18]. In brief, the oven temperature was set at $70{ }^{\circ} \mathrm{C}$ for $2 \mathrm{~min}$, then increased from 70 to $200{ }^{\circ} \mathrm{C}\left(3^{\circ} \mathrm{C} / \mathrm{min}\right)$ and held at $200{ }^{\circ} \mathrm{C}$ for $15 \mathrm{~min}$; the carrier gas was helium $(1.0 \mathrm{~mL} / \mathrm{min})$. The compounds identification was based on the comparison of their retention indices (RI), determined relatively to the retention times of $n$-alkanes $\left(\mathrm{C}_{9}-\mathrm{C}_{25}\right)$, with those reported in the literature [19] and those from Wiley 9 (Wiley, New York, NY, USA) and NIST 17 (D-Gaithersburg) mass spectral libraries. The percentage composition of the samples was computed from the GC peak areas using the normalization method (without correction factors).

\subsection{FTIR-ATR Spectroscopy}

Raw propolis samples were analyzed by Fourier transform mid-infrared spectroscopy (FT-MIR) coupled with an Attenuated Total Reflectance (ATR) accessory. Infrared (IR) spectra of collected raw propolis samples were acquired by Cary 660 Fourier transform mid-infrared spectrometer (Agilent Technologies, Palo Alto, CA, USA) coupled with a Golden Gate single-reflection diamond ATR accessory (Specac). Five replicate spectra of each sample (50 scans/spectrum using nominal resolution of $4 \mathrm{~cm}^{-1}$ ) were recorded in the mid-infrared region (4000-400 $\left.\mathrm{cm}^{-1}\right)$ using five different aliquots of the sample. An average spectrum was determined for each sample (partial inhomogeneity of raw propolis samples was taken into account in order to obtain representative sample's spectrum). The sample measurements were recorded at $25 \pm 2{ }^{\circ} \mathrm{C}$ by using a sapphire self-leveling pressure anvil to create a thin sample layer between the diamond and sapphire for equal spectra acquisition. Approximately $0.05 \mathrm{~g}$ of a sample was used to acquire the spectra. Before the acquisition of the following sample spectrum, the ATR diamond and sapphire anvil were cleaned with ethanol (96\%) using a soft tissue paper. Raw spectral data were stored and pre-analyzed using the Agilent Resolutions Pro version 5.3 .0 (2015) software package (Agilent Technologies, Palo Alto, CA, USA) while further data analysis and chemometric modeling, was carried out using Origin, version 8.1 (Origin Lab Corporation, Northampton, MA, USA). 


\subsection{Preparation of Propolis Extracts for Colorimetric Tests and Liquid Chromatography}

An aliquot of $1 \mathrm{~g}$ of each propolis sample, was accurately weighted and extracted with $70 \%$ ethanol in water, with the ratio 1:10 $(\mathrm{g} / \mathrm{mL})$ in an Sonorex Digital 10 P ultrasonic bath (Bandelin, Berlin, Germany). The extraction was conducted for $45 \mathrm{~min}$ at $40{ }^{\circ} \mathrm{C}$ and the power was set at $90 \%(576 \mathrm{~W})$. Afterwards, the extracts were centrifuged and filtered through CHROMAFIL ${ }^{\circledR} 0.2 \mu \mathrm{m}$ PTFE filters (Macherey-Nagel, Düren, Germany).

\subsection{High Performance Liquid Chromatography and Mass Spectrometry (UHPLC-DAD-QqTOF-MS)}

UHPLC analyses were performed as previously described [20] with a Thermo Scientific UltiMate 3000 system (Thermo Scientific ${ }^{\mathrm{TM}}$ Dionex $^{\mathrm{TM}}$, Sunnyvale, CA, USA), coupled with an autosampler and DAD detector recording spectral data in the 200-600 $\mathrm{nm}$ range and monitoring at 280, 320 and $360 \mathrm{~nm}$. Chromatographic separation was done using Kinetex ${ }^{\circledR}$ F5 $2.6 \mu \mathrm{m}, 100 \AA, 150 \times 2.1 \mathrm{~mm}$ analytical column, equipped with SecurityGuard ${ }^{\mathrm{TM}}$ ULTRA F5 guard column (Phenomenex, Torrence, CA, USA) thermostated at $35^{\circ} \mathrm{C}$. The mobile phase consisted of $0.1 \%$ formic acid in water (solvent A) or acetonitrile (solvent $\mathrm{B}$ ). The flow rate was set at $0.4 \mathrm{~mL} / \mathrm{min}$ and a following gradient program was applied: starting with $100 \%$ of solvent $\mathrm{A}$ and decreasing to reach $91 \%$ at $7 \mathrm{~min}$, held isocratic to $10 \mathrm{~min}$, reaching $80 \% \mathrm{~A}$ at $10.5 \mathrm{~min}$ and $60 \% \mathrm{~A}$ at $18.5 \mathrm{~min}$, held isocratic to $22.5 \mathrm{~min}$ and decreasing to $0 \% \mathrm{~A}$ at $28.5 \mathrm{~min}$, held isocratic until $32 \mathrm{~min}$. Subsequently, it returned to 100\% A and was stabilized for $10 \mathrm{~min}$ before the next analysis. The injection volume was $1 \mu \mathrm{L}$. Before the analysis, all the extracts were dissolved in ethanol and filtered through CHROMAFIL ${ }^{\circledR} 0.2 \mu \mathrm{m}, \varnothing 13 \mathrm{~mm}, \mathrm{H}-\mathrm{PTFE}$ membrane syringe filter (Macherey-Nagel, Düren, Germany). Standard compounds were dissolved in ethanol or mixture of DMSO-ethanol $(1: 10 v / v)$ for hardly soluble compounds and diluted to obtain calibration curves in the range of concentrations $0.5-200 \mathrm{~g} / \mathrm{mL}$. Quantitative results were calculated using the calibration curves of appropriate standard or corresponding parent compound (e.g., amount of pinobanksin-3-O-acetate was calculated as pinobanksin equivalent taking into consideration the differences in molar mass).

UHPLC-DAD-QqTOF-MS was performed in a similar setting and chromatographic conditions using MS-grade solvents. Compact QqTOF-MS detector (Bruker, Darmstadt, Germany) was used in ESI negative mode, ion source temperature was set at $100{ }^{\circ} \mathrm{C}$, nebulizer gas pressure was set at 2.0 bar, dry gas flow $0.8 \mathrm{~L} / \mathrm{min}$ and temperature $210{ }^{\circ} \mathrm{C}$. The capillary voltage was set at $2.20 \mathrm{kV}$ and collision energy at $8.0 \mathrm{eV}$. A $10 \mathrm{mM}$ solution of sodium formate clusters was used for internal calibration. For ESI-MS/MS experiments, collision energy was $35 \mathrm{eV}$ and nitrogen was used as collision gas.

\subsection{Total Flavonoid (TF), Total Phenolic (TP) Content and Antioxidant Potential (DPPH and FRAP Assays)}

\subsubsection{Total Antioxidant Activity (FRAP Assay)}

The ferric reducing antioxidant assay (FRAP) was performed as previously described [20,21]. Briefly, the reagent was prepared by mixing $10 \mathrm{mmol} / \mathrm{L} \mathrm{TPTZ} \mathrm{reagent} \mathrm{(2,4,6-tri(2-pyridyl)-s-triazine)}$ with $20 \mathrm{mmol} / \mathrm{L}$ ferric chloride in acetate buffer ( $\mathrm{pH}$ 3.6). The quantitative results were calculated using a calibration curve of ferrous sulfate used as external standard $(0.02-1.5 \mu \mathrm{mol} / \mathrm{mL})$. Before the analysis, the propolis extracts were diluted 20-200 times and $20 \mu \mathrm{L}$ of the extract solutions were mixed with $200 \mu \mathrm{L}$ of ferric complex. The results were calculated and expressed as micromoles of $\mathrm{Fe}^{2+}$ per gram of propolis. The absorbance $(\lambda=593 \mathrm{~nm})$ was read in disposable optical polystyrene 96-well plates (FL medical, Torreglia, Italy) using a Multiskan ${ }^{\mathrm{TM}}$ GO Microplate Spectrophotometer (Thermo Fisher Scientific, Waltham, MA, USA). All the measurements were performed in triplicate.

\subsubsection{Total Phenolic Content (TP)}

The total phenolic content was measured spectrophotometrically using the Folin-Ciocalteu method, as previously described [22,23]. Before the analysis, the propolis extracts were diluted 20-200 times and $50 \mu \mathrm{L}$ of the ethanolic extract solution were mixed with $20 \mu \mathrm{L}$ of Folin-Ciocalteu reagent. After $5 \mathrm{~min}, 200 \mu \mathrm{L}$ of $100 \mathrm{~g} / \mathrm{L} \mathrm{Na}{ }_{2} \mathrm{CO}_{3}$ solution was added. After $90 \mathrm{~min}$ of incubation at room temperature, 
in dark, the absorbance was read against blank (prepared similarly, using pure solvent instead of sample) at $725 \mathrm{~nm}$ in disposable polystyrene 96-well plates using a microplate spectrophotometer. Total phenolic content was calculated using a calibration curve prepared with fresh gallic acid standard solutions (10-200 $\mu \mathrm{g} / \mathrm{mL}$ ) and expressed as milligrams of gallic acid equivalent (GAE) per gram of propolis. All the measurements were performed in triplicate.

\subsubsection{Total Flavonoid Content (TF)}

The total flavonoid content was measured spectrophotometrically using a modified pharmacopoeial method with aluminum chloride [24]. An aliquot of $50 \mu \mathrm{L}$ of prepared extracts was mixed with $50 \mu \mathrm{L}$ of $2 \%$ ethanolic solution of $\mathrm{AlCl}_{3}(w / v)$ and after $60 \mathrm{~min}$ of incubation at room temperature, in dark, the absorbance was measured at $420 \mathrm{~nm}$ using a microplate reader. Total flavonoid content was calculated using a calibration curve prepared with quercetin standard solutions $(20-400 \mu \mathrm{g} / \mathrm{mL})$ and expressed as milligrams of quercetin equivalent $(\mathrm{QE})$ per gram of propolis. All the measurements were performed in triplicate.

\subsubsection{Antiradical Activity (DPPH Test)}

Determination of antiradical activity using DPPH radical and comparison with the gallic acid activity was performed using previously modified method [25]. Before the analysis, the propolis extracts were diluted 20-200 times and $20 \mu \mathrm{L}$ of diluted test extracts were mixed with $200 \mu \mathrm{L}$ of $0.315 \mathrm{mM}$ DPPH solution in methanol and incubated for $30 \mathrm{~min}$ at room temperature, in dark. The absorbance $(\lambda=517 \mathrm{~nm})$ was read in disposable optical polystyrene 96-well plates using microplate spectrophotometer (as previously). All the measurements were performed in triplicate. The obtained data were calculated from appropriate gallic acid calibration curve $(2.0-100 \mu \mathrm{g} / \mathrm{mL})$ and expressed as gallic acid equivalent antioxidant capacity per gram of propolis (mg GAE/g).

\subsubsection{Statistical Analysis}

Statistical analysis was performed for correlation of the antioxidant potential and phenolic/flavonoid content using STATISTICA 64 ver. 13.1 (Dell Inc., Tulsa, OK, USA). Pearson's product-moment correlation was applied to test relations between the investigated parameters and significance was assessed in two-tailed test at the level of significance $p<0.05$.

\section{Results and Discussion}

\subsection{HS-SPME/GC-MS and HD/GC-MS}

HS-SPME has been used in last decade for the analysis of propolis headspace (HS) volatile organic compounds (VOCs) as a simple and fast method. To obtain comprehensive HS chemical profiles among samples 3 types of fibers were used. For the isolation of volatile and less-volatile compounds HD with solvent trap was used. VOCs composition is strongly dependent on the extraction method. Striking differences were found between chemical profiles of the same sample obtained by HS-SPME and HD and among the samples. It is known that to produce propolis, bees collect various exudates including balsams, resins and waxes from the plants available in specific areas. It results in different typologies of the final product and therefore the samples were divided (according to VOC results) into two groups depending on the probable plant sources.

\subsubsection{Mediterranean Propolis (Non-Poplar Type)}

According to the chemical composition of HS and essential oil (EO) (Tables 1 and 2), the samples $\mathrm{BP}$ and KP were classified in this group. Those two samples were found peculiar as expected, since the islands Biševo and Korčula are more distant from the mainland and are populated by a specific flora. 
Table 1. Volatiles determined by headspace solid-phase microextraction (HS-SPME)/gas chromatography (GC-MS).

\begin{tabular}{|c|c|c|c|c|c|c|c|c|c|c|c|c|c|c|c|c|c|c|c|c|c|c|c|}
\hline \multirow{2}{*}{ No. } & \multirow{2}{*}{ Compound } & \multirow{2}{*}{ RI } & \multicolumn{3}{|c|}{ BP } & \multicolumn{3}{|c|}{ KP } & \multicolumn{3}{|c|}{$\mathbf{R P}$} & \multicolumn{3}{|c|}{ PP } & \multicolumn{3}{|c|}{ K1P } & \multicolumn{3}{|c|}{ K2P } & \multicolumn{3}{|c|}{ K3P } \\
\hline & & & I & II & III & I & II & III & I & II & III & I & II & III & I & II & III & I & II & III & I & II & III \\
\hline 1 & Ethanol & $<900$ & 0.2 & 0.1 & - & - & - & - & - & - & - & - & 0.2 & - & - & - & - & 1.0 & 0.6 & - & 0.6 & 0.8 & - \\
\hline 2 & Acetone & $<900$ & 6.8 & 5.7 & 0.9 & 1.9 & 2.6 & 1.6 & - & 0.3 & 0.1 & - & 0.7 & - & - & - & - & - & 1.2 & - & 1.3 & 2.6 & - \\
\hline 3 & Isoprene & $<900$ & - & - & - & - & - & - & 0.2 & - & - & 0.5 & - & - & 0.4 & - & - & - & - & - & - & - & - \\
\hline 4 & But-2-enal & $<900$ & - & - & - & 0.3 & - & - & - & - & - & - & - & - & - & - & - & - & - & - & - & - & - \\
\hline 5 & Acetic acid & $<900$ & 1.0 & 0.4 & - & - & 22.7 & 4.1 & - & 17.1 & 1.7 & 0.4 & 20.9 & 2.4 & - & 31.9 & 9.7 & 17.8 & 6.6 & 0.6 & 23.1 & 18.8 & 2.6 \\
\hline 6 & Propanoic acid & $<900$ & - & - & - & - & - & - & 0.6 & - & 0.1 & 0.1 & - & - & - & - & - & - & - & - & - & - & - \\
\hline 7 & Butan-2-one & $<900$ & 0.5 & 0.9 & - & - & - & - & - & - & - & - & - & - & - & - & - & - & - & - & - & - & - \\
\hline 8 & Pentanal & $<900$ & - & - & - & 1.6 & 1.5 & 1.4 & - & - & - & - & - & - & - & - & - & 0.5 & 0.1 & - & 0.6 & 2.6 & 1.0 \\
\hline 9 & Heptane & $<900$ & 0.2 & 0.1 & - & - & - & - & - & - & - & - & - & - & - & - & - & - & - & - & - & - & - \\
\hline 10 & 2,5-Dimethylfuran & $<900$ & 0.3 & - & - & - & - & - & - & - & - & - & - & - & - & - & - & - & - & - & - & - & - \\
\hline 11 & 3-Methylbut-3-en-1-ol & $<900$ & - & - & - & - & - & - & 0.1 & 2.1 & 0.6 & 1.7 & 1.2 & 0.5 & 1.7 & 0.8 & 0.7 & - & - & - & 1.7 & 1.8 & 1.7 \\
\hline 12 & 2-Methylbut-2-enal & $<900$ & - & - & - & - & - & - & 0.6 & - & - & 3.2 & 1.4 & 0.3 & 0.9 & - & - & - & - & - & 1.0 & 1.2 & - \\
\hline 13 & 2-Methylpropanoic acid & $<900$ & - & - & - & - & - & - & - & 1.5 & 0.5 & - & - & - & - & 0.6 & - & - & - & - & - & - & - \\
\hline 14 & 3-Methylbut-2-en-1-ol & $<900$ & - & - & - & - & - & - & 1.5 & 2.7 & 0.7 & 2.6 & 1.4 & 0.8 & 3.7 & 1.8 & 1.5 & - & - & - & 2.9 & 2.3 & 1.5 \\
\hline 15 & Toluene & $<900$ & 2.1 & 1.0 & 0.3 & 0.3 & - & - & - & - & - & - & - & - & - & - & - & - & - & - & - & - & - \\
\hline 16 & 3-Methylbut-2-enal & $<900$ & 0.2 & - & - & 0.9 & - & - & 1.2 & 1.2 & 0.2 & 7.9 & 2.8 & 0.5 & 2.9 & - & 0.9 & 0.8 & - & - & 4.5 & 2.2 & 1.1 \\
\hline 17 & Oct-1-ene & $<900$ & 0.3 & 0.3 & - & - & - & - & - & - & - & - & - & - & - & - & - & - & - & - & - & - & - \\
\hline 18 & Octane & $<900$ & 0.4 & 0.3 & - & - & - & - & - & - & - & 0.2 & - & - & - & - & - & - & - & - & - & - & - \\
\hline 19 & Hexanal & $<900$ & - & - & - & 1.9 & 1.3 & 1.0 & - & - & - & - & - & - & - & 0.6 & 0.6 & 1.7 & 0.7 & 0.2 & 1.2 & 1.8 & 0.7 \\
\hline 20 & 2-Furancarboxaldehyde & $<900$ & 0.2 & - & - & 0.9 & 0.3 & - & - & - & - & - & - & - & - & - & - & 1.0 & - & - & 0.8 & - & - \\
\hline 21 & 2-Methylbutanoic acid & $<900$ & - & - & - & - & - & - & 0.4 & 0.3 & 1.2 & 1.2 & 1.9 & 1.2 & 2.0 & 2.0 & 2.2 & - & - & - & 1.0 & 1.4 & 0.7 \\
\hline 22 & Non-1-ene & $<900$ & 0.2 & 0.1 & - & - & - & - & - & - & - & - & - & - & - & - & - & - & - & - & - & - & - \\
\hline 23 & Styrene & $<900$ & 0.9 & 0.1 & - & - & - & - & 0.4 & 0.3 & 0.1 & 0.6 & - & - & 2.7 & 0.8 & 0.6 & - & - & - & 0.8 & 0.3 & 0.6 \\
\hline 24 & Nonane & 900 & 0.5 & 0.3 & - & - & - & - & - & - & - & - & - & - & - & - & - & - & - & - & - & - & - \\
\hline 25 & Heptanal & 905 & 0.3 & - & - & 1.6 & 1.0 & 0.9 & - & - & - & - & - & - & - & 0.6 & 0.6 & 1.3 & 0.5 & 0.1 & 0.6 & 1.3 & 1.0 \\
\hline 26 & Prenyl acetate & 927 & - & - & - & - & - & - & 0.9 & 2.4 & 0.6 & 0.9 & 0.7 & 0.3 & 2.6 & 1.0 & 1.0 & - & - & - & - & - & - \\
\hline 27 & Tricyclene & 932 & 0.2 & 0.3 & 0.2 & - & - & - & - & - & - & - & - & - & - & - & - & - & - & - & 1.0 & - & - \\
\hline 28 & 2-Methylbut-2-enoic acid & 942 & - & - & - & - & - & - & 5.7 & 2.1 & 1.2 & 3.7 & 1.9 & 0.9 & 2.9 & 1.1 & 0.7 & - & - & - & 1.2 & 0.8 & - \\
\hline 29 & $\alpha$-Pinene & 943 & 32.9 & 42.2 & 52.7 & 8.8 & 7.6 & 13.5 & - & - & 0.6 & 5.1 & 5.9 & 3.6 & 1.3 & 1.0 & 1.3 & - & - & - & - & 1.2 & 1.7 \\
\hline 30 & Camphene & 958 & 0.4 & 0.6 & 0.8 & - & 0.1 & 0.2 & - & 0.3 & - & - & - & - & - & - & - & - & - & - & - & - & - \\
\hline 31 & Verbenene & 963 & 1.0 & 1.1 & 1.0 & - & 0.5 & - & - & - & - & 0.2 & 0.5 & 0.3 & - & - & - & - & - & - & - & - & - \\
\hline 32 & Benzaldehyde & 970 & 0.4 & - & - & 2.7 & 0.7 & 0.5 & 2.1 & 0.3 & 0.2 & 5.2 & 0.7 & 0.4 & 9.8 & 2.0 & 1.9 & 17.9 & 5.7 & 3.2 & 4.7 & 2.6 & 3.2 \\
\hline 33 & $\beta$-Pinene & 984 & 0.5 & 0.6 & 0.8 & 0.1 & 0.2 & 0.5 & - & - & - & - & 0.2 & - & - & - & - & - & - & - & - & 0.6 & 0.4 \\
\hline 34 & 6-Methylhept-5-en-2-one & 991 & - & - & - & 0.3 & 0.3 & 0.5 & - & - & - & - & - & - & 1.4 & 2.0 & 2.5 & 1.2 & 0.7 & 0.8 & 0.7 & 2.1 & 1.8 \\
\hline 35 & $\beta$-Myrcene & 995 & 0.3 & - & - & - & - & - & - & - & - & 0.2 & 0.2 & 0.1 & - & - & - & - & - & - & - & 0.8 & - \\
\hline 36 & Octanal & 1006 & 1.3 & 0.8 & 0.5 & 3.2 & 1.6 & 1.5 & - & - & - & 0.2 & 0.2 & 0.1 & 0.9 & 1.1 & 0.9 & 4.0 & 1.7 & 1.4 & 0.8 & 2.2 & 1.7 \\
\hline 37 & $p$-Mentha-1,5,8-triene & 1010 & 0.4 & 0.3 & - & - & - & - & - & - & - & - & - & - & - & - & - & - & - & - & - & - & - \\
\hline 38 & 8-3-Carene & 1016 & 0.6 & 0.5 & 0.6 & 0.7 & 0.5 & 0.8 & - & - & - & 0.5 & 0.2 & 0.1 & - & - & - & - & - & - & - & - & - \\
\hline
\end{tabular}


Table 1. Cont

\begin{tabular}{|c|c|c|c|c|c|c|c|c|c|c|c|c|c|c|c|c|c|c|c|c|c|c|c|}
\hline \multirow{2}{*}{ No. } & \multirow{2}{*}{ Compound } & \multirow{2}{*}{ RI } & \multicolumn{3}{|c|}{ BP } & \multicolumn{3}{|c|}{ KP } & \multicolumn{3}{|c|}{$\mathbf{R P}$} & \multicolumn{3}{|c|}{ PP } & \multicolumn{3}{|c|}{ K1P } & \multicolumn{3}{|c|}{ K2P } & \multicolumn{3}{|c|}{ K3P } \\
\hline & & & I & II & III & I & II & III & I & II & III & I & II & III & I & II & III & I & II & III & I & II & III \\
\hline 39 & o-Allyltoluene ${ }^{*}$ & 1019 & 0.2 & 0.1 & - & - & - & - & - & - & - & - & - & - & - & - & - & - & - & - & - & - & - \\
\hline 40 & $\alpha$-Terpinene & 1023 & - & - & - & - & - & - & - & 0.3 & - & 0.7 & 0.5 & 0.1 & - & - & - & - & 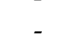 & - & - & - & - \\
\hline 41 & $p$-Cymene & 1031 & 0.7 & 0.6 & 0.6 & 0.6 & 0.2 & 0.3 & 0.2 & 0.6 & 0.1 & 1.8 & 0.7 & 0.3 & 0.3 & - & - & 1.2 & 0.7 & 0.5 & 0.8 & 0.9 & 0.8 \\
\hline 42 & Limonene & 1036 & 1.7 & 1.3 & 1.2 & 1.8 & 0.8 & 1.0 & 0.1 & 0.3 & 0.1 & 2.1 & 0.9 & 0.3 & 0.7 & - & 0.9 & 11.8 & 11.1 & 5.7 & 4.9 & 8.6 & 7.8 \\
\hline 43 & Benzyl alcohol & 1046 & 0.5 & 0.1 & 0.1 & 0.5 & 0.2 & 0.2 & 6.9 & 2.7 & 2.1 & 1.5 & 0.5 & 0.6 & 3.7 & 1.7 & 2.0 & - & - & - & 3.1 & 3.6 & 5.3 \\
\hline 44 & Salicylaldehyde & 1051 & - & - & - & - & - & - & - & - & - & 0.7 & 0.2 & 0.4 & - & - & - & - & - & - & - & - & - \\
\hline 45 & $\gamma$-Terpinene & 1065 & - & - & - & - & - & - & 0.1 & 0.3 & 0.1 & 1.0 & 0.7 & 0.3 & - & - & - & - & - & - & 0.5 & 0.9 & 1.1 \\
\hline 46 & Acetophenone & 1073 & - & - & - & - & - & - & 0.2 & - & - & - & - & - & 0.9 & 0.3 & 0.7 & - & - & - & - & - & - \\
\hline 47 & p-Cymenene & 1094 & 2.4 & 1.0 & 0.9 & 0.6 & 0.6 & 0.7 & 0.1 & 0.3 & - & 0.9 & 0.5 & 0.4 & - & - & - & - & - & - & - & - & - \\
\hline 48 & Linalool & 1103 & - & - & - & - & - & - & 0.3 & 1.2 & 0.4 & 1.0 & 0.9 & 0.6 & 3.0 & 1.8 & 1.9 & 0.3 & 0.3 & 0.3 & 1.6 & 1.3 & 0.7 \\
\hline 49 & Nonanal & 1107 & 5.1 & 2.9 & 2.2 & 16.9 & 7.6 & 7.2 & 0.1 & - & - & 0.5 & 0.5 & 0.4 & 3.2 & 3.3 & 3.6 & 11.0 & 6.1 & 7.5 & 1.9 & 5.7 & 5.8 \\
\hline 50 & 6-Methylhepta-3,5-dien-2-one & 1110 & - & - & - & 6.8 & 3.8 & 3.5 & - & - & - & - & - & - & 5.3 & 4.2 & 5.5 & - & - & 0.5 & 0.8 & 1.7 & 1.5 \\
\hline 51 & 2-Phenylethanol & 1121 & - & - & - & - & - & - & 6.7 & 3.6 & 2.8 & 6.1 & 2.1 & 3.3 & 12.2 & 5.9 & 5.8 & 0.1 & 0.3 & 0.8 & 0.6 & 3.5 & 3.5 \\
\hline 52 & $\alpha$-Campholenal & 1132 & 1.6 & 1.4 & 1.3 & 1.0 & 0.7 & 0.7 & - & - & - & - & - & - & - & - & - & - & - & - & - & - & - \\
\hline 56 & trans-Pinocarveol & 1147 & 0.6 & 1.4 & 1.2 & 0.1 & 0.5 & 0.6 & - & - & - & - & - & 0.3 & - & - & - & - & - & - & - & - & - \\
\hline 54 & cis-Verbenol & 1149 & 0.2 & 0.5 & 0.5 & - & - & - & - & - & - & - & - & - & - & - & - & - & - & - & - & - & - \\
\hline 55 & trans-Verbenol & 1153 & 2.2 & 4.1 & 4.8 & 0.6 & 1.6 & 2.0 & - & - & - & - & 0.5 & 0.3 & - & - & - & - & - & - & - & - & - \\
\hline 56 & Benzoic acid & 1162 & - & - & - & - & - & - & 14.5 & 4.2 & 13.2 & 0.2 & - & - & - & - & - & 13.0 & 39.9 & 29.2 & - & - & - \\
\hline 57 & Benzyl acetate & 1170 & - & - & - & - & - & - & 2.5 & 1.2 & 1.3 & - & - & 0.3 & 1.0 & 0.8 & 1.3 & 0.3 & 0.4 & 0.5 & - & - & - \\
\hline 58 & trans- $p$-Menth-2-ene-1,8-diol & 1174 & 0.5 & 0.6 & 0.6 & - & - & - & - & - & - & - & 0.2 & 0.3 & - & - & - & - & - & - & - & - & - \\
\hline 59 & Terpinen-4-ol & 1183 & 0.2 & 0.3 & 0.1 & 0.9 & 0.9 & 0.9 & - & - & 0.1 & 0.2 & 0.7 & 0.4 & - & - & - & - & - & - & - & - & - \\
\hline 60 & $p$-Cymene-8-ol & 1191 & 0.8 & 0.9 & 1.5 & 0.1 & 0.6 & 1.0 & - & - & - & 0.2 & 0.5 & 0.5 & - & - & - & - & - & - & - & - & - \\
\hline 61 & $\alpha$-Terpineol & 1195 & 1.3 & 1.4 & 1.2 & 0.2 & 0.6 & 0.7 & - & - & - & 0.1 & 0.5 & 0.4 & - & - & - & - & - & - & - & - & - \\
\hline 62 & Myrtenal & 1199 & 0.4 & - & 0.6 & - & - & - & - & - & - & - & - & - & - & - & - & - & - & - & - & - & - \\
\hline 63 & Myrtenol & 1201 & 0.4 & 0.3 & 0.6 & 0.5 & 0.6 & 0.7 & - & 0.3 & - & 0.4 & 0.2 & 0.3 & - & - & - & - & - & - & - & - & - \\
\hline 64 & Decanal & 1208 & 7.5 & 4.2 & 4.0 & 7.8 & 6.6 & 6.2 & - & - & - & - & - & 0.4 & 2.2 & 3.7 & 5.5 & 5.9 & 4.1 & 7.9 & 0.9 & 3.0 & 3.3 \\
\hline 65 & Verbenone & 1213 & 2.3 & 3.2 & 3.1 & 0.1 & 0.6 & 0.6 & - & - & - & - & - & 0.1 & - & - & - & - & - & - & - & - & - \\
\hline 66 & $\beta$-Cyclocitral & 1225 & - & - & - & - & - & - & 0.4 & 0.9 & 0.5 & - & - & - & - & - & 0.3 & - & - & - & - & - & - \\
\hline 67 & trans-Carveol & 1226 & 2.3 & 1.8 & 1.5 & 0.2 & 0.1 & 0.5 & - & - & - & - & - & - & - & - & - & - & - & - & - & - & - \\
\hline 68 & $\begin{array}{l}\text { 2-Methoxy-p-cymene } \\
\text { (Carvacrol methyl ether) }\end{array}$ & 1249 & - & - & - & 8.5 & 6.0 & 6.9 & - & - & - & - & 0.2 & - & - & - & - & - & - & - & - & - & - \\
\hline 69 & Carvone & 1250 & 0.5 & 0.4 & - & - & - & - & - & - & - & - & - & - & - & - & - & - & - & - & - & - & - \\
\hline 70 & Phenethyl acetate & 1262 & - & - & - & - & - & - & 1.0 & 0.6 & 1.2 & 0.1 & 0.5 & 0.9 & 1.7 & 1.4 & 2.8 & - & - & - & - & - & - \\
\hline 71 & 3-Phenylprop-2-enal & 1276 & - & - & - & - & - & - & 0.1 & - & 0.2 & - & - & - & - & - & 0.1 & - & - & - & - & - & - \\
\hline 72 & Bornyl acetate & 1289 & 0.3 & 0.4 & 0.5 & 1.1 & 2.4 & 3.1 & - & - & - & - & 0.2 & - & - & - & - & - & - & - & - & - & - \\
\hline 73 & Thymol & 1301 & 1.6 & 1.1 & 1.4 & - & - & 0.1 & - & - & - & - & - & - & 0.3 & 1.0 & 1.6 & 4.5 & 5.5 & 18.9 & 15.8 & 10.1 & 39.9 \\
\hline 74 & trans-Cinnamyl alcohol & 1315 & - & - & - & - & - & - & - & - & 0.5 & - & - & - & - & - & - & - & - & - & - & - & - \\
\hline 75 & $\alpha$-Longipinene & 1354 & - & - & - & 2.8 & 2.6 & 2.4 & - & - & - & 1.3 & 2.3 & 2.0 & 1.4 & 2.3 & 2.3 & - & - & - & - & 0.3 & - \\
\hline 76 & $\alpha$-Cubebene & 1355 & 0.9 & 1.0 & - & - & - & - & - & - & - & - & - & - & - & - & - & - & - & - & - & - & - \\
\hline
\end{tabular}


Table 1. Cont.

\begin{tabular}{|c|c|c|c|c|c|c|c|c|c|c|c|c|c|c|c|c|c|c|c|c|c|c|c|}
\hline \multirow{2}{*}{ No. } & \multirow{2}{*}{ Compound } & \multirow{2}{*}{ RI } & \multicolumn{3}{|c|}{ BP } & \multicolumn{3}{|c|}{ KP } & \multicolumn{3}{|c|}{ RP } & \multicolumn{3}{|c|}{ PP } & \multicolumn{3}{|c|}{ K1P } & \multicolumn{3}{|c|}{ K2P } & \multicolumn{3}{|c|}{ K3P } \\
\hline & & & I & II & III & I & II & III & I & II & III & I & II & III & I & II & III & I & II & III & I & II & III \\
\hline 77 & Longicyclene & 1374 & - & - & - & 2.6 & 2.6 & 2.9 & - & - & - & - & - & - & 2.0 & 3.9 & 6.1 & - & - & - & - & - & - \\
\hline 78 & $\alpha$-Ylangene & 1375 & - & - & - & 0.3 & - & - & 0.3 & 0.6 & 0.6 & - & - & - & - & - & - & - & - & - & - & - & - \\
\hline 79 & $\alpha$-Copaene & 1378 & 0.9 & 0.6 & 0.6 & 0.3 & 0.5 & 0.1 & 2.8 & 3.3 & 1.9 & - & - & - & - & 0.5 & 0.6 & 0.4 & 0.5 & 2.3 & - & - & - \\
\hline 80 & $\beta$-Bourbonene & 1387 & 1.2 & 1.0 & 0.7 & - & - & - & - & - & - & - & - & - & - & - & - & - & - & - & - & - & - \\
\hline 81 & Geranyl acetate & 1387 & - & - & - & 0.6 & 1.0 & 1.4 & - & - & - & - & - & - & - & - & - & - & - & - & - & - & - \\
\hline 82 & Tetradecane & 1400 & - & - & - & 0.7 & 0.5 & 0.9 & 0.2 & 0.3 & 0.2 & 0.2 & 0.2 & 0.8 & - & - & - & 0.4 & 0.3 & 0.4 & 0.1 & 0.5 & 0.4 \\
\hline 83 & cis-Caryophyllene & 1408 & 0.2 & 0.1 & - & - & - & - & - & - & - & - & - & - & - & - & - & - & - & - & - & - & - \\
\hline 84 & Junipene & 1405 & - & - & - & 0.7 & 0.9 & 0.8 & - & - & - & - & - & - & - & 0.6 & 0.6 & - & - & - & - & - & - \\
\hline 85 & Vanillin & 1407 & - & - & - & - & - & - & - & - & - & - & - & - & - & - & - & 1.9 & 8.1 & 10.7 & - & - & - \\
\hline 86 & Dodecanal & 1411 & 0.4 & 0.1 & 0.2 & 0.1 & 0.3 & 0.5 & - & - & - & - & - & - & - & - & - & - & - & - & - & - & - \\
\hline 87 & trans- $\beta$-Caryophyllene & 1422 & 2.7 & 2.3 & 2.6 & 2.3 & 2.4 & 2.9 & - & 0.9 & - & - & - & - & - & - & - & - & - & - & - & - & - \\
\hline 88 & $\alpha$-Humulene & 1456 & 0.5 & 0.5 & 0.5 & 0.2 & 0.5 & 0.5 & 0.1 & 0.3 & 0.1 & - & - & - & - & - & - & - & - & 0.1 & - & - & - \\
\hline 89 & Aromadendrene & 1463 & - & - & - & - & - & - & 2.0 & 0.3 & 2.2 & - & - & - & - & 0.4 & 0.6 & - & - & - & - & - & - \\
\hline 90 & $\alpha$-Amorphene & 1479 & - & 0.1 & - & - & - & - & 2.3 & 2.7 & 3.5 & - & - & - & - & 0.4 & 0.7 & - & - & - & - & - & - \\
\hline 91 & Ar-curcumene & 1485 & - & - & - & - & - & - & 0.9 & 0.9 & 1.2 & - & - & - & - & - & - & - & - & - & - & - & - \\
\hline 92 & $\alpha$-Muurolene & 1502 & 2.0 & 1.3 & 1.4 & 0.1 & 0.8 & 0.6 & 4.4 & 4.5 & 5.9 & - & - & - & - & 1.0 & 1.5 & - & - & - & - & - & - \\
\hline 93 & $\gamma$-Cadinene & 1517 & - & - & - & - & - & - & 6.8 & 6.6 & 9.3 & - & - & - & - & 1.1 & 1.6 & - & 0.4 & 0.4 & - & - & - \\
\hline 94 & cis-Calamenene & 1525 & 1.1 & 0.9 & 0.6 & 0.3 & 0.5 & 0.2 & - & - & - & - & 0.5 & - & - & - & - & - & - & - & - & - & - \\
\hline 95 & $\delta$-Cadinene & 1526 & - & - & - & - & - & - & 16.4 & 15.0 & 21.5 & 1.1 & 0.7 & 1.0 & 1.9 & 2.0 & 3.2 & - & 1.2 & 1.1 & - & - & - \\
\hline 96 & $\alpha$-Cadinene & 1540 & - & - & - & - & - & - & 1.4 & 1.2 & 2.1 & 1.3 & 1.9 & 3.3 & 0.1 & 1.7 & 2.0 & - & - & - & - & - & - \\
\hline 97 & $\alpha$-Calacorene & 1546 & - & - & - & - & - & - & 1.5 & 1.2 & 1.1 & - & - & 0.3 & - & - & - & - & - & - & - & - & - \\
\hline 98 & Caryophyllene oxide & 1585 & 1.3 & 1.9 & 1.7 & 1.2 & 2.6 & 3.7 & - & - & - & - & - & - & - & - & - & - & - & - & - & - & - \\
\hline 99 & Guaiol & 1601 & - & - & - & - & - & - & 1.8 & 0.9 & 2.7 & 18.5 & 14.3 & 28.9 & 8.9 & 3.2 & 6.5 & - & - & - & 2.3 & 2.6 & 2.9 \\
\hline 100 & Cedrol & 1603 & - & - & - & 7.7 & 4.7 & 1.0 & - & - & 0.5 & - & - & - & - & - & - & - & - & - & - & - & - \\
\hline 101 & $\gamma$-Eudesmol & 1636 & - & - & - & - & - & - & - & - & - & 1.7 & 1.6 & 3.7 & 2.0 & 1.1 & 1.7 & - & - & - & - & - & - \\
\hline 102 & $\alpha$-Cadinol & 1646 & - & - & - & - & - & - & 2.6 & 1.5 & 5.1 & 0.1 & 1.6 & 0.3 & - & - & - & - & - & - & - & - & - \\
\hline 103 & $\beta$-Eudesmol & 1654 & - & - & - & - & - & - & 2.2 & 0.6 & 3.7 & 3.5 & 3.1 & 7.3 & 3.6 & 1.9 & 2.8 & - & - & - & - & - & - \\
\hline 104 & $\alpha$-Eudesmol & 1657 & - & - & - & - & - & - & 2.1 & 0.6 & 3.3 & 2.2 & 1.9 & 4.7 & 2.9 & 1.3 & 1.9 & - & - & - & - & - & - \\
\hline 105 & $\tau$-Muurolol & 1659 & - & - & - & - & - & - & 1.2 & 0.6 & 1.7 & - & - & - & - & - & - & - & - & - & - & - & - \\
\hline 106 & Bulnesol & 1672 & - & - & - & - & - & - & 0.6 & - & - & 10.7 & 7.7 & 16.7 & - & - & - & - & - & - & - & - & - \\
\hline 107 & Benzyl benzoate & 1767 & - & - & - & - & - & - & - & - & - & - & - & - & - & - & - & - & 1.0 & 0.8 & - & - & - \\
\hline 108 & Hexadecanal & 1818 & - & - & - & 0.2 & 0.8 & 1.0 & - & - & - & - & - & - & - & - & 1.9 & - & - & - & - & - & - \\
\hline
\end{tabular}

BP, KP, RP, PP, K1P, K2P, K3P—the codes of the samples (Section 2.1.); I—Carboxen (CAR)/Polydimethylsiloxane (PDMS) fiber; II—Divinylbenzene (DVB)/CAR/PDMS fiber, III—PDMS/DVB fiber, RI = retention indices on HP-5MS column; - = not identified, *- - correct isomer not identified. 
Table 2. Volatiles obtained by hydrodistillation (HD/GC-MS).

\begin{tabular}{|c|c|c|c|c|c|c|c|c|c|}
\hline No. & Compound & RI & BP & KP & $\mathbf{R P}$ & PP & K1P & K2P & K3P \\
\hline 1 & 1,3-Dimethylbenzene & $<900$ & - & - & - & - & - & - & 0.1 \\
\hline 2 & Ethenylbenzene & $<900$ & - & - & - & - & - & - & 0.1 \\
\hline 3 & Nonane & 900 & 0.2 & 0.1 & - & - & - & - & 0.1 \\
\hline 4 & $\alpha$-Pinene & 942 & 11.3 & 0.2 & - & 0.1 & - & - & 0.1 \\
\hline 5 & Camphene & 958 & 0.2 & - & - & - & - & - & - \\
\hline 6 & Verbenene & 962 & 0.3 & - & - & - & - & - & - \\
\hline 7 & Benzaldehyde & 969 & - & - & 0.1 & - & - & - & 0.1 \\
\hline 8 & $\beta$-Pinene & 984 & 0.2 & - & - & - & - & - & - \\
\hline 9 & Octanal & 1005 & 0.2 & 0.1 & - & - & 0.1 & 0.1 & 0.2 \\
\hline 10 & $\delta$-3-Carene & 1015 & 0.2 & - & - & - & - & - & - \\
\hline 11 & p-Cymene & 1031 & 0.2 & - & - & - & - & - & - \\
\hline 12 & Limonene & 1035 & 0.2 & - & - & - & - & - & 0.1 \\
\hline 13 & Nonanal & 1106 & 0.5 & 0.3 & - & - & 0.1 & 0.2 & 0.3 \\
\hline 14 & $\alpha$-Campholene aldehyde & 1132 & 0.5 & - & - & - & - & - & - \\
\hline 15 & cis-Verbenol & 1149 & 1.0 & - & - & - & - & - & - \\
\hline 16 & trans-Verbenol & 1153 & 2.1 & - & - & - & - & - & - \\
\hline 17 & cis- $p$-Menth-2-ene-1,8-diol & 1156 & 0.8 & - & - & - & - & - & - \\
\hline 18 & Pinocarvone & 1167 & 0.2 & - & - & - & - & - & - \\
\hline 19 & Benzyl acetate & 1170 & - & - & 0.1 & - & - & - & - \\
\hline 20 & trans- $p$-Menth-2-ene-1,8-diol & 1174 & 2.9 & - & - & - & - & - & - \\
\hline 21 & Terpinen-4-ol & 1183 & 0.2 & - & - & - & - & - & - \\
\hline 22 & Octanoic acid & 1187 & - & - & 0.1 & - & 0.1 & - & 0.1 \\
\hline 23 & 4-Methylacetophenone & 1189 & 0.2 & - & - & - & - & - & - \\
\hline 24 & p-Cymene-8-ol & 1191 & 0.6 & - & - & - & - & - & - \\
\hline 25 & $\alpha$-Terpineol & 1195 & 0.6 & - & - & - & - & - & - \\
\hline 26 & Myrtenal & 1199 & 0.3 & - & - & - & - & - & - \\
\hline 27 & Myrtenol & 1201 & 0.6 & - & - & - & - & - & - \\
\hline 28 & Decanal & 1208 & 1.5 & 0.9 & 0.1 & 0.2 & 0.7 & 1.1 & 0.8 \\
\hline 29 & Verbenone & 1213 & 2.3 & - & - & - & - & - & - \\
\hline 30 & $\beta$-Cyclocitral & 1225 & - & - & 0.1 & - & - & - & - \\
\hline 31 & trans-Carveol & 1226 & 1.0 & - & - & - & - & - & - \\
\hline 32 & 3-Phenylbutan-2-one & 1249 & - & - & - & - & 0.1 & - & 0.1 \\
\hline 33 & 4-Methoxybenzaldehyde & 1260 & - & - & - & - & - & - & 0.1 \\
\hline 34 & Phenethyl acetate & 1262 & - & - & 0.2 & - & - & - & - \\
\hline 35 & 3-Phenylprop-2-enal & 1276 & - & - & - & - & 0.2 & - & 0.2 \\
\hline 36 & Nonanoic acid & 1284 & 0.2 & 0.2 & 0.1 & 0.1 & 0.4 & 0.1 & 0.1 \\
\hline 37 & Bornyl acetate & 1289 & 0.2 & - & - & - & - & - & - \\
\hline 38 & Thymol & 1301 & 0.8 & - & - & - & 0.2 & 1.3 & 2.4 \\
\hline 39 & Carvacrol & 1312 & 0.2 & - & - & - & - & - & - \\
\hline 40 & 2-Methoxy-4-vinylphenol & 1319 & - & - & 0.2 & 0.1 & 0.2 & 7.3 & 0.6 \\
\hline 41 & $\alpha$-Longipinene & 1354 & - & 0.1 & - & - & 0.1 & - & - \\
\hline 42 & 4-Phenylbut-3-en-2-one & 1362 & - & - & 0.1 & 0.1 & 0.2 & - & 0.1 \\
\hline 43 & Eugenol & 1363 & - & - & - & 0.2 & - & 0.1 & - \\
\hline 44 & 4-Ethenyl-1,2-dimethoxybenzene & 1373 & - & - & 0.2 & - & 0.6 & - & 1.2 \\
\hline 45 & Longicyclene & 1374 & - & 0.1 & - & - & - & - & - \\
\hline 46 & $\alpha$-Copaene & 1378 & 0.2 & - & 0.2 & - & - & - & - \\
\hline 47 & Decanoic acid & 1381 & 0.3 & 0.2 & 0.1 & 0.1 & 0.2 & 0.2 & 0.1 \\
\hline 48 & $\beta$-Bourbonene & 1387 & 0.2 & - & - & - & - & - & - \\
\hline 49 & Tetradecane & 1400 & - & 0.1 & - & - & 0.1 & 0.1 & 0.1 \\
\hline 50 & Junipene & 1405 & - & - & - & - & - & - & 0.1 \\
\hline 51 & Dodecanal & 1411 & 0.3 & 0.1 & - & - & 0.1 & 0.2 & 0.1 \\
\hline 52 & trans- $\beta$-Caryophyllene & 1422 & 0.8 & 0.1 & 0.1 & - & - & - & - \\
\hline 53 & $\alpha$-Humulene & 1456 & 0.2 & - & - & - & - & - & - \\
\hline 54 & Aromadendrene & 1463 & - & - & 0.6 & - & - & 0.1 & - \\
\hline 55 & $\alpha$-Amorphene & 1479 & 0.2 & - & 0.8 & - & 0.1 & - & - \\
\hline 56 & Pentadecane & 1500 & - & - & - & - & - & - & 0.1 \\
\hline 57 & $\alpha$-Muurolene & 1502 & 1.0 & 0.1 & 2.0 & - & 0.2 & 0.2 & - \\
\hline 58 & $\gamma$-Cadinene & 1517 & 0.3 & - & 3.1 & - & 0.2 & 0.3 & - \\
\hline 59 & $\delta$-Cadinene & 1526 & 0.8 & 0.3 & 6.6 & 0.1 & 0.4 & 0.7 & 0.6 \\
\hline 60 & $\alpha$-Cadinene & 1540 & - & - & 1.4 & - & 0.9 & - & - \\
\hline 61 & $\alpha$-Copaen-11-ol & 1541 & - & - & - & 0.9 & - & - & 0.6 \\
\hline 62 & $\alpha$-Calacorene & 1546 & 0.2 & - & 1.2 & - & 0.1 & - & - \\
\hline 63 & Dodecanoic acid & 1578 & 0.2 & - & - & - & 0.5 & 0.6 & - \\
\hline 64 & Caryophyllene oxide & 1585 & 5.8 & 0.5 & - & - & - & 0.1 & - \\
\hline 65 & Guaiol & 1601 & 1.6 & 3.1 & 4.4 & 14.3 & 4.6 & - & 5.2 \\
\hline 66 & $\gamma$-Eudesmol & 1636 & - & - & 5.5 & 3.9 & 2.6 & 0.3 & 1.6 \\
\hline 67 & $\alpha$-Cadinol & 1646 & 0.5 & - & 10.1 & - & 0.5 & 0.8 & 0.6 \\
\hline 68 & $\alpha$-Muurolol (torreyol) & 1652 & 0.5 & - & 1.9 & - & - & 0.3 & - \\
\hline
\end{tabular}


Table 2. Cont

\begin{tabular}{|c|c|c|c|c|c|c|c|c|c|}
\hline No. & Compound & RI & BP & KP & $\mathbf{R P}$ & PP & K1P & K2P & K3P \\
\hline 69 & $\beta$-Eudesmol & 1654 & - & - & 9.6 & 6.4 & 5.1 & 0.5 & 2.7 \\
\hline 70 & $\alpha$-Eudesmol & 1657 & - & - & 9.4 & 4.5 & 4.0 & - & 1.9 \\
\hline 71 & $\tau$-Muurolol & 1659 & - & - & - & - & - & 1.4 & - \\
\hline 72 & Bulnesol & 1672 & - & - & 2.5 & 15.9 & 2.1 & - & 2.4 \\
\hline 73 & Heptadecane & 1700 & 0.2 & - & 0.1 & 0.5 & - & 0.1 & - \\
\hline 74 & Benzyl benzoate & 1767 & 0.2 & - & 0.1 & - & 0.1 & 13.8 & 0.1 \\
\hline 75 & Tetradecanoic acid & 1772 & - & - & - & - & - & - & 0.1 \\
\hline 76 & Hexadecanal & 1818 & 1.0 & 2.9 & - & - & 3.8 & 1.6 & 3.3 \\
\hline 77 & Benzyl salycilate & 1870 & - & - & - & - & - & 2.7 & - \\
\hline 78 & Nonadecane & 1900 & 1.0 & 0.3 & 0.2 & 1.0 & 0.6 & 0.5 & 0.3 \\
\hline 79 & Heptadecan-2-one & 1903 & - & - & 0.1 & 0.3 & 0.1 & - & 0.2 \\
\hline 80 & Hexadecanoic acid & 1972 & - & 0.8 & 0.1 & 0.6 & 1.0 & 0.4 & 0.9 \\
\hline 81 & Manoyl oxide & 1990 & 8.7 & 0.3 & 0.2 & 0.5 & 0.1 & - & - \\
\hline 82 & Eicosane & 2000 & 2.9 & 0.6 & 0.1 & 0.1 & 0.2 & 0.2 & 0.1 \\
\hline 83 & Octadecan-2-one* & 2004 & - & - & 0.1 & 0.5 & 0.2 & - & 0.5 \\
\hline 84 & Dehydroabietan & 2054 & 3.6 & - & - & - & - & - & - \\
\hline 85 & Manool & 2055 & - & 5.7 & 0.6 & 0.3 & 0.5 & - & - \\
\hline 86 & Octadecan-1-ol & 2074 & - & 0.3 & - & - & 0.5 & - & 2.8 \\
\hline 87 & Abietadiene & 2077 & 3.1 & - & - & - & - & - & - \\
\hline 88 & Benzyl cinnamate & 2091 & - & - & - & - & - & 14.9 & 0.1 \\
\hline 89 & Heneicosane & 2100 & 3.2 & 4.1 & 1.0 & 3.5 & 2.3 & 3.7 & 2.2 \\
\hline 90 & Nonadecan-2-one & 2105 & - & - & 0.1 & 1.2 & 0.9 & - & 1.6 \\
\hline 91 & Docosane & 2200 & 4.2 & 13.5 & 11.2 & 12.7 & 23.5 & 2.7 & 26.0 \\
\hline 92 & Methyl sandaracopimarate & 2252 & 0.6 & - & - & - & - & - & - \\
\hline 93 & Dehydroabietal & 2261 & 2.4 & - & - & - & - & - & - \\
\hline 94 & (Z)-Tricos-9-ene & 2272 & 0.5 & 1.6 & 0.3 & 1.5 & 1.7 & 2.9 & 1.6 \\
\hline 95 & Methyl isopimarate & 2290 & 1.1 & - & - & - & - & - & - \\
\hline 96 & Tricosane & 2300 & 11.6 & 31.8 & 5.2 & 22.3 & 24.8 & 35.1 & 27.7 \\
\hline 97 & Abietadien-18-al & 2301 & 2.6 & - & - & - & - & - & - \\
\hline 98 & Dehydroabietic acid & 2350 & 1.0 & - & - & - & - & - & - \\
\hline 99 & Tetracosane & 2400 & - & 25.4 & 9.4 & - & 4.3 & - & - \\
\hline
\end{tabular}

$\mathrm{BP}, \mathrm{KP}, \mathrm{RP}, \mathrm{PP}, \mathrm{K} 1 \mathrm{P}, \mathrm{K} 2 \mathrm{P}, \mathrm{K} 3 \mathrm{P}$ - the codes of the samples (Section 2.1.); RI = retention indices on HP-5MS column; - = not identified, *-correct isomer not identified.

The most striking difference in the HS composition was found in BP. The predominant HS compound was the cyclic monoterpene hydrocarbon $\alpha$-pinene $(32.9-52.7 \%)$ that was present in several other samples and elsewhere (Table 1), but with significantly lower percentages. It was found as the major compound (64.6-77.6\%) of HS volatiles in Brazilian and Uruguayan propolis, and represented the $29.4 \%$ in Estonian propolis [26]. Other abundant monoterpenes in HS of BP, were biosynthetically derived from $\alpha$-terpinyl cation or $\alpha$-pinene: $p$-cymenene $(0.9-2.4 \%)$, limonene $(1.2-1.7 \%), \alpha$-campholenal (1.3-1.6\%), trans-verbenol $(2.2-4.8 \%), \alpha$-terpineol $(1.2-1.4 \%)$, verbenone (2.3-3.2\%) and trans-carveol (1.5-2.3\%). Similar as in BP HS, $\alpha$-campholenal, cis-verbenol, trans-verbenol, verbenone, $\alpha$-terpineol, nonanal, caryophyllene oxide, $\beta$-caryophyllene, $\beta$-bourbonene and cis-calamenene were found in one propolis sample from Southern Italy as unique HS features in distinction from other Italian propolis of different locations [27]. Sesquiterpenes, biosynthetically derived from farnesyl pyrophosphate (FPP), were present as minor HS constituents, the major ones were $\beta$-bourbonene (0.7-1.2\%), trans- $\beta$-caryophyllene (2.3-2.7\%), $\alpha$-muurolene (1.3-2.0\%), cis-calamenene (0.6-1.1\%) and caryophyllene oxide (1.3-1.9\%). No eudesmol isomers were present (Table 1). Two lower aliphatic aldehydes were found among relevant constituents: nonanal (2.2-5.1\%) and decanal (4.0-7.5\%). BP EO contained as the major constituent $\alpha$-pinene (11.3\%), but with ca. $3-5$ times lower abundance in comparison with HS. In general, $\alpha$-pinene has been reported usually as a trace among other dominating volatiles in few European propolis EO [28,29] and tropical propolis EO [30]. In 2006 this compound was identified as the major constituent in Greek propolis EO up to $45.8 \%$ indicating new type of European propolis [31]. Other abundant oxygenated monoterpenes were: trans-verbenol (2.1\%), cis-verbenol (1.0\%), trans- $p$-menth-2-ene-1,8-diol ( $2.9 \%)$, verbenone $(2.3 \%)$ and trans-carveol $(1.0 \%)$. Several oxygenated sesquiterpenes were found in BP EO: caryophyllene oxide $(5.8 \%)$, guaiol $(1.6 \%)$ and manoyl oxide (8.7\%). Among them, only caryophyllene oxide was found in HS with ca. 2 times lower percentage. Tricyclic diterpenes, formed biosynthetically from geranylgeranyl pyrophosphate, 
copalyl diphosphate and sandaracopimarenyl cation, were found only in BP EO: dehydroabietane $(3.6 \%)$, abietadiene $(3.1 \%)$, dehydroabietal $(2.4 \%)$, abietadien-18-al $(2.6 \%)$ and dehydroabietic acid $(1.0 \%)$ and methyl isopimarate (1.1\%). Higher aliphatic hydrocarbons were also present among major constituents of BP EO: eicosane (2.9\%), heneicosane (3.2\%), docosane $(4.2 \%)$ and tricosane $(11.6 \%)$. The same lower aliphatic aldehydes as in BP HS were found: decanal $(1.5 \%)$ and nonanal $(0.5 \%)$.

The major monoterpene of KP HS was $\alpha$-pinene (7.6-13.5\%) followed by minor abundance of limonene and $\alpha$-campholenal. However, it was not present in KP EO. Among sesquiterpenes, the most abundant were longicyclene (2.6-2.9\%), trans- $\beta$-caryophyllene $(2.3-2.9 \%)$, caryophyllene oxide $(1.2-3.7 \%)$ and cedrol $(1.0-7.7 \%)$. It is interesting to note that cedrol was exclusively found in KP HS and longicyclene only in KP HS and K1P HS. Tricyclic sesquiterpene alcohol $\alpha$-cedrol and tetracyclic sesqiterpene longicyclene are in general rarely found in propolis. $\alpha$-Cedrol was found by HS-SPME/GC-MS of Turkish (North Eastern Anatolia) propolis [32] in the range 7.0-15.6\%, and in Greek propolis by HD/GC-MS (6.3\% [31]). Longicyclene was found in HS of Chinese propolis (9.41\% [26]). Aliphatic aldehydes were abundant in KP HS: pentanal (1.4-1.6\%), hexanal (1.0-1.9\%), heptanal (0.9-1.6\%), octanal (1.5-3.2\%), nonanal (7.2-16.9\%) and decanal (6.2-7.8\%). Nonanal and decanal were found with higher percentages in Greek propolis by HD/GC-MS [31] and in the headspace of Turkish (Eastern Anatolia) propolis with minor abundance [32]. Another carbonyl compound was 6-methylhepta-3,5-dien-2-one (3.5-6.8\%), previously identified in Taiwanese green propolis EO (12.2\%; [33]). 2-Methoxy-p-cymene (carvacrol methyl ether) was the only aromatic compound that was present in KP HS (6.0-8.5\%). It was found previously in Greek propolis by HD/GC-MS (0.4-1.5\% [31]) and in traces in Portugese propolis by HD/GC-MS [34]. Another aromatic compound was benzaldehyde $(0.5-2.7 \%)$. KP EO is quite different in comparison with KP HS containing higher alkanes as the major constituents: heneicosane $(4.1 \%)$, docosane $(13.5 \%)$, tricosane $(31.8 \%)$ and tetracosane $(25.4 \%)$. Indian propolis EO contained [35] among major constituents long-chain alkanes (tricosane (13.6\%), hexacosane, heptacosane and heneicosane). Two sesquiterpene alcohols were found as major compounds in KP EO: guaiol (3.1\%) and manool (5.7\%). They were found in EO of Greek propolis [31] with relevant percentages (guaiol up to $5 \%$ and manool up to $5.2 \%$ ).

\subsubsection{Comparison with Probable Plant Source Volatiles}

Cupressus spp. and Juniperus spp. have been most frequently reported in last decade as sources of Mediterranean type propolis [27,31] and those plants are naturally widespread, among others parts of the Adriatic region, on the islands Biševo and Korčula as reported in the Flora Croatica Database [36]. $\alpha$-Pinene found in the investigated samples could originate from exudates of Cupressus sempervirens $\mathrm{L}$. known as one of the source plants utilized by the bees to form propolis $[27,31]$ and it is known that EO of C. sempervirens from Croatia [37] contains $\alpha$-pinene as the main component (up to $79.2 \%$ ). In propolis samples from Southern Italy (Adriatic coast) and Greece $\alpha$-pinene was also identified at high percentage and other coniferous species were also suggested as the plant source [27,31]. However, the abundance of monoterpene fraction, with a high $\alpha$-pinene content, was also described for the species of the genus Juniperus [38] and it was reported that monoterpenes may also contribute to propolis in specific geographical locations [34]. $\alpha$-Pinene is found as the main component of the needles EO $(41.37 \%)$ and berries EO $(66.30 \% ; 61,21 \%)$ of the wild Croatian Juniperus oxycedrus L. [39]. However, the contribution of other plant sources is also possible, especially Pinus spp. that are well known to contain $\alpha$-pinene in the resin EO (21.39-25.40\% [40]) and in the headspace (66.2\%; 73.4\% [41]). Limonene, found with minor abundance in VP HS and EO, was identified in the EO of C. sempervirens and J. oxycedrus from Croatia [37-39] and Pinus spp. resin [40,41]. Manoyl oxide (12.29\%) and $\alpha$-campholene aldehyde $(0.15 \%)$ were present in J. oxycedrus needles EO from Croatia [39], in Pinus spp. resin $(0.4-0.9 \%$ [41]) and in BP EO. Manoyl oxide was also identified in C. sempervirens EO [37,38]. Manool and guaiol present in KP EO were also found in Cupressus and Juniperus plants [42,43]. Tricyclic diterpenes (particularly methyl isopimarate, dehydroabietic acid, dehydroabietane, dehydroabietal) were found in Juniperus plants [43]. Abietane diterpenoids from C. sempervirens were also reported [44] 
and dehydroabietane was isolated from the cypress EO [45] and in BP EO. $\alpha$-Cedrol, having a woody and spicy characteristic smell, was found in C. sempervirens EO at $23.68 \%$ [45] and in the range $1.2-12.9 \%$ [37]. Although it was not found in J. oxycedrus from Croatia [39] it was found in J. oxycedrus from Turkey (2.3\%-9.7\% [44]). Some of the volatile compounds in BP EO may be linked to other Cistus species-for example Cistus salvifolius L. and their chemotypes, that provide high volatiles diversity and are dominated by oxygenated sesquiterpenes and monoterpenes [46]. Manoyl oxide is also one of the major constituents of BP EO, but was also the main component of essential oil obtained from Cistus creticus L. [47], while essential oil of C. creticus subsp. eriocephalus was characterized by i.a. manoyl oxide, $\alpha$ - and $\delta$-cadinene, viridiflorol and bulnesol [48]. On the other hand, essential oil of other Cistus species cultivated in Corsica, such as Cistus ladaniferus L. was dominated by $\alpha$-pinene (11.1-47.4\%), that is another relevant compound found in BP EO [49]. In general, the size of $n$-alkanes from black pine needles wax ranged from $C_{16}$ to $C_{33}$ and the most abundant were $C_{23}, C_{25}, C_{27}$ and $C_{29}$ [50]. Cupressaceae leaf wax has been characterized (chemotaxonomic significance) by moderate percentages of $n$-alkanes [51], particularly of $C_{31}, C_{33}, C_{27}$ and $C_{21}$, including $C_{22}, C_{23}$ and $C_{24}$. Heneicosane, docosane, tricosane and tetracosane were found as major constituents in KP EO. Heneicosane was found with very high percentages only in C. sempervirens [52]. In addition, all leaf-wax samples of $J$. communis showed predominance of $n$-alkane $C_{33}$ in the needle wax (30.0-61.4\%), which appears to be a common feature for Juniperus species [53] (the range of $n$-alkanes reported by different authors varied from mid-length $\left(C_{23}\right)$ to long-chain $n$-alkanes $\left(C_{25}-C_{35}\right)$ ).

\subsubsection{Mediterranean Propolis (Poplar Type) Volatiles}

According to the chemical composition (Tables 1 and 2), the samples RP, PP, K1P, K2P and K3P were classified in this group. The islands Rab, Pag and Krk are located closer to the Adriatic coast, characterized by an abundance of Populus spp. [36].

Sesquiterpenes represent the most abundant group of compounds in RP HS being dominated by the bicyclic hydrocarbons of cadinane type: $\delta$-cadinene (15.0-21.5\%) and $\gamma$-cadinene $(6.6-9.3 \%)$ followed by $\alpha$-cadinene (1.2-2.1\%), $\alpha$-muurolene (4.4-5.9\%), $\alpha$-copaene $(1.9-3.3 \%)$ and $\alpha$-amorphene (2.3-3.5\%). Higher percentages of cadinene isomers were previously found as abundant in Albanian propolis EO [54] and HS and EO of northern Italian propolis [27]. Two oxygenated sesquiterpene isomeric alcohols of the selinane series were identified: $\beta$-eudesmol $(0.6-3.7 \%)$ and $\alpha$-eudesmol (0.6-3.3\%). Another group of present constituents was non-terpene aromatic compounds: benzaldehyde (0.2-2.1\%), benzyl alcohol (2.1-6.9\%), 2-phenylethanol (2.8-6.7\%), benzyl acetate (1.2-2.5\%), benzoic acid $(4.2-14.5 \%)$ and phenethyl acetate $(0.6-1.2 \%)$. Lower aliphatic $C_{5}$-compounds were identified in RP HS (not found in RP EO), the major ones were 3-methylbut-3-en-1-ol (0.1-2.1\%), 3-methylbut-2-en-1-ol $(0.7-2.7 \%)$, 3-methylbut-2-enal (0.2-1.2\%) and 2-methylbut-2-enoic acid (1.2-5.7\%). $\gamma$-Cadinene (3.1\%) and $\delta$-cadinene $(6.6 \%)$ were present in RP EO as well as $\gamma$-eudesmol $(5.5 \%), \beta$-eudesmol $(9.6 \%)$ and $\alpha$-eudesmol (9.4\%). Isomers of cadinene were present with lower abundance in comparison to RP HS. Sesquiterpene alcohols exclusively found in RP EO were: guaiol (4.4\%), $\alpha$-cadinol (10.1\%), $\alpha$-muurolol $(1.9 \%)$ and bulnesol (2.5\%). High abundance of $\alpha$-cadinol can be pointed as a distinctive characteristic of RP EO. Higher alkanes were also present: heneicosane (1.0\%), docosane $(11.2 \%)$, tricosane $(5.2 \%)$ and tetracosane (9.4\%). EO of Indian propolis [35] was shown to contain $45.83 \%$ of long-chain alkanes (including heneicosane, tricosane, hexacosane and heptacosane).

PP HS is quite distinct from other samples, containing two isomeric tertiary bicyclic alcohols with a structure of azulene type guaiol (14.3-28.9\%) and bulnesol (7.7-16.7\%) as predominant components. They are biosynthetically derived from guaiyl cation and germacryl cation derived from $(E, E)$-farnesyl cation. Three typical sesquiterpene alcohols were present: $\gamma$-eudesmol (1.6-3.7\%), $\beta$-eudesmol (3.1-7.3\%) and $\alpha$-eudesmol (1.9-4.7\%). The most abundant monterpene in PP HS was $\alpha$-pinene (3.6-5.9\%). Relatively high content of lower aliphatic $\mathrm{C}_{5}$-compounds was found in PP HS: 3-methylbut-3-en-1-ol (0.5-1.7\%), 2-methylbut-2-enal (0.3-3.2\%), 3-methylbut-2-en-1-ol (0.8-2.6\%), 3-methylbut-2-enal $(0.5-7.9 \%)$, 2-methylbutanoic acid (1.2-1.9\%) and 2-methylbut-2-enoic acid 
(0.9\%-3.7\%). They belong to hemiterpene compounds derived from 3,3-dimethylallyl pyrophosphate and isopentenyl pyrophosphate [55]. Several aromatic compounds were present as minor constituents: benzaldehyde (0.2-2.1\%), benzyl alcohol (0.5-1.5\%) and 2-phenylethanol (2.1-6.1\%). The composition of PP EO is quite peculiar. Guaiol (14.3\%) and bulnesol (15.9\%) were also found among major PP EO constituents (similar as in PP HS) followed by $\gamma$-eudesmol (3.9\%), $\beta$-eudesmol (6.4\%) and $\alpha$-eudesmol (4.5\%). Higher alkanes were predominant in PP EO: heneicosane (3.5\%), docosane (12.7\%) and tricosane $(22.3 \%)$. Guaiol was found as major constituent in the extract of French propolis [56] and in the sample of Greek propolis [31]. Bulnesol was found in the extract of Lebanese propolis [57].

In distinction from other samples, acetic acid was abundant in K1P, K2P and K3P HS up to $31.9 \%$. It was already found as the most abundant compound in Chinese propolis (Heilongjiang) HS, accounting for about $60 \%$ of the total GC area [58]. It is interesting to note high abundance of monoterpene hydrocarbon limonene, particularly in K2P HS (5.7-11.8\%). High content of limonene was found in Croatian propolis EO (10.5\%; 11.2\% [28]) and Uruguayan propolis HS (15.6\%; [26]). $\alpha$-Longipinene $(1.4 \% ; 2.3 \% ; 2.3 \%)$ and longicyclene $(2.0 \% ; 3.9 \% ; 6.1 \%)$ were present only in K1P HS. Benzene derivatives were abundant: benzaldehyde in K1P HS (1.9-9.8\%), K2P HS (3.2-17.9\%) and K3P HS (2.6-4.7\%), benzyl alcohol in K1P HS (1.7-3.7\%), 2-phenylethanol in K1P HS (5.8-12.2\%) and K3P HS (3.1-5.3\%), benzoic acid in K2P HS (13.0-29.2\%). Lower aldehydes were present: nonanal in K1P HS (3.2-3.6\%), K2P HS (6.1-11.0\%) and K3P HS (1.9-5.8\%) and decanal in K1P HS (2.2-5.5\%), K2P HS (4.1-7.9\%) and K3P HS (0.9-3.3\%). Guaiol was present in K1P HS (3.2-8.9\%) and K3P HS (2.3-2.9\%). Aliphatic $\mathrm{C}_{5}$-compounds were found: 3-methylbut-3-en-1-ol in K1P HS (0.7-1.7\%) and K3P HS (1.7-1.8\%), 3-methylbut-2-en-1-ol in K1P HS (1.5-3.7\%) and K3P HS (1.5-2.9\%), 3-methylbut-2-enal in K3P HS (1.1-4.5\%) and 2-methylbutanoic acid in K1P HS (2.0-2.2\%) and K3P HS (0.7-1.4\%). Thymol was the most abundant in K3P HS (10.1-39.9\%). However, thymol is not a typical propolis constituent and can be connected with anti-Varroa treatment $[18,59]$. Typical sesquiterpenes were found in EO (K1P; K2P; K3P): $\alpha$-eudesmol (0.3-2.6\%), $\beta$-eudesmol (0.5-5.1\%), $\gamma$-eudesmol $(0.3-2.6 \%)$, guaiol $(0.0-5.2 \%)$ and $\alpha$-cadinol (0.5-0.8\%). Benzyl benzoate was most abundant in K2P EO $(13.8 \%)$ as well as benzyl cinnamate $(14.9 \%)$ and benzyl salicylate (2.7\%). Several higher alkanes were found in EO (K1P; K2P; K3P): heneicosane (2.2-3.7\%), docosane (2.7-23.5\%) and tricosane (24.8-35.1\%).

\subsubsection{Comparison with Populus spp. Volatiles}

Poplar spp. (Populus nigra L., Populus tremula L. and Populus alba L.) and the buds resin have been reported as a primary source of propolis from temperate zones [6]. As reported in the Flora Croatica Database [36], the area of the islands Pag, Rab and Krk is within the range of different Poplar ssp. abundance (particularly P. nigra, P. tremula and P. alba). Black poplar (P. nigra) buds exhibited different EO profiles (both qualitatively and quantitatively). Some buds contained mainly oxygenated sesquiterpenes, particularly $\alpha$-, $\beta$ - and $\gamma$-eudesmols that are present in P. nigra buds $\mathrm{EO}[60,61]$ as well as their $\mathrm{CO}_{2}$ extracts [20]. These compounds are present in K1P, K2P and K3P EO, PP HS and EO as well as RP HS and EO that could be connected with the P. nigra (eudesmol chemotype) distribution on the islands Krk, Rab and Pag. P. nigra buds EO [20] contained bulnesol (4.4\%) and guaiol (5.7\%), as well as their supercritical $\mathrm{CO}_{2}$ extracts (guaiol (2.7-3.7\%); bulnesol (2.5-3.4\%)). Hexane extracts of P. nigra buds [62] analyzed by GC-MS contained, among other constituents, guaiol ( $8.7 \%)$ and bulnesol (3.8\%). Isomers guaiol and bulnesol were characteristic for PP HS and EO as well as RP EO indicating dominant influence of $P$. nigra (bulnesol/guaiol chemotype) from the islands Pag and Rab. Several P. nigra buds EO [60] were mainly composed of sesquiterpene hydrocarbons (mainly ar- and $\gamma$-curcumene and $\delta$-cadinene). Isomers $\delta-, \gamma$ - and $\alpha$-cadinene were typical for RP HS and EO that can be also connected with P. nigra (cadinene chemotype) distribution on the island Rab. P. nigra buds EO was reported also with different profiles containing a mix of sesquiterpenes and derivates of benzoic acid, mainly prenyl benzoate [60]. About $50 \%$ of the GC chromatograms of hexane extracts of $P$. nigra buds [62] consisted of higher alkanes including docosane and tricosane (found in RP, PP, K1P, K2P and K3P EO), but $\mathrm{C}_{25}-\mathrm{C}_{31}$ alkanes dominated (they were not present in investigated propolis EO probably due to lower volatility). Higher alkanes 
are known to be one of the main components of cuticular waxes of plant leaves and stems. Aliphatic alcohols 2-methylbut-3-en-2-ol, 3-methylbutan-1-ol, (E)-2-methylbut-2-en-1-ol and (E)-2-metylbut-2-enoic acid were identified in P. nigra buds EO [61]. These hemiterpenes were present in total amount up to $8 \%$. Hemiterpenes were present in RP HS, PP HS, K1P HS and K3P HS. The esters of hemiterpene (prenyl) alcohols and cis/trans caffeic, ferulic and isoferulic acids were previously identified in the bud exudate of P. nigra [63], but as non-volatile compounds they cannot be isolated by hydrodistillation. Aspen buds (P. tremula) also exhibited different EO profiles. Several aspen buds [60] contained mostly benzoic acid derivates (benzyl benzoate, salicyl benzoate and trans-benzyl cinnamate). They were identified in K2P EO indicating aspen (P. tremula)-type propolis and P. tremula is reported on the island Krk [36].

\subsection{Chemical Characterization by FTIR-ATR Spectroscopy}

In most of the FTIR spectroscopic studies, propolis research has been focused on ethanolic propolis extracts (EPE) [64-69] while raw beehive propolis that serves as a source (raw material) for preparing propolis-based products (such as the most commonly used propolis ethanolic tincture) has been covered only by two reports [70,71].

Complexity of FTIR-ATR spectrum of raw propolis arises from its complex chemical composition that varies significantly depending on the source of the plant exudate which bees have collected. Still, chemical composition of propolis has generally been represented by two groups of constituents: balsam content (40-70\%) mostly comprised of numerous phenolics, and non-balsam content containing beeswax (20-35\%), essential oil (3-5\%; mono and sesquiterpenes) and other organic compounds (ca. 5\%; ash content, polysaccharides: proteins, amino acids, mechanical impurities, etc.). Balsam content is the most complex compositional segment of propolis and includes the following substances: phenols, phenolic acids, esters, flavanones, dihydroflavanones, flavons, flavonols, chalkones, phenolic glycerides and other minor compounds [72].

Given that FTIR spectrum of propolis reflects its overall chemical composition, identification of absorption bands, i.e., assignment of functional groups within the IR spectrum of raw propolis material represents a demanding task due to a large number of various organic compounds and corresponding molecular vibrations that can be observed in it. Nevertheless, it is possible to distinguish signals that are highly specific for particular organic compound based on the comprehensive literature data on propolis chemical composition, as well as various sources of FTIR spectral data (e.g., spectral libraries and atlases).

General assignment of molecular vibrations in the propolis spectrum is presented on an average FTIR-ATR spectrum of K3 sample from Krk island (Figure 1). The complexity of its absorptions is arising from a complex composition dominated by substances from the balsam group of compounds. A broad strong band at $3350 \mathrm{~cm}^{-1}$ observed in analyzed propolis samples occurs due to the $\mathrm{O}-\mathrm{H}$ stretching vibration of the phenolic group. Spectral features related to phenols are also characterized by interaction of $\mathrm{O}-\mathrm{H}$ deformation and $\mathrm{C}-\mathrm{O}$ stretching vibrations which can be observed in the spectral range between 1405 and $1220 \mathrm{~cm}^{-1}$ (with maximum absorbance at $1375 \mathrm{~cm}^{-1}$ ) and in the form of series of weak vibrations between $1260-1180 \mathrm{~cm}^{-1}$. Phenols are also represented with a doublet at $1640 \mathrm{~cm}^{-1}$ assigned to aromatic ring $\mathrm{C}=\mathrm{C}$ stretching and aromatic $\mathrm{C}-\mathrm{H}$ deformation vibration at $1110 \mathrm{~cm}^{-1}[73]$. A medium absorption at $720 \mathrm{~cm}^{-1}$ is peaking due to $\mathrm{CH}_{2}$ rocking of hydrocarbons originating from beeswax [72]. An overlapping effect with out-of-plane deformation of the $\mathrm{O}-\mathrm{H}$ group of phenols is possible in this region. A weak band peaking at $1515 \mathrm{~cm}^{-1}$ can be assigned to flavonoids; $\mathrm{C}=\mathrm{C}$ (aromatic ring) stretching [68]. C-H deformations and aromatic stretching at $1461 \mathrm{~cm}^{-1}$ is assigned to flavonoids (hydrocarbons $\mathrm{CH}_{3}$ and $\mathrm{CH}_{2}$ vibrations are overlapping). The most prominent absorption in the fingerprint region is a broad band with absorption maximum observed at $1170 \mathrm{~cm}^{-1}$ that corresponds to the $\mathrm{C}-\mathrm{O}$ asymmetric stretching vibration of esters related to long-chain aliphatic acids. Saturated aliphatic esters typically absorb at $1750-1725 \mathrm{~cm}^{-1}$ [73]. Thus, absorption occurring at $1736 \mathrm{~cm}^{-1}$ is due to the carbonyl group $(\mathrm{C}=\mathrm{O})$ stretching vibrations of the ester bond. This vibration can be attributed to the monoesters from beeswax in propolis, as the major ester component of beeswax $(\sim 40 \%)$ [74]. As 
shown in Figure 1B, other medium and weak intensity absorption bands are attributed to the vibrations of various functional groups of phenols, flavonoids and hydrocarbons, some of which overlap.
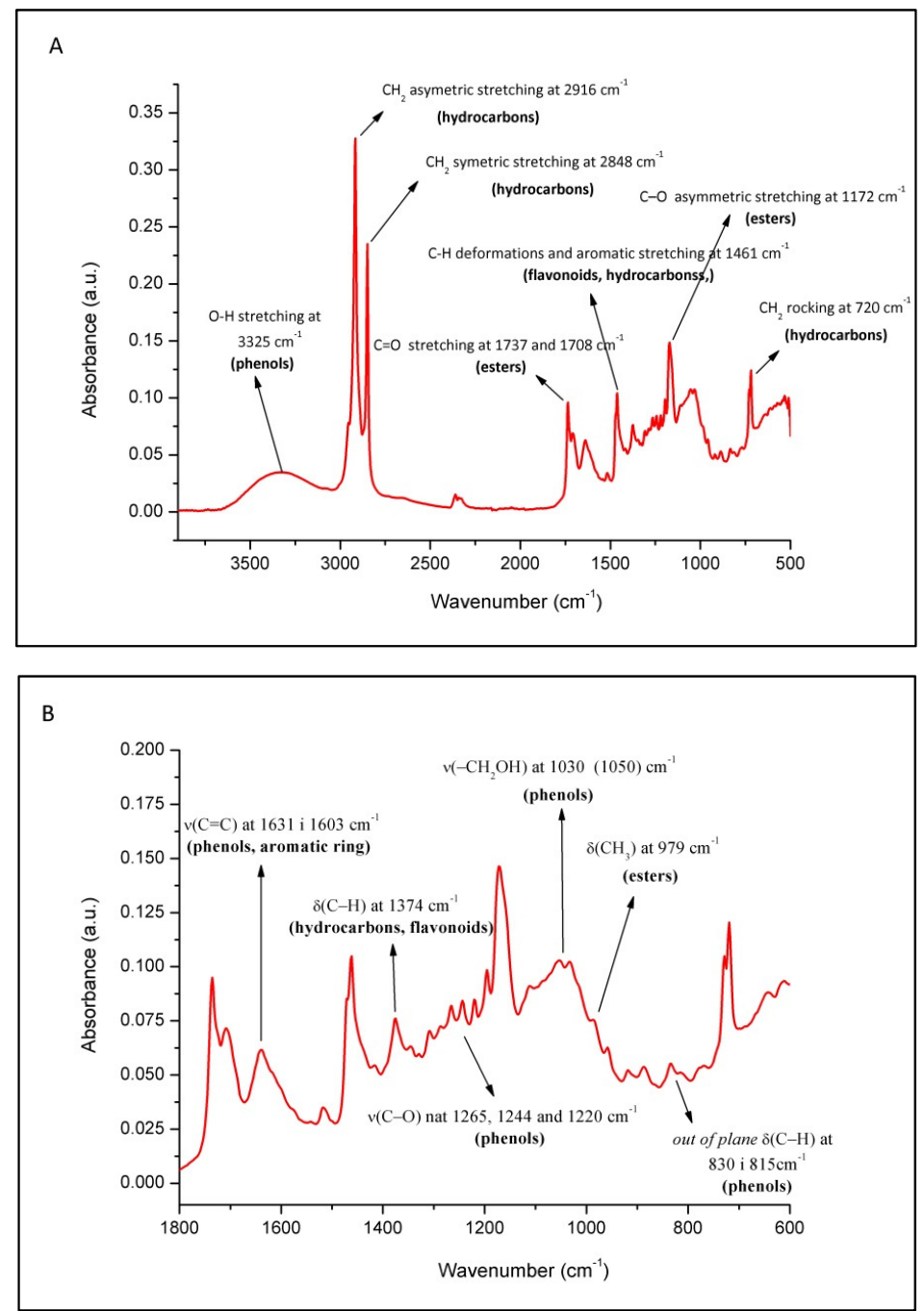

Figure 1. Characteristic FTIR-ATR spectrum of raw propolis (average K3 sample) with assigned underlying molecular vibrations: Spectral region from 3800 to $500 \mathrm{~cm}^{-1}$ (A); fingerprint region $1800-600 \mathrm{~cm}^{-1}$ (B).

As presented in Figure 2, unique spectral patterns of propolis from different Adriatic Sea islands reflect compositional differences (different band positions and intensities) between the samples and indicate significant compositional differences. Variations in hydrocarbon content (at 2916, 2848, 1461, 730 and $720 \mathrm{~cm}^{-1}$ ) and esters (at $1736 \mathrm{~cm}^{-1}$ ) originating from beeswax present in propolis [70,73] are not distinguished significantly between analyzed propolis samples, as opposed to spectral variations associated with phenolics and other balsam-related components that are clearly observable. These differences are mainly related to the content of phenols, flavonoids and esters, and corresponding spectral variations are most prominent in the fingerprint region $\left(1800-600 \mathrm{~cm}^{-1}\right)$. The results of spectral analysis revealed great similarity of propolis samples from the islands Biševo and Korčula indicating similar botanical origin. Two propolis samples from Krk (K1P and K3P) were also found to be similar, while propolis from Pag, Rab, as well as K3P from Krk, showed specificities due to characteristic phenolic and ester bands (indicating that propolis was collected from different resin sources). As presented in Figures 3 and 4, fingerprint region displays a series of multiple absorption bands occurring due to mentioned groups of organic compounds. It can be observed that propolis from Biševo and 
Korčula exhibit similar spectral pattern in this region, while propolis from other islands (Pag, Rab, Krk) reflect unique spectral features. Among them, Pag propolis and K2P propolis (Krk propolis from Pinezići) are the most distinguished ones due to the high phenolic content (represented by the most prominent phenolic band at $1030 \mathrm{~cm}^{-1}$ ), while Rab (RP) and K2P propolis stand out for their higher ester content (absorption maximum at $1070 \mathrm{~cm}^{-1}$ ).

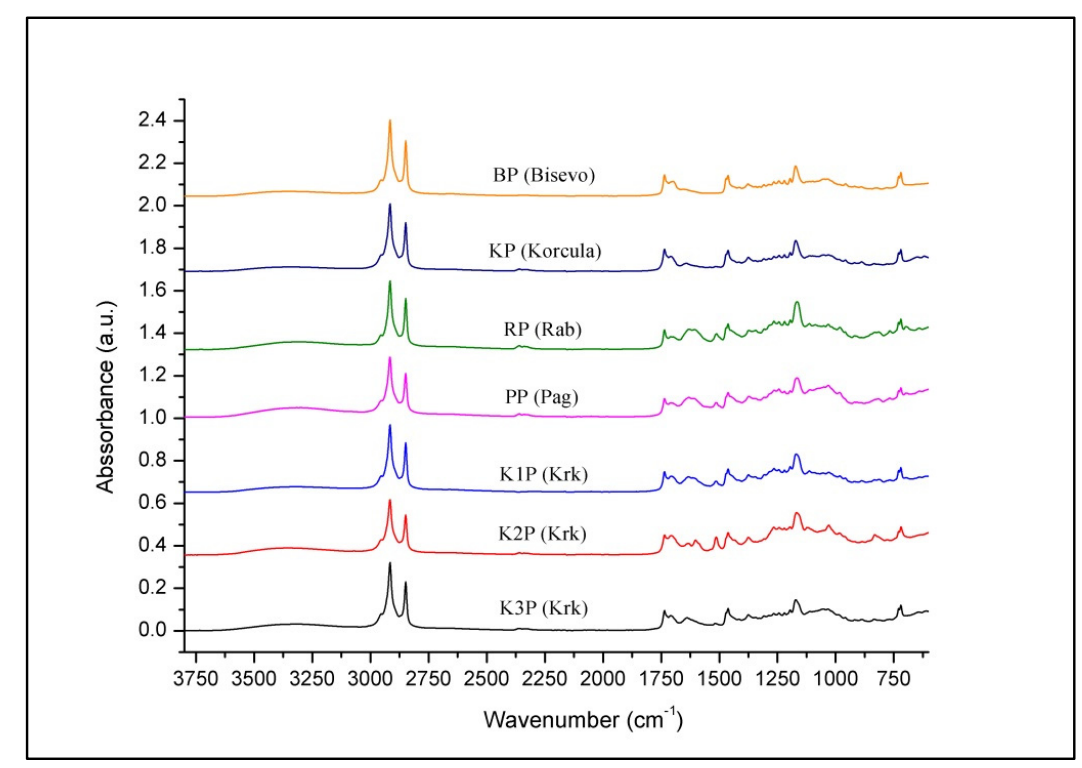

Figure 2. Average FTIR ATR spectrum of investigated propolis collected from five Adriatic Sea islands (Krk, Rab, Pag, Biševo and Korčula).

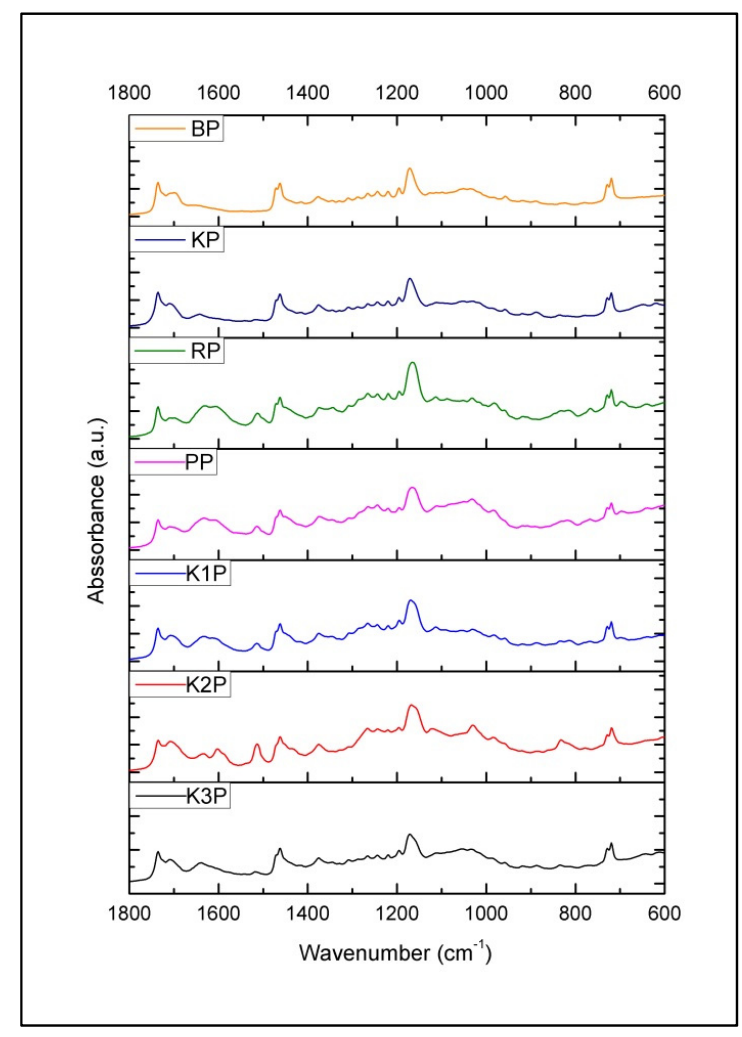

Figure 3. Average FTIR ATR spectrum of investigated propolis collected from five Adriatic Sea islands (Krk, Rab, Pag, Biševo and Korčula)—fingerprint region $\left(1800-600 \mathrm{~cm}^{-1}\right)$ emphasizing the most significant spectral variations. 


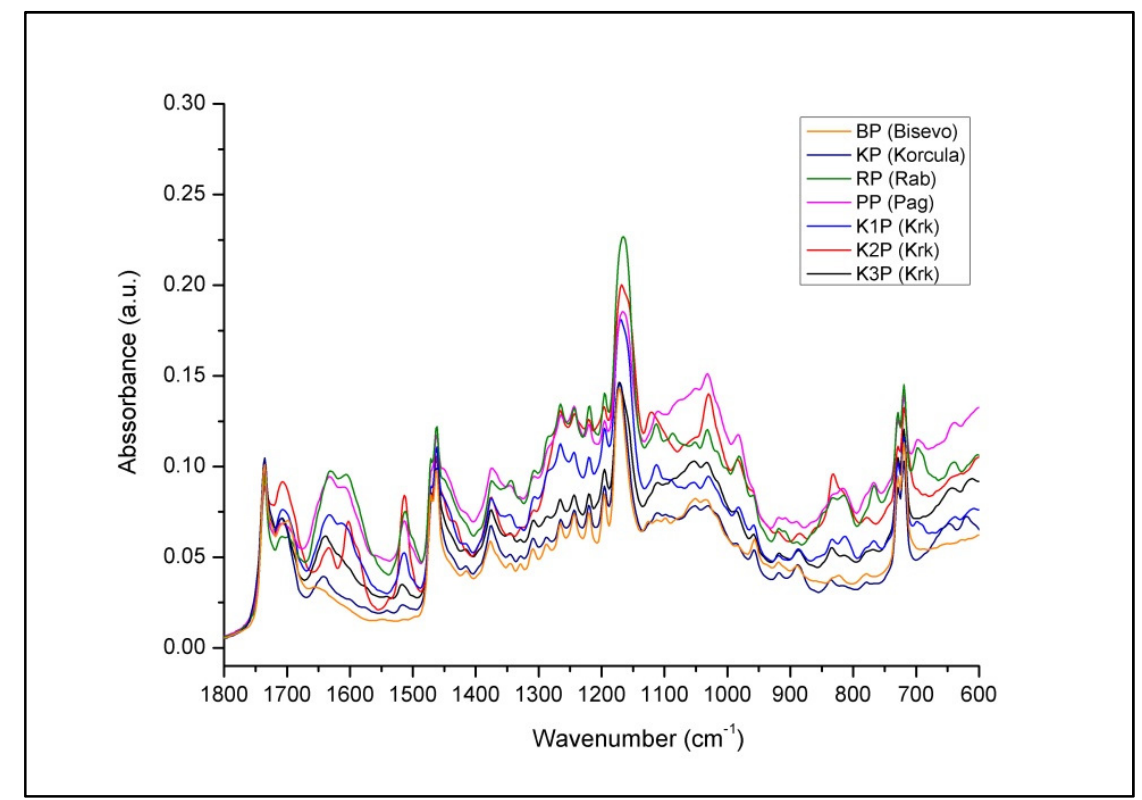

Figure 4. Overlaid average FTIR ATR spectrum of investigated propolis collected from five Adriatic Sea islands (Krk, Rab, Pag, Biševo and Korčula)—fingerprint region (1800-600 cm ${ }^{-1}$ ) emphasizing comparative spectral variations.

\subsection{UHPLC-DAD-QqTOF-MS}

The ethanolic extracts of seven propolis samples were analyzed, disclosing high diversity between the samples collected from different Croatian islands. Nearly 120 compounds were identified or tentatively identified in the samples (mainly derivatives of phenolic acids, flavonoids and terpenes (Table 3). Selected major phenolics were quantified and significant differences in their abundance were found. Content of phenolics in RP was much higher than in other samples (Table 4).

The most relevant groups of compounds determined by UHPLC-DAD-QqTOF-MS were phenolics, including flavonoids, phenylpropanoids and simple phenols. The extracts were rich in variety of flavonoids, including numerous methylated derivatives, represented mainly by flavones: chrysin, chysin 5-methyl ether, apigenin, luteolin, luteolin 5-methyl ether; flavanones: pinocembrin, pinocembrin 7-methyl ether (pinostrobin), naringenin, naringenin 7-methyl ether (sakuranetin), eriodyctiol, 4'-methoxy eriodictyol (hesperetin); flavonols: quercetin, quercetin 3-methyl ether, quercetin 7-methyl ether (rhamnetin), quercetin $3^{\prime}$-methyl ether (isorhamnetin), isomers of quercetin dimethyl ether, quercetin 3,7,4'-trimethylether, kaempferol, kaempferol 4' -methyl ether (kaempferide), kaempferol 3,4'-dimethyl ether, pinobanksin, pinobanksin 5-methyl ether, pinobanksin 7-methyl ether, galangin, galangin 5-methyl ether and only in BP: myricetin 7,4'-dimethylether, myricetin 3,7, $4^{\prime}$-trimethylether, myricetin 3,7, $4^{\prime}, 5^{\prime}$-tetramethylether. Most of those compounds were present in majority of the samples at least in traces.

The amounts of the most common, quantified compounds determined in all the samples were $0.05-1.76 \mathrm{mg} / \mathrm{g}$ (isorhamnetin), $0.24-12.28 \mathrm{mg} / \mathrm{g}$ (luteolin-5-O-methyl ether), $0.08-1.94 \mathrm{mg} / \mathrm{g}$ (rhamnetin; in BP it was found in traces), $0.04-30.71 \mathrm{mg} / \mathrm{g}$ (chrysin), $1.70-17.08 \mathrm{mg} / \mathrm{g}$ (sakuranetin), $0.13-3.01 \mathrm{mg} / \mathrm{g}$ (kaempferol). Elevated abundance of pinobanksin, chrysin, pinocembrin, pinobanksin-3-O-acetate, pinobanksin-3-O-propanoate were particularly pronounced in RP, K1P, and K3P. Myrycetin $3,7,4^{\prime}, 5^{\prime}$-tetramethyl ether $(4.29 \mathrm{mg} / \mathrm{g})$ was found only in BP. The particularly high amounts of different flavonoids were found in RP. The MS data for particular, rarely occurring flavonoid myricetin $3,7,4^{\prime}, 5^{\prime}$-tetramethyl ether were consistent with those previously reported. The exact mass 375.1088 $\left(\mathrm{ESI}^{+}\right)$corresponded to $\left[\mathrm{M}+\mathrm{H}^{+}\right]^{+}$and the MS/MS spectrum obtained at $35 \mathrm{eV}$ was $(\mathrm{m} / \mathrm{z}): 360,345,332$, $331,330,318,317,315,314$ [75]. 
Phenylpropanoids were found both as free caffeic $(0.15-6.80 \mathrm{mg} / \mathrm{g}, \mathrm{BP}, \mathrm{KP}$-traces), $p$-coumaric $(0.17-4.22 \mathrm{mg} / \mathrm{g}, \mathrm{KP}$-traces), ferulic $(0.31-4.10 \mathrm{mg} / \mathrm{g}$, $\mathrm{KP}$-traces) and isoferulic acids $(0.09-8.30 \mathrm{mg} / \mathrm{g}$, $\mathrm{BP}$ - traces, $\mathrm{KP}$ - not detected) but also their derivatives including variety of glyceryl and prenyl esters. The latter were quantified in RP, PP, K1P, K2P, K3P but found as traces in other samples. Other compounds included benzyl esters, cinnamyl esters of caffeic, $p$-coumaric and ferulic acids. Only KP did not contain these compounds (or only traces were found).

UHPLC-QqTOF-MS analyses allowed also to tentatively identify a number of terpenic compounds in the extracts. Among terpenic compounds-labdane type diterpenes: cupressic and isocupressic acid (samples KP, BP); abietane type diterpenoids: dehydroabietic (BP, KP, PP, K1P, K2P), abietic and pimaric acid isomers (BP, KP, traces in some other samples). The MS data for cuppressic acid and isocupressic acid were consistent with literature data [75]. For isocupressic acid the exact mass 321.2445 and $303.2332\left(\mathrm{ESI}^{+}\right)$corresponded to $\left[\mathrm{M}+\mathrm{H}^{+}\right]^{+}$and $\left[\mathrm{M}-\mathrm{H}_{2} \mathrm{O}+\mathrm{H}^{+}\right]^{+}$, respectively and the MS/MS spectrum obtained at $35 \mathrm{eV}$ was $(\mathrm{m} / \mathrm{z}): 285,257,247,215,201,193,187,175,161,147$ and 133. Other diterpenes were found only in BP: 8-hydroxylabdan-15-oic acid (labdane type), 18-hydroxy-cis-clerodan-3-ene-15-oic acid and 18-acetoxy-cis-clerodan-3-ene-15-oic acid (clerodane type). The MS data for 18-hydroxy-cis-clerodan-3-ene-15-oic acid was consistent with the literature data. The exact mass $305.2477\left(\mathrm{ESI}^{+}\right)$corresponded to $\left[\mathrm{M}-\mathrm{H}_{2} \mathrm{O}+\mathrm{H}^{+}\right]^{+}$and the MS/MS spectrum obtained at $35 \mathrm{eV}$ was $(\mathrm{m} / \mathrm{z}): 287,269,263,249,235,223,221,209,195,191,177,175,163,149,135,121$ and 107 [75]. The MS data for 18-acetoxy-cis-clerodan-3-ene-15-oic acid was: 363.2544 (ESI ${ }^{-}$) and the fragments (obtained by MS/MS at $35 \mathrm{eV}) 321$ (322), and 303 corresponded respectively to the loss of acetyl group and $\mathrm{H}_{2} \mathrm{O}$. The main pseudomolecular ions in positive ionization 387.2521, and 305.2493 $\left(\mathrm{ESI}^{+}\right)$corresponded to $\left[\mathrm{M}+\mathrm{Na}^{+}\right]^{+}$and $\left[(\mathrm{M}+\mathrm{H})-\mathrm{CH}_{3} \mathrm{CO}-\mathrm{H}_{2} \mathrm{O}+\mathrm{H}^{+}\right]^{+}$. The MS/MS spectrum of the latter fragment obtained at $35 \mathrm{eV}$ was consistent with data for 18-hydroxy-cis-clerodan-3-ene-15-oic acid containing $(\mathrm{m} / \mathrm{z})$ : 287, 269, 263, 249, 235, 223, 209, 195, 177, 163, 149, 135, 121 and 107 [75]. Other tentatively identified compounds include triterpenes: oleanoic, moronic (oleanane type) and iso-/masticadienoic acids (euphane type) found in BP, KP, PP, K2P, K3P.

The major compounds reported in most samples of Croatian propolis were phenolic acids (ferulic, $p$-coumaric acid) and flavonoids (galangin, pinocembrin, chrysin) [16,18,76-78]. These findings are very similar to the profiles of RP, K1P and K3P from the current study. However, Croatian samples that did not contain these compounds were also reported, demonstrating occurrence of different propolis types in Croatia [16,18]. Saftić et al. recently reported LC-MS analysis of propolis from different regions of Croatia, including Mediterranean samples. The latter contained diterpenes, e.g., pimaric acid, isocupressic acid (found also in some of the currently analyzed samples) but on the other hand also totarol, agathadiol and artepillin C (corresponding exact masses not found in the currently analyzed samples) [15]. These compounds were previously proposed as markers for Mediterranean propolis poor in flavonoids and phenolic acids, deriving mainly from Cupressus spp. [5].

Possible Botanical Origin of the Samples Based on LC-MS Profiles

All the samples contained at least traces of prenyl caffeates, recognized as typical for the most common European black poplar-type propolis [60], however their total amount was more relevant only in three samples RP, K1P and K3P $(37.74,11.49,5.92 \mathrm{mg} / \mathrm{g}$, respectively), demonstrating primary (RP) or secondary (K1P and K3P) contribution of P. nigra balsam in those specimens (Table 4). The same samples contained also another typical compounds from this source, such as pinobanksin 3-O-acetate, chrysin, pinocembrin and others [60] which again were very abundant in RP. RP contained particularly high amount of isoferulic acid $(8.30 \mathrm{mg} / \mathrm{g})$, while K1P and K3P only its slightly elevated amount $(0.67-0.80 \mathrm{mg} / \mathrm{g})$; though the amount of isoferulic acid was 2-4 times higher than of ferulic acid, which suggests that the bud exudate was partially collected from P. nigra var. italica Münchh. [79]. Different profiles of other poplar polyphenols were described in literature [60,79]. The highest differences between various Populus species were connected to the presence of various flavonoids, presence of both flavonoids and phenolic acids as well as their monoesters, or the presence of mainly free phenolic 
acids. Sakuranetin was found in both P. nigra $[60,80]$ and P. tremula [60]. This may partially explain the origin of higher amounts of this compound $(4.45-16.36 \mathrm{mg} / \mathrm{g}$ ) also in PP, K2P or even KP. The samples PP, BP and K2P, but partially also RP, K1P and K3P contained notable peaks of glycerides of phenolic acids that could be attributed to P. tremula: e.g., $p$-coumaroyl glycerol, acetyl-p-coumraoylglycerol, 2 -acetyl-1,3-di-p-coumaroylglycerol, 2-acetyl-3- $p$-coumaroyl-1-feruloylglycerol [79]. However, various glycerides of phenolic acids were found also in other natural sources such as aerial parts of Asparagus officinalis L. [81] or Aegilops ovata L. [82].

The samples KP, BP and K2P contained relevant amounts of terpene compounds. Among them KP and BP contained relevant abundance of abietic acid derivatives that could be attributed to Pinus resin but also other conifers [83]. Some small amounts of these compounds were present also in some other samples. BP was most rich in these compounds and also contained 6"-O-p-coumaroyltrifolin (kaempferol 3-(6-p-coumaroylgalactoside)), that was previously found in Pinus sylvestris L. needles [83]. In addition to this, in BP particular flavonols, e.g., myricetin-3,7, $4^{\prime}, 5^{\prime}$-tetramethyl-ether, 3,7,4' -trimethylquercetin (ayanin) were found along with terpenes 18-acetoxy-cis-clerodan-3-ene-15-oic acid, 18-hydroxy-cis-clerodan-3-ene-15-oic acid, 15-hydroxycis-clerodan-3-ene-18-oic acid, 8-hydroxylabdan-15-oic acid, that were previously found in Cistus exudates [84].

Some samples (KP, PP, K2P, K3P and partially BP) contained also few peaks with pseudomoecular ion mass $453.3372\left[\mathrm{M}-\mathrm{H}^{+}\right]^{-}$, that could be tentatively identified as oleanoic acid, moronic acid or masticadienonic acid and could be potentially attributed as deriving from Pistacia lentiscus L. resin [85]. Samples KP and BP (traces) contained also small amounts of cupressic and isocupressic acid [75], that could be linked to Cupressus spp. [86] however totarol or agathadiol (considered markers of this type of propolis) were not detected [5]. This may suggest other conifers as possible sources of this propolis. Nevertheless, literature data showed also variability of totarol concentrations in different samples obtained from Cupressus spp. [86].

Considering all the data, notable contribution of Poplar species as source of propolis from Rab, $\mathrm{Pag}$, Krk is found in contrast to the samples from Korčula and Biševo, which is consistent to the geographical location of the islands and distribution of poplars in Croatia [36]. Among the samples, RP contained particularly high levels of compounds typical for black poplar bud exudate, which may indicate dominating contribution of poplar in RP. In other samples its amount was at least several-fold lower, suggesting secondary contribution in total mass of propolis. The samples RP, K1P and K3P contained higher contribution of isoferulic acid than ferulic acid, which indicated italica variety of $P$. nigra as source plant. On the other side, the occurrence of various glycerides along with sakuranetin present in all samples (except BP) may be connected to other Populus species, such as P. tremula. These sources are quite common for European propolis from temperate climate zone [79]. On the other hand, some of the samples contained different terpenoids and unusual flavonoids that could be attributed to Mediterranean plants. Abietic and pimaric acid isomers as well as cupressic and isocupressic acids may be attributed to different, common coniferous tree species such as Pinus, Cypressus and Juniperus. These sources were also indicated as possible for other Mediterranean propolis, containing diterpenes, from Croatia but also west Algeria and Crete $[15,87,88]$. These compounds were more abundant in $\mathrm{BP}$ and KP. Some of the samples contained other compounds, possible to link with Pistacia. This source was suggested as one of the possible for Moroccan propolis [89]. The most interesting propolis, collected on island Biševo, distant from the land, was much different from other samples and contained compounds that could be linked to Cistus spp. Such origin was suggested also for diterpene propolis from Algeria which was very similar to the investigated Croatian sample [75]. Similarly, Tunisian propolis containing myricetin 3,7, $4^{\prime}, 5^{\prime}$-methylether, that is typical for Cistus spp. leaf exudates, was recognized as source plant [90]. This confirms, that in areas where poplars are not always available, other plant sources can be used to form propolis. 
Table 3. Compounds identified by ultra high performance liquid chromatography with diode array detector and quadrupole time-of-flight mass spectrometry (UHPLC-DAD-QqTOF-MS) in extracts of Croatian propolis samples.

\begin{tabular}{|c|c|c|c|c|c|c|c|c|c|c|c|c|c|}
\hline No. & Component & RT & UV $\max [\mathrm{nm}]$ & {$\left[\mathbf{M}-\mathbf{H}^{+}\right]^{-}$} & $\begin{array}{c}{\left[\mathrm{M}+\mathrm{H}^{+}\right]^{+} /} \\
{\left[\mathrm{M}+\mathrm{Na}^{+}\right]^{+} /} \\
{\left[\mathrm{M}-\mathrm{H}_{2} \mathrm{O}+\mathbf{H}^{+}\right]^{+}}\end{array}$ & BP & KP & $\mathbf{R P}$ & PP & K1P & K2P & К3P & References \\
\hline 1 & 4-Hydroxybenzoic acid a,b,c & 7.33 & 256 & 137.0246 & 139.0388 & - & - & + & $\operatorname{tr}$ & + & + & + & [91] \\
\hline 2 & 3-Hydroxybenzoic acid b,c & 7.97 & 258 & 137.0247 & 139.0398 & $\operatorname{tr}$ & - & - & $\operatorname{tr}$ & - & + & $\operatorname{tr}$ & [91] \\
\hline 3 & 4-Hydroxybenzaldehyde $b, c$ & 9.46 & 282 & 121.0296 & 123.0440 & - & - & - & - & - & + & - & [92] \\
\hline 4 & Caffeic acid a,b,c & 11.02 & $323,295 \mathrm{sh}$ & 179.0351 & 181.0498 & $\operatorname{tr}$ & $\operatorname{tr}$ & ++ & + & + & + & + & {$[79,91,93-98]$} \\
\hline 5 & Vanillin a,b,c & 12.41 & $310,280,230$ & 151.0404 & 153.0543 & tr & tr & $\operatorname{tr}$ & + & $\operatorname{tr}$ & ++ & $\operatorname{tr}$ & {$[86,91]$} \\
\hline 6 & Benzoic acid a,b,c & 13.46 & 230,274 & 121.0296 & 123.0434 & $\operatorname{tr}$ & tr & + & $\operatorname{tr}$ & $\operatorname{tr}$ & ++ & $\operatorname{tr}$ & {$[86,91]$} \\
\hline 7 & $p$-Coumaric acid $\mathrm{a}, \mathrm{b}, \mathrm{c}$ & 13.81 & $310,300 \mathrm{sh}$ & 163.0401 & 165.0542 & + & $\operatorname{tr}$ & ++ & + & + & ++ & + & {$[79,86,91,94-97]$} \\
\hline 8 & $p$-Coumaroyl glycerol $\mathrm{b}, \mathrm{c}$ & 13.94 & 310,300 sh, 229 & 237.0773 & $-/ 261.0733$ & $\operatorname{tr}$ & - & $\operatorname{tr}$ & + & $\operatorname{tr}$ & + & $\operatorname{tr}$ & {$[60,99,100]$} \\
\hline 9 & Ferulic acid $a, b, c$ & 14.63 & $322,298 \mathrm{sh}$ & 193.0497 & 195.0641 & + & $\operatorname{tr}$ & + & + & + & ++ & + & {$[79,86,91,94,95$,} \\
\hline 10 & Isoferulic acid ${ }^{a, b, c}$ & 14.74 & 324,300 sh & 193.0497 & 195.0660 & $\operatorname{tr}$ & - & ++ & + & ++ & + & ++ & {$[79,86,91,94,95$,} \\
\hline 11 & ${ }^{*}$ Caffeoylmalic acid (Phaseolic acid) isomer ${ }^{\mathrm{b}, \mathrm{c}}$ & 15.29 & $328,298 \mathrm{sh}$ & 295.0824 & $-/ 319.0778$ & - & - & + & - & - & + & - & {$[101,102]$} \\
\hline 12 & $\begin{array}{l}\text { 4-Hydroxy-3-methoxycinnamaldehyde (Coniferyl } \\
\text { aldehyde) b,c }\end{array}$ & 15.37 & 339 & 177.0556 & 179.0701 & $\operatorname{tr}$ & - & - & - & - & ++ & - & {$[103,104]$} \\
\hline 13 & ${ }^{*} p$-Coumaric acid derivative ${ }^{\mathrm{b}}$ & 15.64 & 310,225 & 329.1042 & $-/ 353.0977$ & - & - & - & $\operatorname{tr}$ & - & + & - & - \\
\hline 14 & ${ }^{*} p$-Coumaric acid derivative ${ }^{b}$ & 15.72 & 310,226 & 359.1134 & $-/ 383.1081$ & $\operatorname{tr}$ & - & - & $\operatorname{tr}$ & - & + & $\operatorname{tr}$ & - \\
\hline 15 & ${ }^{*} p$-Coumaric acid derivative ${ }^{b}$ & 15.83 & 310,227 & 359.1137 & $-/ 383.1090$ & $\operatorname{tr}$ & - & - & + & - & ++ & $\operatorname{tr}$ & - \\
\hline 16 & ${ }^{*} p$-Coumaric acid derivative ${ }^{\mathrm{b}}$ & 15.90 & 311,228 & 359.1137 & /383.1087 & $\operatorname{tr}$ & - & - & + & - & + & - & - \\
\hline 17 & * Aromadendrin (dihydrokaempferol) $b_{, c}$ & 15.98 & 292 & 287.0559 & 289.0705 & $\operatorname{tr}$ & ++ & + & + & + & + & + & [105] \\
\hline 18 & ${ }^{*}$ Ferulic acid derivative ${ }^{b}$ & 16.09 & $322,298 \mathrm{sh}$ & 389.1253 & $-/ 413.1204$ & $\operatorname{tr}$ & - & - & + & - & + & $\operatorname{tr}$ & - \\
\hline 19 & ${ }^{*}$ Ferulic acid derivative ${ }^{\mathrm{b}}$ & 16.18 & $322,298 \mathrm{sh}$ & 389.1239 & $-/ 413.1200$ & + & - & - & + & - & ++ & & - \\
\hline 20 & * Acetyl-p-coumraoylglycerol b,c & 16.29 & 311 & 279.0879 & $-/ 303.0829$ & + & - & $\operatorname{tr}$ & + & $\operatorname{tr}$ & ++ & $\operatorname{tr}$ & {$[60,99,100]$} \\
\hline 21 & Apigetrin (apigenin 7-O-glucoside) $\mathrm{b}, \mathrm{c}$ & 16.30 & 315sh, 265 & 431.0976 & $-/ 455.0966$ & - & - & + & $\operatorname{tr}$ & - & - & - & {$[94,95]$} \\
\hline 22 & Dimethylcaffeic acid (DMCA) b,c & 16.40 & $324,294 \mathrm{sh}$ & 207.0664 & 209.0943 & - & $\operatorname{tr}$ & ++ & + & + & $\operatorname{tr}$ & + & {$[94,95]$} \\
\hline 23 & Cinnamic acid a,b,c & 16.75 & 278 & 147.0444 & 149.0601 & $\operatorname{tr}$ & - & + & $\operatorname{tr}$ & $\operatorname{tr}$ & + & $\operatorname{tr}$ & {$[6,91,94,95]$} \\
\hline 24 & ${ }^{*}$ Caffeic acid derivative ${ }^{\mathrm{b}}$ & 17.15 & $328,298 \mathrm{sh}$ & 277.1082 & $-/ 301.1052$ & - & - & + & - & + & - & $\operatorname{tr}$ & - \\
\hline 25 & Pinobanksin 5-methylether $\mathrm{b}, \mathrm{c}$ & 17.32 & 288 & 285.0762 & 287.0884 & - & - & ++ & $\operatorname{tr}$ & $\operatorname{tr}$ & $\operatorname{tr}$ & + & {$[6,94-96,98]$} \\
\hline 26 & Eriodyctiol (4'-hydroxynaringenin) ${ }^{b, c}$ & 17.39 & 288 & 287.0562 & 289.0695 & - & + & - & + & - & $\operatorname{tr}$ & + & [95] \\
\hline 27 & Pinusenocarp $\mathrm{b}, \mathrm{c}$ & 17.49 & - & 291.1597 & 293.1749 & + & $\operatorname{tr}$ & - & $\operatorname{tr}$ & - & - & - & [106] \\
\hline 28 & ${ }^{*}$ Quercetin dimethyl ether $\mathrm{b}, \mathrm{c}$ & 17.69 & 363,245 & 329.0667 & 331.0809 & $\operatorname{tr}$ & - & ++ & $\operatorname{tr}$ & $\operatorname{tr}$ & - & - & {$[91,94,96]$} \\
\hline 29 & $\begin{array}{c}\text { 6"-O-p-Coumaroyltrifolin (Kaempforol } \\
\text { 3-(6-p-coumaroylgalactoside) })^{b, c}\end{array}$ & 17.71 & $350 \mathrm{sh}, 313,262$ & 593.1290 & 595.1483 & + & - & - & - & - & - & - & [83] \\
\hline 30 & Quercetin $a, b, c$ & 17.89 & 364,270 sh, 265 & 301.0349 & 303.0488 & + & + & ++ & + & $\operatorname{tr}$ & + & + & {$[6,91,94,95]$} \\
\hline 31 & Luteolin a,b,c & 17.93 & 345,254 & 285.0407 & 287.0553 & + & - & + & $\operatorname{tr}$ & $\operatorname{tr}$ & $\operatorname{tr}$ & $\operatorname{tr}$ & {$[91,95]$} \\
\hline 32 & ${ }^{*}$ Caffeic acid derivative ${ }^{b}$ & 18.10 & $328,329 \mathrm{sh}$ & 349.1658 & $-/ 373.1628$ & - & - & + & $\operatorname{tr}$ & $\operatorname{tr}$ & - & + & - \\
\hline 33 & 1-Caffeoyl-3-p-coumaroyl glycerol b,c & 18.37 & $315,298 \mathrm{sh}, 235$ & 399.1085 & 401.1190 & - & - & - & - & - & + & - & {$[60,79,95]$} \\
\hline 34 & Pinobanksin $a, b, c$ & 18.45 & 292 & 271.0611 & 273.0763 & $\operatorname{tr}$ & + & ++ & + & + & $\operatorname{tr}$ & + & {$[79,94-96]$} \\
\hline 35 & Quercetin 3-methyl ether b,c & 18.46 & $355,268 \mathrm{sh}, 255$ & 315.0497 & 317.0657 & + & + & + & + & + & + & + & [94] \\
\hline 36 & $7,4^{\prime}$-Di-O-methylmyricetin ${ }^{\mathrm{b}, \mathrm{c}}$ & 18.60 & 361,259 & 345.0608 & 347.0764 & + & - & - & - & - & - & - & [107] \\
\hline 37 & Caffeoyl-feruloylglycerol $\mathrm{b}, \mathrm{c}$ & 18.64 & $326,298 \mathrm{sh}, 240$ & 429.1175 & $-/ 453.1153$ & + & - & + & + & + & + & - & {$[60,99]$} \\
\hline 38 & Chrysin-5-methyl ether b,c & 18.70 & $314 \mathrm{sh}, 264$ & 267.0663 & 269.0814 & tr & $\operatorname{tr}$ & + & $\operatorname{tr}$ & tr & $\operatorname{tr}$ & $\operatorname{tr}$ & {$[98,108]$} \\
\hline
\end{tabular}


Table 3. Cont.

\begin{tabular}{|c|c|c|c|c|c|c|c|c|c|c|c|c|c|}
\hline No. & Component & RT & UV $\max [\mathrm{nm}]$ & {$\left[\mathrm{M}-\mathrm{H}^{+}\right]^{-}$} & $\begin{array}{c}\left.\left[\mathrm{M}+\mathrm{H}^{++}\right]^{+}\right] \\
{\left[\mathrm{M}+\mathrm{Na}^{+}\right]^{+}} \\
{\left[\mathrm{M}-\mathrm{H}_{2} \mathrm{O}+\mathrm{H}^{+}\right]^{+}}\end{array}$ & BP & KP & RP & PP & K1P & K2P & К3Р & References \\
\hline 39 & Hesperetin & 18.69 & 290 & 301.0716 & 303.0851 & - & + & + & + & - & - & - & [109] \\
\hline 40 & Naringenin $\mathrm{a}, \mathrm{b}, \mathrm{c}$ & 18.92 & 289 & 271.0612 & 273.0746 & $\operatorname{tr}$ & ++ & + & + & $\operatorname{tr}$ & + & + & {$[95,108]$} \\
\hline 41 & ${ }^{*}$ Caffeic acid derivative ${ }^{b}$ & 19.17 & 321 & 299.0932 & 323.0905 & - & - & + & + & + & - & + & - \\
\hline 42 & Apigenin $a, b, c$ & 19.26 & 338,290 sh, 263 & 269.0450 & 271.0592 & $\operatorname{tr}$ & $\operatorname{tr}$ & ++ & $\operatorname{tr}$ & + & + & tr & {$[6,94,95]$} \\
\hline 43 & Kaempferol ${ }^{a, b, c}$ & 19.44 & $366,295 \mathrm{sh}, 265$ & 285.0403 & 287.0544 & $\operatorname{tr}$ & + & + & + & + & + & + & {$[6,79,91,94,95]$} \\
\hline 44 & $\beta$-Styrylacrilic acid (cinnamylideneacetic acid) ${ }^{b, c}$ & 19.52 & $311,240 \mathrm{sh}$ & 173.0613 & 175.0757 & - & - & ++ & - & $\operatorname{tr}$ & - & tr & {$[94,110]$} \\
\hline 45 & 1,3-Di-p-coumaroylglycerol b,c & 19.57 & 312,300 sh & 383.1129 & $-/ 407.1096$ & + & - & - & + & + & + & + & {$[60,79]$} \\
\hline 46 & Isorahmnetin (quercetin $3^{\prime}$-methyl ether) $\mathrm{a}, \mathrm{b}, \mathrm{c}$ & 19.72 & $371,268 \mathrm{sh}, 256$ & 315.0502 & 317.0661 & + & + & + & + & + & + & + & {$[6,79,91,95,96]$} \\
\hline 47 & $p$-Coumarovl-ferulovlglycerol $\mathrm{b}, \mathrm{c}$ & 19.85 & $316,298 \mathrm{sh}$ & 413.124 & $-/ 437.1196$ & + & - & + & + & + & + & tr & {$[60,86]$} \\
\hline 48 & 2-Acetyl-1,3-di-caffeovlglycerol b,c & 19.92 & $328,298 \mathrm{sh}$ & 457.1133 & $-/ 481.1099$ & + & _- & + & + & + & + & + & {$[95,97]$} \\
\hline 49 & Caffeic acid butenoic or isobutenoic ester b,c & 19.98 & $326,298 \mathrm{sh}, 245$ & 233.0827 & $235.0969 / 257.0800$ & - & - & + & - & + & - & + & {$[60,111]$} \\
\hline 50 & Luteolin-5-methyl ether $\mathrm{b}, \mathrm{c}$ & 20.06 & $350,298 \mathrm{sh}, 267$ & 299.0549 & $-/ 323.0543$ & + & + & + & + & + & + & + & [94] \\
\hline 51 & Di-1,3-feruloylglycerol b,c & 20.07 & $323,298 \mathrm{sh}$ & 443.1329 & $-/ 467.1300$ & + & - & - & - & - & ++ & - & {$[60,79,95]$} \\
\hline 52 & ${ }_{*}^{*}$ Quercetin-dimethyl ether b,c & 20.23 & 358,260 & 329.066 & 331.0808 & + & + & + & + & tr & - & + & {$[91,94,96]$} \\
\hline 53 & Galangin-5-methyl ether $\mathrm{b}, \mathrm{c}$ & 20.26 & $352,300 \mathrm{sh}, 260$ & 283.0602 & 285.0726 & tr & $\begin{array}{l}+ \\
+\end{array}$ & + & $\begin{array}{l}+ \\
+\end{array}$ & tr & - & + & {$[94,96]$} \\
\hline 54 & Quercetin-3,3'-dimethyl ether $b, c$ & 20.36 & $356,269 \mathrm{sh}, 255$ & 329.0651 & 331.0809 & + & $\operatorname{tr}$ & + & $\operatorname{tr}$ & $\operatorname{tr}$ & $\operatorname{tr}$ & + & {$[94,95]$} \\
\hline 55 & Myricetin $3,7,4^{\prime}$-trimethyl ether $b, c$ & 20.63 & 344,266 & 359.0772 & 361.0922 & + & - & - & - & - & - & - & [112] \\
\hline 56 & ${ }^{*}$ Hydroxy-tetramethoxyflavone ${ }^{c}$ & 20.63 & 370,282 & 357.0976 & $359.1118 / 381.0954$ & - & - & + & - & - & $\operatorname{tr}$ & $\operatorname{tr}$ & - \\
\hline 57 & Caffeic acid prenyl or isoprenyl ester $\mathrm{I} \mathrm{b}, \mathrm{c}$ & 20.69 & $324,298 \mathrm{sh}$ & 247.0987 & 249.1634 & $\operatorname{tr}$ & - & + & + & + & - & + & {$[91,94-96,98]$} \\
\hline 58 & Caffeic acid butyl or isobutyl ester b,c & 20.73 & $326,298 \mathrm{sh}$ & 235.0972 & - & - & $\operatorname{tr}$ & + & + & + & - & + & {$[79,113]$} \\
\hline 59 & ${ }^{*} p$-Coumaric acid derivative ${ }^{\mathrm{b}}$ & 20.77 & 312,282 & 445.1651 & $-/ 469.1612$ & _- & - & - & - & - & + & - & - \\
\hline 60 & Rhamnetin (quercetin 7-methyl ether) $\mathrm{b}, \mathrm{c}$ & 20.91 & $356,268 \mathrm{sh}, 256$ & $\begin{array}{l}435.1631 \\
315.0504\end{array}$ & $\begin{array}{l}-14499.1612 \\
317.0639\end{array}$ & + & + & + & + & + & + & + & {$[6,95,114]$} \\
\hline 61 & Caffeic acid prenyl or isoprenyl ester II $\mathrm{b}, \mathrm{c}$ & 21.04 & $325,298 \mathrm{sh}$ & 247.0979 & 249.1273 & $\operatorname{tr}$ & $\operatorname{tr}$ & ++ & + & ++ & tr & ++ & {$[91,94-96,98]$} \\
\hline 62 & 2-Acetyl-1-caffeoyl-3-p-coumarovlglycerol b, & 21.22 & $316,299 \mathrm{sh}$ & 441.1182 & $-/ 465.1147$ & + & - & - & + & - & + & - & {$[79,95,97,99]$} \\
\hline 63 & Caffeic acid prenyl or isoprenyl ester III b, $\mathrm{c}$ & 21.23 & $324,298 \mathrm{sh}$ & 247.0976 & $-/ 271.1105$ & tr & $\operatorname{tr}$ & ++ & + & ++ & + & ++ & {$[91,94-96,98]$} \\
\hline 64 & Caffeic acid prenyl or isoprenyl ester IV $\mathrm{b}, \mathrm{c}$ & 21.33 & $325,298 \mathrm{sh}$ & 247.0973 & $249.1123 / 271.099$ & tr & tr & ++ & + & ++ & tr & ++ & {$[91,94-96,98]$} \\
\hline 65 & ${ }^{*}$ Quercetin dimethyl ether $\mathrm{b}, \mathrm{c}$ & 21.43 & 368,254 & 329.0659 & 331.0801 & tr & + & $\operatorname{tr}$ & + & - & tr & + & {$[91,94-96,98]$} \\
\hline 66 & 2-Acetyl-1-caffeoyl-3-feruloylglycerol b,c & 21.50 & $322,300 \mathrm{sh}$ & 471.1300 & 495.1259 & $\operatorname{tr}$ & - & - & tr & tr & + & tr & {$[97,99]$} \\
\hline 67 & Caffeic acid benzyl ester $b, c$ & 21.65 & $328,298 \mathrm{sh}$ & 269.0818 & 271.0971 & $\operatorname{tr}$ & + & + & + & + & $\operatorname{tr}$ & + & {$[94-96]$} \\
\hline 68 & Quercetin-3,7-dimethyl ether $\mathrm{b}, \mathrm{c}$ & 21.66 & $356,268 \mathrm{sh}, 256$ & 329.0674 & 331.0827 & + & $\operatorname{tr}$ & tr & $\operatorname{tr}$ & tr & tr & tr & {$[91,95]$} \\
\hline 69 & 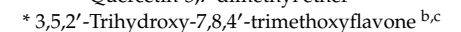 & 21.79 & 360,256 & 359.0768 & 361.0927 & + & $\operatorname{tr}$ & - & tr & $\operatorname{tr}$ & + & + & [115] \\
\hline 70 & Chrysin a,b,c & 21.93 & $312 \mathrm{sh}, 268$ & 253.0505 & 255.0659 & $\operatorname{tr}$ & + & + & + & ++ & + & ++ & {$[79,91,94-96,98]$} \\
\hline 71 & Pinocembrin a,b,c & 22.12 & 290 & 255.0666 & 257.0799 & + & tr & ++ & + & + & tr & + & {$[91,94-96,98]$} \\
\hline 72 & Caffeic acid phenethyl ester $\mathrm{b}, \mathrm{c}$ & 22.36 & 325,295 & $\begin{array}{l}233.06006 \\
283.0984\end{array}$ & 285.0940 & tr & - & $\begin{array}{l}++ \\
++\end{array}$ & $t_{\text {tr }}^{+}$ & $\begin{array}{l}+ \\
+\end{array}$ & $\begin{array}{l}\text { tr } \\
\text { tr }\end{array}$ & tr & {$[91,94-96,98]$} \\
\hline 73 & Sakuranetin b,c & 22.38 & 290 & 285.0773 & 287.0908 & $\operatorname{tr}$ & + & + & ++ & + & ++ & ++ & {$[91,95,108]$} \\
\hline 74 & Galangin $a, b, c$ & 22.43 & 360,266 & 269.0454 & 271.0761 & tr & tr & + & tr & tr & tr & tr & {$[79,91,95,96,98]$} \\
\hline 75 & ${ }^{*} p$-Coumaric derivative ${ }^{c}$ & 22.52 & 311 & 325.109 & $-/ 349.1033$ & - & - & - & - & - & + & - & {$[-\infty, 0,0]$} \\
\hline 76 & ${ }^{*}$ Pinobanksin-7-methyl ether $\mathrm{b}, \mathrm{c}$ & 22.62 & 290 & 285.0777 & 287.0898 & - & $\operatorname{tr}$ & + & + & + & tr & + & [94] \\
\hline 77 & 2-Acetyl-1,3-di-p-coumaroylglycerol b, & 22.72 & 312,300 & 425.1232 & $-/ 449.1202$ & + & - & - & + & tr & ++ & tr & {$[79,95,99]$} \\
\hline
\end{tabular}


Table 3. Cont.

\begin{tabular}{|c|c|c|c|c|c|c|c|c|c|c|c|c|c|}
\hline No. & Component & RT & UV $\max [\mathrm{nm}]$ & {$\left[\mathbf{M}-\mathbf{H}^{+}\right]^{-}$} & $\begin{array}{c}\left.\left[\mathrm{M}+\mathrm{H}^{+}\right]^{+}\right] \\
\left.\left[\mathrm{M}+\mathrm{Na}^{+}\right]^{+}\right] \\
{\left[\mathrm{M}-\mathrm{H}_{2} \mathrm{O}+\mathrm{H}^{+}\right]^{+}}\end{array}$ & BP & KP & RP & PP & K1P & K2P & К3Р & References \\
\hline 78 & 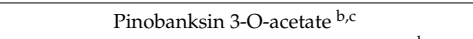 & 22.80 & 295 & 313.0713 & 315.0875 & $\operatorname{tr}$ & tr & ++ & $\operatorname{tr}$ & + & tr & + & {$[79,94-96]$} \\
\hline 79 & Kaempferide (kaempferol 4'-methyl ether) ${ }^{b, c}$ & 22.93 & 365,267 & 299.0555 & 301.0698 & $\operatorname{tr}$ & ++ & + & + & $\operatorname{tr}$ & $\operatorname{tr}$ & + & [91] \\
\hline 80 & $p$-Coumaric acid prenyl or isoprenyl ester $\mathrm{I}^{\mathrm{b}, \mathrm{c}}$ & 23.11 & $311,299 \mathrm{sh}$ & 231.1028 & 233.1178 & - & tr & + & + & + & - & + & {$[94,96,98]$} \\
\hline 81 & 2-Acetyl-3-p-coumaroyl-1-feruloylglycerol b,c & 23.12 & $318,299 \mathrm{sh}$ & 455.134 & 479.1310 & + & - & - & + & + & ++ & + & {$[79,97]$} \\
\hline 82 & Methoxychrysin $\mathrm{b}, \mathrm{c}$ & 23.21 & $310 \mathrm{sh}, 266,245 \mathrm{sh}$ & 283.0611 & 285.0714 & - & $\operatorname{tr}$ & + & $\operatorname{tr}$ & $\operatorname{tr}$ & - & + & {$[94,96,110]$} \\
\hline 83 & $p$-Coumaric acid prenyl or isoprenyl ester II $\mathrm{b}, \mathrm{c}$ & 23.38 & $310,299 \mathrm{sh}$ & 231.1025 & $-/ 255.1003$ & - & tr & + & + & + & + & $\operatorname{tr}$ & {$[94,96,98]$} \\
\hline 84 & 2-Acetyl-1,3-di-feruloylglycerol b,c & 23.62 & $328,298 \mathrm{sh}$ & 485.1423 & 487.1578 & + & - & - & + & - & + & - & {$[97,100]$} \\
\hline 85 & Kaempferol $3,4^{\prime}$-dimethyl ether b,c & 23.72 & 350,267 & 313.0722 & 315.0854 & + & ++ & - & + & - & $\operatorname{tr}$ & + & {$[116,117]$} \\
\hline 86 & Cupressic acid $b, c$ & 23.82 & - & 319.2287 & 321.2437 & $\operatorname{tr}$ & + & - & - & - & - & - & [75] \\
\hline 87 & $p$-Coumaric acid benzyl ester $\mathrm{b}, \mathrm{c}$ & 23.88 & $312,298 \mathrm{sh}$ & 253.0870 & $-/ 277.0826$ & + & - & + & + & $\operatorname{tr}$ & ++ & + & {$[79,94,96]$} \\
\hline 88 & ${ }^{*}$ 15-Hydroxy-cis-clerodan-3-ene-18-oic acid b,c & 23.95 & - & 321.2442 & 323.2589 & + & - & - & - & - & - & - & [75] \\
\hline 89 & 18-Hydroxy-cis-clerodan-3-ene-15-oic acid b,c & 24.14 & - & 321.2449 & $-/ 305.2481$ & + & - & - & - & - & - & - & [75] \\
\hline 90 & Isocupressic acid b,c & 24.20 & - & 319.2284 & 321.2445/303.2332 & - & + & - & - & - & - & - & [75] \\
\hline 91 & Caffeic acid cinnamyl ester $b, c$ & 24.32 & $326,300 \mathrm{sh}$ & 295.0971 & $-/ 319.0945$ & - & - & ++ & tr & + & tr & + & {$[94,95,110]$} \\
\hline 92 & Ferulic acid benzyl ester ${ }^{*} \mathrm{~b}, \mathrm{c}$ & 24.65 & 326,298 & 283.0968 & 285.0725 & + & - & + & ++ & + & ++ & + & {$[79,86,111]$} \\
\hline 93 & 3,7, $4^{\prime}$-Trimethylquercetin (ayanin) ${ }^{\mathrm{b}, \mathrm{c}}$ & 24.78 & 355,255 & 343.0825 & 345.0977 & + & - & - & - & - & - & - & [90] \\
\hline 94 & Pinobanksin 3-O-propanoate $\mathrm{b}, \mathrm{c}$ & 25.05 & 294 & 327.0876 & 329.1023/351.0835 & - & $\operatorname{tr}$ & ++ & tr & + & $\operatorname{tr}$ & + & [94-96] \\
\hline 95 & $p$-Coumaric acid phenethyl ester $\mathrm{b}, \mathrm{c}$ & 25.06 & $310,300 \mathrm{sh}$ & 267.1033 & $-/ 291.0991$ & - & tr & + & + & + & + & + & [98] \\
\hline 96 & ${ }^{*}$ Hydroxydehydroabietic acid isomer $\mathrm{b}, \mathrm{c}$ & 25.00 & - & 315.1969 & 317.2118 & + & $\operatorname{tr}$ & - & $\operatorname{tr}$ & $\operatorname{tr}$ & - & - & [106] \\
\hline 97 & 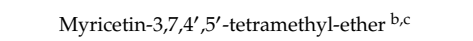 & 25.11 & 344,265 & 373.0937 & 375.1088 & ++ & - & - & - & - & - & - & $75,90,95,118$, \\
\hline 98 & $p$-Coumaric acid cinnamyl ester b,c & 26.83 & $312,300 \mathrm{sh}$ & 279.1024 & $-/ 303.0986$ & - & $\operatorname{tr}$ & + & $\operatorname{tr}$ & $\operatorname{tr}$ & tr & tr & [95] \\
\hline 99 & ${ }^{*}$ Trihydroxytriterpene carboxylic acid ${ }^{c}$ & 26.41 & - & 487.3439 & 489.3595 & - & ++ & - & ++ & - & ++ & ++ & - \\
\hline 100 & ${ }^{*}$ Hydroxyditerpene carboxylic acid b,c & 26.80 & - & 321.2439 & $-/ 345.2411$ & + & - & - & - & - & - & - & [120] \\
\hline 101 & Pinobanksin 3-O-butanoate or isobutanoate $\mathrm{b}, \mathrm{c}$ & 26.93 & 293 & 341.1022 & 343.1178 & - & + & + & + & - & + & + & {$[94,96]$} \\
\hline 102 & Pinostrobin chalcone $\mathrm{b}, \mathrm{c}$ & 26.94 & $339,287 \mathrm{sh}$ & 269.0811 & 271.0972 & $\operatorname{tr}$ & - & ++ & + & + & + & + & [95] \\
\hline 103 & *Trihydroxyflavanone & 27.03 & 267,290 & 271.0977 & 273.1115 & $\operatorname{tr}$ & - & ++ & + & + & - & + & - \\
\hline 104 & Pinobanksin 3-O-pentenoate or isopentenoate $\mathrm{I}^{\mathrm{b}, \mathrm{c}}$ & 27.06 & 295 & 353.1038 & 355.1181 & - & - & ++ & - & $\operatorname{tr}$ & $\operatorname{tr}$ & + & {$[95,96,121]$} \\
\hline 105 & Pinostrobin (pinocembrin-7-methyl ether) a,b,c & 27.20 & 289 & 269.2126 & $-/ 293.2093$ & - & $\operatorname{tr}$ & tr & + & $\operatorname{tr}$ & tr & + & [95] \\
\hline 106 & $*$ 8-Hydroxylabdan-15-oic acid b,c & 27.26 & - & 323.2601 & $-/ 347.2569$ & ++ & - & - & - & - & - & - & [84] \\
\hline 107 & Pinobanksin 3-O-pentanoate or isopentanoate II $\mathrm{b}, \mathrm{c}$ & 27.68 & 292 & 355.1198 & $357.1342 / 379.1159$ & - & + & + & + & + & $\operatorname{tr}$ & + & [94-96] \\
\hline 108 & Methoxycinnamic acid cinnamyl ester b,c & 27.74 & 280 & 293.2131 & $295.2278 / 317.2098$ & - & - & + & + & + & + & + & {$[94,110]$} \\
\hline 109 & * 18-Acetoxy-cis-clerodan-3-ene-15-oic acid b,c & 28.08 & - & 363.2544 & $-/ 387.2521$ & + & - & - & - & - & - & - & [84] \\
\hline 110 & Dehydroabietic acid isomer $\mathrm{b}, \mathrm{c}$ & 28.16 & - & 299.2023 & 301.2173 & ++ & + & $\operatorname{tr}$ & + & + & + & $\operatorname{tr}$ & [122] \\
\hline 111 & Pinobanksin 3-O-hexanoate $\mathrm{b}, \mathrm{c}$ & 28.21 & 282 & 369.1349 & 371.1497 & - & - & + & - & - & - & tr & {$[94,96,110,121]$} \\
\hline 112 & Abietic or pimaric acid isomer I b,c & 28.59 & - & 301.2175 & 303.2327 & + & + & - & $\operatorname{tr}$ & + & $\operatorname{tr}$ & - & [106] \\
\hline 113 & Abietic or pimaric acid isomer II ${ }^{b, c}$ & 28.70 & - & 301.2173 & 303.2328 & + & + & - & $\operatorname{tr}$ & $\operatorname{tr}$ & - & - & [106] \\
\hline 114 & Abietic or pimaric acid isomer III $\mathrm{b}, \mathrm{c}$ & 28.83 & - & 301.2180 & 303.2326 & ++ & + & - & tr & - & - & - & [106] \\
\hline 115 & Abietic or pimaric acid isomer IV $\mathrm{b}, \mathrm{c}$ & 29.06 & - & 301.2180 & 303.2318 & + & - & - & - & + & - & - & [106] \\
\hline 116 & $*$ Oleanoic acid ${ }^{b, c}$ & 29.39 & - & 453.3372 & 455.3549 & + & ++ & - & ++ & - & ++ & + & [85] \\
\hline 117 & ${ }^{*}$ Moronic acid b,c & 29.60 & - & 453.3372 & 455.3549 & - & + & - & + & - & + & + & [85] \\
\hline 118 & ${ }^{*}$ Masticadienonic acid ${ }^{b, c}$ & 29.70 & - & 453.3372 & 455.3549 & $\operatorname{tr}$ & + & - & + & - & + & + & [85] \\
\hline
\end{tabular}

* Component tentatively identified; ${ }^{a}$ Confirmed with standard; ${ }^{b}$ Confirmed with HR-MS, MS/MS (data not shown) and/or UV; ${ }^{c}$ Confirmed with references; $++/+$ compound detected (different relative abundance); - compound not detected; tr-compound found in traces. 
Table 4. Quantities of the selected compounds identified by UHPLC-DAD-QqTOF-MS in extracts of Croatian propolis samples.

\begin{tabular}{|c|c|c|c|c|c|c|c|c|c|}
\hline \multirow[t]{2}{*}{ No. } & \multirow[t]{2}{*}{ Compound } & \multirow[t]{2}{*}{ Rt [min] } & BP & KP & $\mathbf{R P}$ & PP & K1P & K2P & K3P \\
\hline & & & \multicolumn{7}{|c|}{$[\mathrm{mg} / \mathrm{g}]$} \\
\hline 1 & Caffeic acid & 11.02 & $\operatorname{tr}$ & $\operatorname{tr}$ & 6.80 & 0.15 & 0.68 & 0.22 & 0.51 \\
\hline 2 & Vanillin & 12.41 & $\operatorname{tr}$ & $\operatorname{tr}$ & $\operatorname{tr}$ & 1.89 & $\operatorname{tr}$ & 8.71 & $\operatorname{tr}$ \\
\hline 3 & Benzoic acid & 13.46 & $\operatorname{tr}$ & $\operatorname{tr}$ & 8.11 & $\operatorname{tr}$ & $\operatorname{tr}$ & 17.96 & $\operatorname{tr}$ \\
\hline 4 & $p$-Coumaric acid & 13.81 & 0.17 & $\operatorname{tr}$ & 2.60 & 0.41 & 0.54 & 4.22 & 0.48 \\
\hline 5 & Ferulic acid & 14.63 & 0.34 & $\operatorname{tr}$ & 1.78 & 0.54 & 0.34 & 4.10 & 0.31 \\
\hline 6 & Isoferulic acid & 14.74 & $\operatorname{tr}$ & nd & 8.30 & 0.17 & 0.80 & 0.09 & 0.67 \\
\hline 7 & Dimethylcaffeic acid a & 16.40 & nd & $\operatorname{tr}$ & 11.57 & 0.47 & 4.01 & $\operatorname{tr}$ & 2.59 \\
\hline 8 & Cinnamic acid & 16.75 & $\operatorname{tr}$ & nd & 6.12 & $\operatorname{tr}$ & $\operatorname{tr}$ & 1.93 & $\operatorname{tr}$ \\
\hline 9 & Pinobanksin 5-methylether ${ }^{b}$ & 17.32 & nd & nd & 17.80 & $\operatorname{tr}$ & $\operatorname{tr}$ & $\operatorname{tr}$ & 0.83 \\
\hline 10 & Quercetin & 17.89 & 0.38 & 0.88 & 1.82 & 0.66 & $\operatorname{tr}$ & 0.47 & 0.76 \\
\hline 11 & Pinobanksin & 18.45 & $\operatorname{tr}$ & 0.20 & 13.53 & 0.21 & 0.16 & $\operatorname{tr}$ & 0.43 \\
\hline 12 & Chrysin-5-methyl ether ${ }^{c}$ & 18.70 & $\operatorname{tr}$ & $\operatorname{tr}$ & 0.19 & $\operatorname{tr}$ & $\operatorname{tr}$ & $\operatorname{tr}$ & $\operatorname{tr}$ \\
\hline 13 & Naringenin & 18.92 & $\operatorname{tr}$ & 1.43 & 0.71 & 0.90 & $\operatorname{tr}$ & 0.46 & 0.73 \\
\hline 14 & Apigenin & 19.26 & $\operatorname{tr}$ & $\operatorname{tr}$ & 3.80 & $\operatorname{tr}$ & 0.10 & 0.34 & $\operatorname{tr}$ \\
\hline 15 & Kaempferol & 19.44 & $\operatorname{tr}$ & 1.40 & 3.01 & 1.64 & 0.13 & 1.76 & 1.72 \\
\hline 16 & Isorhamnetin & 19.72 & 0.20 & 0.44 & 1.76 & 0.35 & 0.05 & 0.14 & 0.29 \\
\hline 17 & Luteolin-5-methyl ether ${ }^{\mathrm{d}}$ & 20.06 & 0.24 & 0.32 & 12.28 & 2.91 & 1.74 & 0.54 & 1.54 \\
\hline 18 & Galangin 5-methyl ether $\mathrm{e}$ & 20.26 & $\operatorname{tr}$ & 0.85 & 1.66 & 0.02 & $\operatorname{tr}$ & nd & 0.20 \\
\hline 19 & Quercetin 3,3'-dimethyl ether $\mathrm{f}$ & 20.36 & 0.52 & $\operatorname{tr}$ & 1.26 & $\operatorname{tr}$ & $\operatorname{tr}$ & $\operatorname{tr}$ & 0.03 \\
\hline 20 & Myricetin 3,7,4'-trimethyl ether ${ }^{\mathrm{f}}$ & 20.63 & 0.67 & nd & nd & nd & nd & nd & nd \\
\hline 21 & Rhamnetin (quercetin-7-methyl ether) & 20.91 & 0.08 & 0.09 & 1.94 & 0.18 & 0.15 & 0.14 & 0.35 \\
\hline 22 & Caffeic acid prenyl or isoprenyl ester II ${ }^{\text {a }}$ & 21.04 & $\operatorname{tr}$ & $\operatorname{tr}$ & 14.07 & 0.28 & 3.36 & $\operatorname{tr}$ & 1.66 \\
\hline 23 & Caffeic acid prenyl or isoprenyl ester III ${ }^{\text {a }}$ & 21.23 & $\operatorname{tr}$ & $\operatorname{tr}$ & 20.05 & 0.73 & 6.19 & 1.56 & 3.06 \\
\hline 24 & Caffeic acid prenyl or isoprenyl ester IV a & 21.33 & $\operatorname{tr}$ & $\operatorname{tr}$ & 3.62 & 0.15 & 1.94 & nd & 1.20 \\
\hline 25 & ${ }^{*}$ Quercetin dimethyl ether ${ }^{\mathrm{f}}$ & 21.43 & $\operatorname{tr}$ & 0.63 & $\operatorname{tr}$ & 0.53 & nd & $\operatorname{tr}$ & 0.67 \\
\hline 26 & Caffeic acid benzyl ester ${ }^{a}$ & 21.65 & $\operatorname{tr}$ & 0.05 & 12.11 & 0.16 & 0.85 & $\operatorname{tr}$ & 0.75 \\
\hline 27 & Quercetin-3,7-dimethyl ether ${ }^{\mathrm{f}}$ & 21.66 & 0.15 & $\operatorname{tr}$ & $\operatorname{tr}$ & $\operatorname{tr}$ & $\operatorname{tr}$ & $\operatorname{tr}$ & $\operatorname{tr}$ \\
\hline 28 & Chrysin & 21.93 & $\operatorname{tr}$ & 0.04 & 30.71 & 0.70 & 7.50 & 0.17 & 5.72 \\
\hline 29 & Pinocembrin & 22.12 & 0.11 & $\operatorname{tr}$ & 39.86 & 0.81 & 3.50 & $\operatorname{tr}$ & 2.03 \\
\hline 30 & Caffeic acid phenethyl ester ${ }^{\text {a }}$ & 22.36 & $\operatorname{tr}$ & nd & 9.31 & $\operatorname{tr}$ & 4.69 & $\operatorname{tr}$ & $\operatorname{tr}$ \\
\hline 31 & Sakuranetin & 22.38 & $\operatorname{tr}$ & 4.45 & 6.95 & 16.36 & 1.70 & 10.03 & 17.08 \\
\hline 32 & Galangin & 22.43 & $\operatorname{tr}$ & $\operatorname{tr}$ & 16.67 & $\operatorname{tr}$ & $\operatorname{tr}$ & $\operatorname{tr}$ & $\operatorname{tr}$ \\
\hline
\end{tabular}


Table 4. Cont.

\begin{tabular}{|c|c|c|c|c|c|c|c|c|c|}
\hline \multirow{2}{*}{ No. } & \multirow{2}{*}{ Compound } & \multirow{2}{*}{ Rt [min] } & $\mathbf{B P}$ & KP & $\mathbf{R P}$ & PP & K1P & K2P & K3P \\
\hline & & & \multicolumn{7}{|c|}{$[\mathrm{mg} / \mathrm{g}]$} \\
\hline 33 & *Pinobanksin-7-methyl ether ${ }^{b}$ & 22.62 & nd & $\operatorname{tr}$ & 10.78 & 0.17 & 3.43 & $\operatorname{tr}$ & 1.61 \\
\hline 34 & 2-Acetyl-1,3-di- $p$-coumaroylglycerol g & 22.72 & 0.64 & nd & nd & 2.01 & $\operatorname{tr}$ & 13.04 & $\operatorname{tr}$ \\
\hline 35 & Pinobanksin-3-O-acetate ${ }^{\mathrm{b}}$ & 22.80 & $\operatorname{tr}$ & $\operatorname{tr}$ & 43.92 & $\operatorname{tr}$ & 1.11 & $\operatorname{tr}$ & 0.99 \\
\hline 36 & Kaempferide $\left(4^{\prime} \text {-methylkaempferol }\right)^{\mathrm{h}}$ & 22.93 & $\operatorname{tr}$ & 0.82 & 1.48 & 1.07 & $\operatorname{tr}$ & $\operatorname{tr}$ & 1.85 \\
\hline 37 & $p$-Coumaric acid prenyl or isoprenyl ester I $g$ & 23.11 & nd & $\operatorname{tr}$ & 1.57 & 0.35 & 0.26 & nd & 0.08 \\
\hline 38 & Methoxychrysin ${ }^{c}$ & 23.21 & nd & $\operatorname{tr}$ & 3.87 & $\operatorname{tr}$ & $\operatorname{tr}$ & nd & 0.06 \\
\hline 39 & $p$-Coumaric acid prenyl or isoprenyl ester II $g$ & 23.38 & nd & $\operatorname{tr}$ & 2.88 & 0.09 & 0.48 & 0.45 & $\operatorname{tr}$ \\
\hline 40 & $p$-Coumaric acid benzyl ester $\mathrm{g}$ & 23.88 & 0.35 & nd & 1.35 & 0.81 & $\operatorname{tr}$ & 8.17 & 0.08 \\
\hline 41 & Ferulic acid benzyl ester ${ }^{\mathrm{i}}$ & 24.65 & 0.33 & nd & 3.09 & 0.61 & 0.40 & 4.78 & 0.40 \\
\hline 42 & Pinobanksin 3-O-propanoate ${ }^{\mathrm{b}}$ & 25.05 & nd & $\operatorname{tr}$ & 6.50 & $\operatorname{tr}$ & 0.88 & $\operatorname{tr}$ & 0.34 \\
\hline 43 & Myricetin-3,7,4', $5^{\prime}$-tetramethyl-ether ${ }^{\mathrm{f}}$ & 25.11 & 4.29 & nd & nd & nd & nd & nd & nd \\
\hline 44 & p-Coumaric acid cinnamyl ester $\mathrm{g}$ & 26.83 & nd & $\operatorname{tr}$ & 1.65 & $\operatorname{tr}$ & $\operatorname{tr}$ & $\operatorname{tr}$ & $\operatorname{tr}$ \\
\hline 45 & Pinobanksin 3-O-pentenoate or isopentenoate b & 27.06 & nd & nd & 15.70 & nd & $\operatorname{tr}$ & $\operatorname{tr}$ & 2.85 \\
\hline 46 & Pinostrobin & 27.20 & nd & $\operatorname{tr}$ & $\operatorname{tr}$ & 0.50 & $\operatorname{tr}$ & $\operatorname{tr}$ & 4.16 \\
\hline
\end{tabular}

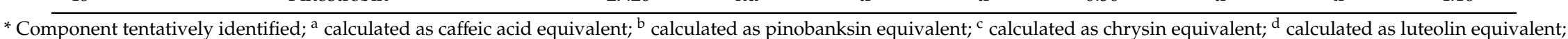
e calculated as galangin equivalent; ${ }^{\mathrm{f}}$ calculated as quercetin equivalent; $\mathrm{g}$ calculated as $p$-coumaric acid equivalent; ${ }^{\mathrm{h}}$ calculated as kaempferol equivalent; ${ }^{\mathrm{i}}$ calculated as ferulic acid equivalent. 


\subsection{Total Phenol Content and Antioxidant Potential}

The total content of phenolic compounds assessed using Folin-Ciocalteu reagent ranged from 14.0 to $189.7 \mathrm{mg} \mathrm{GAE} / \mathrm{g}$ of propolis for the investigated samples. The highest value was observed for RP and the lowest for BP, however all other values did not exceed $37 \mathrm{mg}$ GAE/g. The total flavonoid content ranged between 7.2 and $103.9 \mathrm{mg} \mathrm{QE} / \mathrm{g}$ of propolis, and was the highest in RP and lowest in K2P, but it did not exceed $18 \mathrm{mg} \mathrm{QE} / \mathrm{g}$ for any other samples. These result are consistent with those obtained by UHPLC, where content of phenolics in RP was much higher than in other samples (Table 4). The values obtained for RP, were very similar to those reported for Chinese poplar propolis (233.98 mg GAE/g, $124.92 \mathrm{mg} \mathrm{QE} / \mathrm{g}$ ) and extracts from poplar buds (145.54 mg GAE/g, $126.23 \mathrm{mg} \mathrm{QE} / \mathrm{g}$ ) [123]. These values are consistent also with other obtained from other samples of Chinese poplar-type propolis that ranged from 87.11 to $257.93 \mathrm{mg} \mathrm{GAE} / \mathrm{g}$ and 105.25 to $351.25 \mathrm{mg}$ QE/g as well as those obtained for Croatian propolis 70-220 mg GAE/g [16,96]. This may suggest, that this sample was mostly originating form Populus exudates, while the other samples may contain no more than just a small percentage of this balsam. Similar observation was done for Anatolian propolis, where 3 different types were identified including those deriving from P. nigra, P. tremula and non-poplar type propolis. The amount of phenolics and flavonoids in the latter two, ranged from 11.24 to $47.15 \mathrm{mg}$ GAE/g and from 3.88 to $48.70 \mathrm{mg} \mathrm{QE} / \mathrm{g}$, respectively [124]. Interestingly, the non-poplar type propolis from Anatolia was found to contain mainly Pinaceae and Cistus spp. pollen which suggest such plants to be major sources of these samples [124].

The antioxidant potential determined by DPPH ranged 2.6-81.6 mg GAE/g and in FRAP assay $0.1-0.8 \mathrm{mmol} \mathrm{Fe}^{2+} / \mathrm{g}$. The highest activity was observed for RP and the lowest in BP. The antioxidant potential and phenolic/flavonoid content were positively (Table 5), significantly correlated (TP-DPPH $R^{2}=0.9368$, TP-FRAP $R^{2}=0.7870$, TF-DPPH $R^{2}=0.9019$, TF-FRAP $R^{2}=0.7060$, at $\left.p<0.05\right)$ which links the activity with these groups of compounds. More varied activities in FRAP test ranging from 0.04 to $1.3 \mathrm{mmol} \mathrm{Fe}^{2+} / \mathrm{g}$ were found for Croatian propolis by Tlak-Gajger et al. [16].

Comparison of the obtained results with other reports on Croatian propolis was not possible, due to the different extraction, methodology or way of data presentation $[18,78,125,126]$.

Table 5. Total phenol, flavonoid content and antioxidant properties of the propolis samples.

\begin{tabular}{|c|c|c|c|c|c|c|c|c|}
\hline \multirow[b]{2}{*}{ Propolis } & \multicolumn{2}{|l|}{$\mathrm{TP}^{\mathrm{a}}$} & \multicolumn{2}{|l|}{$\mathbf{T F}^{\mathbf{b}}$} & $\mathrm{DPPH}^{\mathrm{c}}$ & \multicolumn{3}{|c|}{ FRAP $^{d}$} \\
\hline & [mg GAE/g] & $\pm \mathrm{SD}$ & [mg QE/g] & $\pm \mathrm{SD}$ & [mg GAE/g] & $\pm \mathrm{SD}$ & $\left.\mathrm{ol} \mathrm{Fe} \mathrm{F}^{2+} / \mathrm{g}\right]$ & $\pm \mathrm{SD}$ \\
\hline $\mathrm{BP}$ & 14.0 & 0.9 & 8.8 & 0.1 & 2.6 & 0.1 & 0.1 & 0.0 \\
\hline $\mathrm{KP}$ & 15.9 & 0.9 & 11.1 & 0.3 & 2.7 & 0.1 & 0.2 & 0.0 \\
\hline $\mathrm{RP}$ & 189.7 & 1.5 & 103.9 & 4.2 & 81.6 & 5.2 & 0.8 & 0.0 \\
\hline PP & 22.5 & 1.2 & 11.1 & 0.2 & 6.3 & 0.2 & 0.3 & 0.0 \\
\hline $\mathrm{K} 1 \mathrm{P}$ & 36.7 & 1.8 & 14.9 & 0.3 & 31.8 & 2.2 & 0.5 & 0.1 \\
\hline $\mathrm{K} 2 \mathrm{P}$ & 33.2 & 0.3 & 7.2 & 0.4 & 11.2 & 0.2 & 0.4 & 0.0 \\
\hline $\mathrm{K} 3 \mathrm{P}$ & 26.1 & 0.8 & 18.0 & 0.6 & 12.7 & 0.4 & 0.4 & 0.0 \\
\hline
\end{tabular}

Data are expressed as average of 3 measurements \pm standard deviation (SD); ${ }^{\text {a }}$ Total phenolics (TP) value is expressed as gallic acid equivalent (GAE). ${ }^{\mathrm{b}}$ Total flavoniods (TF) value is expressed as quercetin equivalent $(\mathrm{QE})^{\mathrm{c}} \mathrm{DPPH}$ value is expressed as gallic acid equivalent (GAE) having an equivalent antiradical capacity. ${ }^{d}$ FRAP value is expressed as millimolar concentration of $\mathrm{Fe}^{2+}$, obtained from a dilution of $\mathrm{FeSO}_{4}$ having an equivalent antioxidant capacity.

\section{Conclusions}

Typical propolis from Croatian islands along Adriatic Sea coast (Krk, Rab, Pag, Biševo and Korčula) were collected. The volatiles of the samples were isolated by HS-SPME and HD followed by GC-MS. The variability of the volatiles enabled differentiation of the samples in 2 groups of Mediterranean propolis: non-poplar type (dominated by $\alpha$-pinene) and poplar type (cadinane type sesquiterpenes). Spectral variations (FT-MIR) associated with phenolics and other balsam-related components were significant among the samples. The quantitative data obtained from colorimetric tests and UHPLC-DAD suggests that only one sample was a typical black poplar-type propolis (characterized e.g., by abundance of caffeic 
acid prenyl esters, pinobanksin-3-O-acetate, pinocembrin). Few samples contained just its small, but visible contribution and derive mostly from other botanical sources such as other poplars or coniferous trees (e.g., Pinus, Cupressus or Juniperus). The latter may be linked with presence of abietic, dehydroabietic or pimaric acids, $6^{\prime \prime}-O-p$-coumaroyltrifolin. One sample from Biševo was most particular and could be classified as Mediterranean diterpene propolis that derived i.a. from Cistus spp. exudates (characteristic compounds included myricetin-3,7,4', $5^{\prime}$-tetramethyl-ether, 15-hydroxy-cis-clerodan-3-ene-18-oic acid, 18-hydroxy-cis-clerodan-3-ene-15-oic acid, 18-acetoxy-cis-clerodan-3-ene-15-oic acid). The highest activity was observed for the samples of Populus origin. The antioxidant potential and phenolic/flavonoid content was positively, significantly correlated.

Author Contributions: Conceptualization, I.J., L.S. and P.M.K.; methodology, I.J., L.S., P.M.K. and Z.M.; formal analysis, Z.M., P.O., P.M.K., L.S.; data curation, I.J., L.S., P.O., P.M.K.; writing-original draft preparation, I.J., L.S., P.M.K.; writing-review and editing, I.J., L.S., P.M.K.; funding acquisition, L.S., I.J., P.M.K. All authors have read and agreed to the published version of the manuscript.

Funding: This research was funded by the OpenAccess Publication Fund of the University of Zagreb Faculty of Agriculture.

Acknowledgments: Publication was supported by the OpenAccess Publication Fund of the University of Zagreb Faculty of Agriculture.

Conflicts of Interest: The authors declare no conflict of interest.

\section{References}

1. Pasupuleti, V.R.; Sammugam, L.; Ramesh, N.; Gan, S.H. Honey, propolis, and royal jelly: A comprehensive review of their biological actions and health benefits. Oxid. Med. Cell. Longev. 2017, 2017, 1259510. [CrossRef]

2. Bankova, V.; Popova, M.; Trusheva, B. Propolis volatile compounds: Chemical diversity and biological activity: A review. Chem. Cent. J. 2014, 8, 28. [CrossRef]

3. Sforcin, J.M.; Bankova, V. Propolis: Is there a potential for the development of new drugs? J. Ethnopharmacol. 2011, 133, 253-260. [CrossRef]

4. Banskota, A.H.; Tezuka, Y.; Kadota, S. Recent progress in pharmacological research of propolis. Phyther. Res. 2001, 15, 561-571. [CrossRef] [PubMed]

5. Bankova, V.; Bertelli, D.; Borba, R.; Conti, B.J.; da Silva Cunha, I.B.; Danert, C.; Eberlin, M.N.; I Falcão, S.; Isla, M.I.; Moreno, M.I.N.; et al. Standard methods for Apis mellifera propolis research. J. Apic. Res. 2019, 7366-7376. [CrossRef]

6. Ristivojević, P.; Trifković, J.; Andrić, F.; Milojković-Opsenica, D. Poplar-type propolis: Chemical composition, botanical origin and biological activity. Nat. Prod. Commun. 2015, 1869-1875. [CrossRef]

7. Salatino, A.; Fernandes-Silva, C.C.; Righi, A.A.; Salatino, M.L.F. Propolis research and the chemistry of plant products. Nat. Prod. Rep. 2011, 925-936. [CrossRef] [PubMed]

8. Huang, W.J.; Huang, C.H.; Wu, C.L.; Lin, J.K.; Chen, Y.W.; Lin, C.L.; Chuang, S.E.; Huang, C.Y.; Chen, C.N. Propolin G, a prenylflavanone, isolated from Taiwanese propolis, induces caspase-dependent apoptosis in brain cancer cells. J. Agric. Food Chem. 2007, 55, 7366-7376. [CrossRef] [PubMed]

9. Kumazawa, S.; Nakamura, J.; Murase, M.; Miyagawa, M.; Ahn, M.R.; Fukumoto, S. Plant origin of Okinawan propolis: Honeybee behavior observation and phytochemical analysis. Naturwissenschaften 2008, 781-786. [CrossRef]

10. Trusheva, B.; Popova, M.; Koendhori, E.B.; Tsvetkova, I.; Naydenski, C.; Bankova, V. Indonesian propolis: Chemical composition, biological activity and botanical origin. Nat. Prod. Res. 2011, 452-461. [CrossRef]

11. Kalogeropoulos, N.; Konteles, S.J.; Troullidou, E.; Mourtzinos, I.; Karathanos, V.T. Chemical composition, antioxidant activity and antimicrobial properties of propolis extracts from Greece and Cyprus. Food Chem. 2009, 116, 452-461. [CrossRef]

12. Popova, M.P.; Graikou, K.; Chinou, I.; Bankova, V.S. GC-MS profiling of diterpene compounds in mediterranean propolis from Greece. J. Agric. Food Chem. 2010, 3167-3176. [CrossRef] [PubMed]

13. Radović, J.; Čivić, K.; Topić, R. Biodiversity of Croatia; State Institute for Nature Protect, Ministry of Culture of the Republic of Croatia: Velika Gorica, Croatia, 2006. 
14. Kosalec, I.; Bakmaz, M.; Pepeljnjak, S. Analysis of propolis from the continental and Adriatic regions of Croatia. Acta Pharm. 2003, 275-285.

15. Saftić, L.; Peršurić, Ž.; Fornal, E.; Pavlešić, T.; Kraljević Pavelić, S. Targeted and untargeted LC-MS polyphenolic profiling and chemometric analysis of propolis from different regions of Croatia. J. Pharm. Biomed. Anal. 2019, 162-172. [CrossRef]

16. Tlak-Gajger, I.; Pavlović, I.; Bojić, M.; Kosalec, I.; Srećec, S.; Vlainić, T.; Vlainić, J. Components responsible for antimicrobial activity of propolis from continental and Mediterranean regions in Croatia. Czech J. Food Sci. 2017, 275-285. [CrossRef]

17. Milojković Opsenica, D.; Ristivojević, P.; Trifković, J.; Vovk, I.; Lušić, D.; Tešić, Ž. TLC Fingerprinting and pattern recognition methods in the assessment of authenticity of poplar-type propolis. J. Chromatogr. Sci. 2016, 54, 1077-1083. [CrossRef]

18. Jerković, I.; Marijanović, Z.; Kuś, P.M.; Tuberoso, C.I.G. Comprehensive study of Mediterranean (Croatian) propolis peculiarity: Headspace, volatiles, anti-Varroa-treatment residue, phenolics, and antioxidant properties. Chem. Biodivers. 2016, 13, 210-218. [CrossRef]

19. El-Sayed, A.M. The Pherobase: Database of Insect Pheromones and Semiochemicals. 2012. Available online: http://www.pherobase.com (accessed on 5 March 2020).

20. Kuś, P.M.; Okińczyc, P.; Jakovljević, M.; Jokić, S.; Jerković, I. Development of supercritical $\mathrm{CO}_{2}$ extraction of bioactive phytochemicals from black poplar (Populus nigra L.) buds followed by GC-MS and UHPLC-DAD-QqTOF-MS. J. Pharm. Biomed. Anal. 2018, 158, 15-27. [CrossRef]

21. Benzie, I.F.F.; Strain, J.J. The ferric reducing ability of plasma (FRAP) as a measure of "antioxidant power": The FRAP Assay. Anal. Biochem. 1996, 239, 70-76. [CrossRef]

22. Singleton, V.L.; Rossi, J.A.J. Colorimetry of total phenolics with acid reagents. Am. J. Enol. Vitic. 1965, 16, 144-158. [CrossRef]

23. Kuś, P.; Jerković, I.; Jakovljević, M.; Jokić, S. Extraction of bioactive phenolics from black poplar (Populus nigra L.) buds by supercritical $\mathrm{CO}_{2}$ and its optimization by response surface methodology. J. Pharm. Biomed. Anal. 2018, 152, 128-136. [CrossRef]

24. European Pharmacopoeia, 9th ed.; Strasbourg, France, 2019.

25. Blois, M.S. Antioxidant determinations by the use of a stable free radical. Nature 1958, 181, 1199-1200. [CrossRef]

26. Kaškonienė, V.; Kaškonas, P.; Maruška, A.; Kubilienè, L. Chemometric analysis of volatiles of propolis from different regions using static headspace GC-MS. Cent. Eur. J. Chem. 2014, 12, 736-746. [CrossRef]

27. Pellati, F.; Prencipe, F.P.; Benvenuti, S. Headspace solid-phase microextraction-gas chromatography-mass spectrometry characterization of propolis volatile compounds. J. Pharm. Biomed. Anal. 2013, 84, 103-111. [CrossRef] [PubMed]

28. Borčić, I.; Radonić, A.; Grzunov, K. Comparison of the volatile constituents of propolis gathered in different regions of Croatia. Flavour Fragr. J. 1996, 11, 311-313. [CrossRef]

29. Greenaway, W.; May, J.; Scaysbrook, T.; Whatley, F.R. Identification by gas chromatography-mass spectrometry of 150 compounds in propolis. Z. Naturforsch. Sect. C J. Biosci. 1991, 46, 111-121. [CrossRef]

30. Bankova, V.; Christov, R.; Kujumgiev, A.; Marcucci, M.C.; Podov, S. Chemical composition and antibacterial activity of Brazilian propolis. Z. Naturforsch. Sect. C J. Biosci. 1995, 50, 167-172. [CrossRef]

31. Melliou, E.; Stratis, E.; Chinou, I. Volatile constituents of propolis from various regions of Greece Antimicrobial activity. Food Chem. 2007, 103, 375-380. [CrossRef]

32. Kocabas E, E.H.; Betul, D.; Atac, U.; Fatih, D. Volatile composition of Anatolian propolis by headspace-solidphase microextraction (HS-SPME), antimicrobial activity against food contaminants and antioxidant activity. J. Med. Plants Res. 2013, 7, 2140-2149. [CrossRef]

33. Trusheva, B.; Ivanova, D.; Popova, M.; Bankova, V. Insights into the essential oil compositions of Brazilian red and Taiwanese green propolis. Nat. Prod. Commun. 2017, 12, 197-200. [CrossRef]

34. Falcão, S.I.; Freire, C.; Cristina Figueiredo, A.; Vilas-Boas, M. The volatile composition of Portuguese propolis towards its origin discrimination. Rec. Nat. Prod. 2015, 10, 176-188.

35. Naik, D.G.; Vaidya, H.S.; Namjoshi, T.P. Essential oil of Indian propolis: Chemical composition and repellency against the honeybee Apis florea. Chem. Biodivers. 2013, 10, 649-657. [CrossRef] [PubMed]

36. Nikolić, T. Flora Croatica Database, Faculty of Science, University of Zagreb. 2015. Available online: http: //hirc.botanic.hr/fcd (accessed on 2 March 2020). 
37. Milos, M.; Radonic, A.; Mastelic, J. Seasonal variation in essential oil compositions of Cupressus sempervirens L. J. Essent. Oil Res. 2002, 14, 222-223. [CrossRef]

38. Adams, R.P. The leaf essential oils and chemotaxonomy of Juniperus sect. Juniperus. Biochem. Syst. Ecol. 1998, 26, 637-645. [CrossRef]

39. Milos, M.; Radonic, A. Gas chromatography mass spectral analysis of free and glycosidically bound volatile compounds from Juniperus oxycedrus L. growing wild in Croatia. Food Chem. 2000, 68, 333-338. [CrossRef]

40. Ulukanli, Z.; Karabörklü, S.; Bozok, F.; Ates, B.; Erdogan, S.; Cenet, M.; Karaaslan, M.G. Chemical composition, antimicrobial, insecticidal, phytotoxic and antioxidant activities of Mediterranean Pinus brutia and Pinus pinea resin essential oils. Chin. J. Nat. Med. 2014, 12, 901-910. [CrossRef]

41. Jerković, I.; Marijanović, Z.; Gugić, M.; Roje, M. Chemical profile of the organic residue from ancient amphora found in the adriatic sea determined by direct GC and GC-MS analysis. Molecules 2011, 16, 7936-7948. [CrossRef]

42. Piovetti, L.; Gonzalez, E.; Diara, A. Diterpene composition of Cupressus dupreziana and Cupressus sempervirens. Phytochemistry 1980, 19, 2772-2773. [CrossRef]

43. Seca, A.; Silva, A. The chemical composition of the Juniperus Genus (1970-2004). In Recent Progress in Medicinal Plants; Studium Press (India) Pvt. Ltd.: Houston, TX, USA, 2006; ISBN 0-9761849-8-2.

44. Zhang, J.; Rahman, A.; Jain, S.; Tekwani, B.; Khan, S.; Jacob, M.; Muhammad, I. Antimicrobial and antiparastic abietane diterpenoids from Cupressus sempervirens. Planta Med. 2012, 78. [CrossRef]

45. Ibrahim, N.A.; El-Seedi, H.R.; Mohammed, M.M.D. Constituents and biological activity of the chloroform extract and essential oil of Cupressus sempervirens. Chem. Nat. Compd. 2009, 45, 309-313. [CrossRef]

46. Demetzos, C.; Angelopoulou, D. A comparative study of the essential oils of Cistus salviifolius in several populations of Crete (Greece). Biochem. Syst. Ecol. 2002, 30, 651-665. [CrossRef]

47. Demetzos, C.; Loukis, A.; Spiliotis, V.; Zoakis, N.; Stratigakis, N.; Katerinopoulos, H.E. Composition and antimicrobial activity of the essential oil of Cistus creticus L. J. Essent. Oil Res. 1995, 7, 407-410. [CrossRef]

48. Demetzos, C.; Katerinopoulos, H.; Kouvarakis, A.; Stratigakis, N.; Loukis, A.; Ekonomakis, C.; Spiliotis, V.; Tsaknis, J. Composition and antimicrobial activity of the essential oil of Cistus creticus subsp. eriocephalus. Planta Med. 1997, 63, 477-479. [CrossRef] [PubMed]

49. Mariotti, J.P.; Tomi, F.; Casanova, J.; Costa, J.; Bernardini, A.F. Composition of the essential oil of Cistus ladaniferus L. cultivated in Corsica (France). Flavour Fragr. J. 1997, 12, 147-151. [CrossRef]

50. Srdjan, B.; Šarac, Z.; Biljana, N.; Tešević, V.; Todosijević, M.; Veljić, M.; Marin, P.D. Composition of $n$-alkanes in natural populations of Pinus nigra from Serbia-Chemotaxonomic implications. Chem. Biodivers. 2012, 9, 2761-2774. [CrossRef]

51. Sezik, E.; Kocakulak, E.; Baser, K.H.C.; Ozek, T. Composition of the essential oils of Juniperus oxycedrus subsp. macrocarpa from Turkey. Chem. Nat. Compd. 2005, 41, 352-354. [CrossRef]

52. Maffei, M.; Badino, S.; Bossi, S. Chemotaxonomic significance of leaf wax n-alkanes in the Pinales (Coniferales). J. Biol. Res. 2004, 1, 3-19.

53. Rajčević, N.; Janaćković, P.; Dodoš, T.; Tešević, V.; Marin, P.D. Biogeographic variation of foliar n-alkanes of Juniperus communis var. saxatilis Pallas from the Balkans. Chem. Biodivers. 2014, 11, 1923-1938. [CrossRef] [PubMed]

54. Bankova, V.; Christov, R.; Popov, S.; Pureb, O.; Bocari, G. Volatile constituents of propolis. Z. Naturforsch. Sect. C J. Biosci. 1994, 49, 6-10. [CrossRef]

55. Banthrope, D.V. Terpenoids. In Natural Products; Mann, J., Davidson, R.S., Hobbs, R.B., Banthrope, D.V., Harborne, J.B.E., Eds.; Longman: Essex, UK, 1996; pp. 306-327.

56. Clair, G.; Peyron, L. The study of propolis essential oil. Riv. Ital. Eppos 1981, 168-170.

57. Noureddine, H.; Hage-Sleiman, R.; Wehbi, B.; Fayyad-Kazan, A.H.; Hayar, S.; Traboulssi, M.; Alyamani, O.A.; Faour, W.H.; ElMakhour, Y. Chemical characterization and cytotoxic activity evaluation of Lebanese propolis. Biomed. Pharmacother. 2017, 95, 298-307. [CrossRef] [PubMed]

58. Cheng, H.; Qin, Z.H.; Guo, X.F.; Hu, X.S.; Wu, J.H. Geographical origin identification of propolis using GC-MS and electronic nose combined with principal component analysis. Food Res. Int. 2013, 51, 813-822. [CrossRef]

59. Miguel, M.G.; Nunes, S.; Cruz, C.; Duarte, J.; Antunes, M.D.; Cavaco, A.M.; Mendes, M.D.; Lima, A.S.; Pedro, L.G.; Barroso, J.G.; et al. Propolis volatiles characterisation from acaricide-treated and -untreated beehives maintained at Algarve (Portugal). Nat. Prod. Res. 2013, 27, 743-749. [CrossRef] [PubMed] 
60. Okinczyc, P.; Szumny, A.; Szperlik, J.; Kulma, A.; Franiczek, R.; Zbikowska, B.; Krzyzanowska, B.; Sroka, Z. Profile of polyphenolic and essential oil composition of Polish propolis, black poplar and aspens buds. Molecules 2018, 23, 1262. [CrossRef] [PubMed]

61. Jerković, I.; Mastelić, J. Volatile compounds from leaf-buds of Populus nigra L. (Salicaceae). Phytochemistry 2003, 63, 109-113. [CrossRef]

62. Isidorov, V.A.; Vinogorova, V.T. GC-MS analysis of compounds extracted from buds of Populus balsamifera and Popul. Nigra. Z. Naturforsch. Sect. C J. Biosci. 2003, 58, 355-360. [CrossRef]

63. Greenaway, W.; English, S.; Whatley, F.R. Variation in bud exudate composition of Populus nigra assessed by gas chromatography-mass spectrometry. Z. Naturforsch. Sect. C J. Biosci. 1990, 45, 931-936. [CrossRef]

64. do Nascimento, T.G.; da Silva, P.F.; Azevedo, L.F.; da Rocha, L.G.; de Moraes Porto, I.C.C.; Lima e Moura, T.F.A.; Basílio-Júnior, I.D.; Grillo, L.A.M.; Dornelas, C.B.; Fonseca, E.J.d.S.; et al. Polymeric nanoparticles of Brazilian red propolis extract: Preparation, characterization, antioxidant and leishmanicidal activity. Nanoscale Res. Lett. 2016, 11, 301. [CrossRef]

65. Oliveira, R.N.; Mancini, M.C.; de Oliveira, F.C.S.; Passos, T.M.; Quilty, B.; Thiré, R.M.d.S.M.; McGuinness, G.B. FTIR analysis and quantification of phenols and flavonoids of five commercially available plants extracts used in wound healing. Matéria (Rio Jan.) 2016, 21, 767-779. [CrossRef]

66. Franca, J.R.; De Luca, M.P.; Ribeiro, T.G.; Castilho, R.O.; Moreira, A.N.; Santos, V.R.; Faraco, A.A.G. Propolis-Based chitosan varnish: Drug delivery, controlled release and antimicrobial activity against oral pathogen bacteria. Bmc Complement. Altern. Med. 2014, 14, 478. [CrossRef]

67. Dewi, Y.N.; Hanny Wijaya, C.; Nasrullah, N. Classification of Trigona spp. bee propolis from four regions in Indonesia using FTIR metabolomics approach. In Proceedings of the 13th ASEAN Food Conference, Meeting Future Food Demands: Security \& Sustainability, Singapore, 9-11 November 2013.

68. Moţ, A.C.; Silaghi-Dumitrescu, R.; Sârbu, C. Rapid and effective evaluation of the antioxidant capacity of propolis extracts using DPPH bleaching kinetic profiles, FT-IR and UV-Vis spectroscopic data. J. Food Compos. Anal. 2011, 24, 516-522. [CrossRef]

69. Wu, Y.W.; Sun, S.Q.; Zhao, J.; Li, Y.; Zhou, Q. Rapid discrimination of extracts of Chinese propolis and poplar buds by FT-IR and 2D IR correlation spectroscopy. J. Mol. Struct. 2008, 883-884, 48-54. [CrossRef]

70. Jerman, S.D.; Prđun, S.; Bubalo, D.; Svečnjak, L. Chemical characterization and variations in the composition of propolis in the honey bee colony (Apis mellifera L.). In Proceedings of the 54 Croatian \& 14 International Symposium on Agriculture, Vodice, Croatia, 17-22 February 2019; pp. 373-377.

71. Vahur, S.; Teearu, A.; Peets, P.; Joosu, L.; Leito, I. ATR-FT-IR spectral collection of conservation materials in the extended region of 4000-80 $\mathrm{cm}^{-1}$. Anal. Bioanal. Chem. 2016, 408, 3373-3379. [CrossRef] [PubMed]

72. Bogdanov, S.; Bankova, V. Propolis: Origin, Production, Composition. The Propolis Book, Chapter 1. Available online: http://www.bee-hexagon.net/propolis/ (accessed on 3 March 2020).

73. Socrates, G. Infrared and Raman Characteristic Group Frequencies. Tables and Charts; Wiley: Hoboken, NJ, USA, 2001; ISBN 978-0-470-09307-8.

74. Svečnjak, L.; Chesson, L.A.; Gallina, A.; Maia, M.; Martinello, M.; Mutinelli, F.; Muz, M.N.; Nunes, F.M.; Saucy, F.; Tipple, B.J.; et al. Standard methods for Apis mellifera beeswax research. J. Apic. Res. 2019, 58, 1-108. [CrossRef]

75. Piccinelli, A.L.; Mencherini, T.; Celano, R.; Mouhoubi, Z.; Tamendjari, A.; Aquino, R.P.; Rastrelli, L. Chemical composition and antioxidant activity of Algerian propolis. J. Agric. Food Chem. 2013, 61, 5080-5088. [CrossRef]

76. Barbarić, M.; Mišković, K.; Bojić, M.; Lončar, M.B.; Smolčić-Bubalo, A.; Debeljak, Z.; Medić-Šarić, M. Chemical composition of the ethanolic propolis extracts and its effect on HeLa cells. J. Ethnopharmacol. 2011, 135, 772-778. [CrossRef]

77. Cvek, J.; Medić-Šarić, M.; Jasprica, I.; Mornar, A. High-performance thin-layer chromatographic analysis of the phenolic acid and flavonoid content of Croatian propolis samples. J. Planar Chromatogr. 2007, 20, 429-435. [CrossRef]

78. Sobočanec, S.; Šverko, V.; Balog, T.; Šarić, A.; Rusak, G.; Likić, S.; Kušić, B.; Katalinić, V.; Radić, S.; Marotti, T. Oxidant/antioxidant properties of Croatian native propolis. J. Agric. Food Chem. 2006, 54, 8018-8026. [CrossRef]

79. Isidorov, V.A.; Szczepaniak, L.; Bakier, S. Rapid GC/MS determination of botanical precursors of Eurasian propolis. Food Chem. 2014, 142, 101-106. [CrossRef] 
80. Isidorov, V.A.; Bakier, S.; Pirożnikow, E.; Zambrzycka, M.; Swiecicka, I. Selective behaviour of honeybees in acquiring European propolis plant precursors. J. Chem. Ecol. 2016, 42, 475-485. [CrossRef] [PubMed]

81. Jang, D.S.; Cuendet, M.; Fong, H.H.S.; Pezzuto, J.M.; Kinghorn, A.D. Constituents of Asparagus officinalis evaluated for inhibitory activity against cyclooxygenase-2. J. Agric. Food Chem. 2004, 52, 2218-2222. [CrossRef]

82. Cooper, R.; Gottlieb, H.E.; Lavie, D. New phenolic diglycerides from Aegilops ovata. Phytochemistry 1978, 17, 1673-1675. [CrossRef]

83. Zapesochnaya, G.G.; Ivanova, S.Z.; Medvedeva, S.A.; Tyukavkina, N.A. O-acylated flavonoid glycosides of the needles of Pinus sylvestris L. O-acetylated derivatives of flavonol glycosides. Chem. Nat. Compd. 1978, 14, 156-158. [CrossRef]

84. Nicoletti, M.; Toniolo, C.; Venditti, A.; Bruno, M.; Ben Jemia, M. Antioxidant activity and chemical composition of three Tunisian Cistus: Cistus monspeliensis Cistus villosus and Cistus libanotis. Nat. Prod. Res. 2015, 29, 223-230. [CrossRef]

85. Van Der Doelen, G.A.; Van Den Berg, K.J.; Boon, J.J.; Shibayama, N.; René De La Rie, E.; Wim, W.J. Analysis of fresh triterpenoid resins and aged triterpenoid varnishes by high-performance liquid chromatography-atmospheric pressure chemical ionisation (tandem) mass spectrometry. J. Chromatogr. A 1998, 809, 21-37. [CrossRef]

86. Popova, M.; Giannopoulou, E.; Skalicka-Wózniak, K.; Graikou, K.; Widelski, J.; Bankova, V.; Kalofonos, H.; Sivolapenko, G.; Gaweł-Bȩben, K.; Antosiewicz, B.; et al. Characterization and biological evaluation of propolis from Poland. Molecules 2017, 22, 1159. [CrossRef] [PubMed]

87. Debab, M.; Toumi-Benali, F.; Dif, M.M. Antioxidant activity of propolis of West Algeria. Phytotherapie 2017, 15, 230-234. [CrossRef]

88. Popova, M.P.; Chinou, I.B.; Marekov, I.N.; Bankova, V.S. Terpenes with antimicrobial activity from Cretan propolis. Phytochemistry 2009, 70, 1262-1271. [CrossRef]

89. El-Guendouz, S.; Aazza, S.; Lyoussi, B.; Bankova, V.; Popova, M.; Neto, L.; Faleiro, M.L.; Da Graça Miguel, M. Moroccan propolis: A natural antioxidant, antibacterial, and antibiofilm against Staphylococcus aureus with no induction of resistance after continuous exposure. Evid.-Based Complement. Altern. Med. 2018, 2018, 9759240. [CrossRef]

90. Martos, I.; Cossentini, M.; Ferreres, F.; Toma, F.A. Flavonoid composition of Tunisian honeys and propolis. J. Agric. Food Chem. 1997, 2, 2824-2829. [CrossRef]

91. Smith, C.A.; O’Maille, G.; Want, E.J.; Qin, C.; Trauger, S.A.; Brandon, T.R.; Custodio, D.E.; Abagyan, R.; Siuzdak, G. METLIN: A metabolite mass spectral database. Ther. Drug Monit. 2005, 27, 747-751. [CrossRef]

92. Christov, R.; Trusheva, B.; Popova, M.; Bankova, V.; Bertrand, M. Chemical composition of propolis from Canada, its antiradical activity and plant origin. Nat. Prod. Res. 2006, 19, 673-678. [CrossRef]

93. Popova, M.; Trusheva, B.; Cutajar, S.; Antonova, D.; Mifsud, D.; Farrugia, C.; Bankova, V. Identification of the plant origin of the botanical biomarkers of Mediterranean type propolis. Nat. Prod. Commun. 2012, 7, 569-570. [CrossRef] [PubMed]

94. Pellati, F.; Orlandini, G.; Pinetti, D.; Benvenuti, S. HPLC-DAD and HPLC-ESI-MS/MS methods for metabolite profiling of propolis extracts. J. Pharm. Biomed. Anal. 2011, 55, 934-948. [CrossRef] [PubMed]

95. Ristivojević, P.; Trifković, J.; Gašić, U.; Andrić, F.; Nedić, N.; Tešić, Ž.; Milojković-Opsenica, D. Ultrahighperformance liquid chromatography and mass spectrometry (UHPLC-LTQ/Orbitrap/MS/MS) study of phenolic profile of Serbian poplar type propolis. Phytochem. Anal. 2015, 26, 127-136. [CrossRef]

96. Shi, H.; Yang, H.; Zhang, X.; Yu, L. Identification and quantification of phytochemical composition and anti-inflammatory and radical scavenging properties of methanolic extracts of Chinese propolis. J. Agric. Food Chem. 2012, 60, 12403-12410. [CrossRef] [PubMed]

97. Shi, H.; Yang, H.; Zhang, X.; Sheng, Y.; Huang, H.; Yu, L. Isolation and characterization of five glycerol esters from wuhan propolis and their potential anti-inflammatory properties. J. Agric. Food Chem. 2012, 60, 10041-10047. [CrossRef] [PubMed]

98. Trudić, B.; Anđelković, B.; Orlović, S.; Tešević, V.; Pilipović, A.; Cvetković, M.; Stanković, J. HPLC/MS-TOF analysis of surface resins from three poplar clones grown in Serbia. South-East Eur. 2016, 2, 129-133.

99. Bertrams, J.; Müller, M.B.; Kunz, N.; Kammerer, D.R.; Stintzing, F.C. Phenolic compounds as marker compounds for botanical origin determination of German propolis samples based on TLC and TLC-MS. J. Appl. Bot. Food Qual. 2013, 153, 143-153. [CrossRef] 
100. Isidorov, V.A.; Brzozowska, M.; Czyzewska, U.; Glinka, L. Gas chromatographic investigation of phenylpropenoid glycerides from aspen (Populus tremula L.) buds. J. Chromatogr. A 2008, 1198, 169-201. [CrossRef]

101. Tian, Y.; Liimatainen, J.; Alanne, A.L.; Lindstedt, A.; Liu, P.; Sinkkonen, J.; Kallio, H.; Yang, B. Phenolic compounds extracted by acidic aqueous ethanol from berries and leaves of different berry plants. Food Chem. 2017, 220, 226-281. [CrossRef]

102. Mai, F.; Glomb, M.A. Isolation of phenolic compounds from iceberg lettuce and impact on enzymatic browning. J. Agric. Food Chem. 2013, 61, 2868-2874. [CrossRef]

103. Midorikawa, K.; Banskota, A.H.; Tezuka, Y.; Nagaoka, T.; Matsushige, K.; Message, D.; Huertas, A.A.G.; Kadota, S. Liquid chromatography-mass spectrometry analysis of propolis. Phytochem. Anal. 2001, 12, 366-373. [CrossRef] [PubMed]

104. Jarrell, T.M.; Marcum, C.L.; Sheng, H.; Owen, B.C.; O’Lenick, C.J.; Maraun, H.; Bozell, J.J.; Kenttämaa, H.I. Characterization of organosolv switchgrass lignin by using high performance liquid chromatography/high resolution tandem mass spectrometry using hydroxide-doped negative-ion mode electrospray ionization. Green Chem. 2014, 16, 2713-2727. [CrossRef]

105. Sanz, M.; Cadahía, E.; Esteruelas, E.; Muñoz, Á.M.; Fernández De Simón, B.; Hernández, T.; Estrella, I. Phenolic compounds in cherry (Prunus avium) heartwood with a view to their use in cooperage. J. Agric. Food Chem. 2010, 58, 4907-4914. [CrossRef] [PubMed]

106. Cisilotto, J.; Sandjo, L.P.; Faqueti, L.G.; Fernandes, H.; Joppi, D.; Biavatti, M.W.; Creczynski-Pasa, T.B. Cytotoxicity mechanisms in melanoma cells and UPLC-QTOF/MS ${ }^{2}$ chemical characterization of two Brazilian stingless bee propolis: Uncommon presence of piperidinic alkaloids. J. Pharm. Biomed. Anal. 2018, 149, 502-511. [CrossRef] [PubMed]

107. Nair, A.G.R.; Kotiyal, J.P.; Bhardwaj, D.K. Myricetin 7,4'-dimethyl ether and its 3-galactoside from Rhus lancea. Phytochemistry 1983, 22, 318-319. [CrossRef]

108. Justesen, U. Negative atmospheric pressure chemical ionisation low-energy collision activation mass spectrometry for the characterisation of flavonoids in extracts of fresh herbs. J. Chromatogr. A 2000, 902, 369-379. [CrossRef]

109. Zhang, B.; Ye, X.; Chen, Z.; Jiang, X.; Yuan, L.; Yi, J.; Li, X. Synthesis and antimicrobial activity of 7-alkoxyhesperetin. Med. Chem. Res. 2011, 1200-1205. [CrossRef]

110. Gardana, C.; Scaglianti, M.; Pietta, P.; Simonetti, P. Analysis of the polyphenolic fraction of propolis from different sources by liquid chromatography-tandem mass spectrometry. J. Pharm. Biomed. Anal. 2007, 45, 390-399. [CrossRef]

111. English, S.; Greenaway, W.; Whatley, F.R. Bud exudate composition of Populus tremuloides. Can. J. Bot. 1991, 69, 2291-2295. [CrossRef]

112. Voirin, B. UV spectral differentiation of 5-hydroxy- and 5-hydroxy-3-methoxyflavones with mono- $\left(4^{\prime} ;\right)$, di- $\left(3^{\prime}, 4^{\prime}\right)$ or tri- $\left(3^{\prime}, 4^{\prime}, 5^{\prime}\right)$-substituted B rings. Phytochemistry 1983, 22, 2107-2145. [CrossRef]

113. Greenaway, W.; Wollenweber, E.; Whatley, F.R. Esters of caffeic acid with aliphatic alcohols in bud exudate of Populus nigra. Z. Naturforsch. Sect. C J. Biosci. 1988, 43, 795-798. [CrossRef]

114. Justesen, U. Collision-induced fragmentation of deprotonated methoxylated flavonoids, obtained by electrospray ionization mass spectrometry. J. Mass Spectrom. 2001, 36, 169-178. [CrossRef] [PubMed]

115. Purwar, C.; Rai, R.; Srivastava, N.; Singh, J. New flavonoid glycosides from Cassia occidentalis. Indian J. Chem. Sect. B Org. Med. Chem. 2003, 42B, 434-436. [CrossRef]

116. Nakatani, N.; Jitoe, A.; Masuda, T.; Yonemori, S. Flavonoid constituents of Zingiber zerumbet Smith. Agric. Biol. Chem. 1991, 455-460. [CrossRef]

117. Popravko, S.A.; Gurevieh, A.I.; Kolosov, M.N. Flavonoid components of propolis. Khimiya Prir. Soedin. 1969, 476-482. [CrossRef]

118. Gurni, A.A.; König, W.A.; Kubitzki, K. Flavonoid glycosides and sulphates from the Dilleniaceae. Phytochemistry 1981, 20, 1057-1059. [CrossRef]

119. Zaiter, L.; Bouheroum, M.; Hammoud, L.; Sarri, D.; Benayache, S.; Leon, F.; Brouard, I.; Bermejo, J.; Benayache, F. Phytochemical study of Halimium halimifolium. Chem. Nat. Compd. 2012, 47, 1023-1024. [CrossRef]

120. Velikova, M.; Bankova, V.; Sorkun, K.; Houcine, S.; Tsvetkova, I.; Kujumgiev, A. Propolis from the Mediterranean region: Chemical composition and antimicrobial activity. Z. Naturforsch. Sect. C J. Biosci. 2000, 9-10, 790-793. [CrossRef] 
121. Kečkeš, S.; Gašić, U.; Veličković, T.Ć.; Milojković-Opsenica, D.; Natić, M.; Tešić, Ž. The determination of phenolic profiles of Serbian unifloral honeys using ultra-high-performance liquid chromatography/high resolution accurate mass spectrometry. Food Chem. 2013, 138, 32-40. [CrossRef]

122. Axelsson, S.; Eriksson, K.; Nilsson, U. Determination of resin acids during production of wood pellets - A comparison of HPLC/ESI-MS with the GC/FID MDHS 83/2 method. J. Environ. Monit. 2011, 13, 2940-2945. [CrossRef] [PubMed]

123. Wang, K.; Zhang, J.; Ping, S.; Ma, Q.; Chen, X.; Xuan, H.; Shi, J.; Zhang, C.; Hu, F. Anti-inflammatory effects of ethanol extracts of Chinese propolis and buds from poplar (Populus $\times$ canadensis). J. Ethnopharmacol. 2014, 155, 1-12. [CrossRef] [PubMed]

124. Tugba Degirmencioglu, H.; Guzelmeric, E.; Yuksel, P.I.; Kırmızıbekmez, H.; Deniz, I.; Yesilada, E. A new type of Anatolian propolis: Evaluation of its chemical composition, activity profile and botanical origin. Chem. Biodivers. 2019, 16, e1900492. [CrossRef] [PubMed]

125. Mašek, T.; Perin, N.; Racané, L.; Cindrić, M.; Paljetak, H.Č.; Perić, M.; Matijašić, M.; Verbanac, D.; Radić, B.; Šran, J.; et al. Chemical composition, antioxidant and antibacterial activity of different extracts of poplar type propolis. Croat. Chem. Acta 2018, 91, 81-88. [CrossRef]

126. Kosalec, I.; Bakmaz, M.; Pepeljnjak, S.; Vladimir-Knežević, S. Quantitative analysis of the flavonoids in raw propolis from northern Croatia. Acta Pharm. 2004, 54, 65-72.

(C) 2020 by the authors. Licensee MDPI, Basel, Switzerland. This article is an open access article distributed under the terms and conditions of the Creative Commons Attribution (CC BY) license (http://creativecommons.org/licenses/by/4.0/). 